\title{
A COMPARATIVE STUDY OF THE FEEDING MECHANISMS OF SOME AFRICAN CYPRINIDAE (PISCES, CYPRINIFORMES)
}

\author{
by
}

\author{
H. MATTHES \\ Zoological Laboratory, University of Amsterdam
}

with 12 plates

\begin{abstract}
Although there exists an extremely voluminous literature on Cyprinid fishes and the morphology and physiology of some species has been intensively studied by various authors, very little is yet known about feeding mechanisms and their functioning in most members of this family.

So far as known, only some European species e.g. Cyprinus carpio, Carassius auratus, Rutilus rutilus, Gobio gobio - one Asian (Labeo rohita), and one African (Labeo horie) have been investigated thoroughly as regards their morphology in relation to their feeding habits. Moreover ,the ecology of most African species is only scantily known.

This study of the feeding mechanisms of one or more typical representatives of most of the African genera, will, I hope, serve to clarify some interesting points and lead to new lines of research in a field where so much is still left to be done.
\end{abstract}

\section{ACKNOWLEDGEMENTS}

For generous help in providing material of African Cyprinidae as well as working facilities at the "Musée Royal d'Afrique Centrale" (Tervuren), I'm deeply indepted to Prof. M. PoLx, conservator of vertebrates there. My thanks also for the help received from Prof. Dr. E. J. Strjper, under whose guidance this work was carried out, and to his assistants at the "Zoölogisch Laboratorium", Amsterdam University. I'm also very thankful to Prof. Dr. H. Engex, director of the "Zoölogisch Museum" (Amsterdam), who kindly allowed me the full use of the library of the Ichthyology section.

\section{MATERIALS AND METHODS}

Species belonging to the following genera were taken under consideration:

Labeo, Garra, Barbus, Varicorhinus, Barbopsis, Coptostomabarbus, Leptocypris, Barilius, Engraulicypris, Chelaethiops.

Of the three other African genera not studied here, namely: Phreatichthys VINcig., 1924, Xenobarbus Norman, 1923, and Caecobarbus BLGR., 1921, only the last has had its biology investigated, though with no special reference to its feeding habits and morphology (Heuts, 1951), and all are directly derived from Barbus, from which they apparently differ little. Amongst non-African species, Cyprinus carpio LinN., 1758, Leuciscus cephalus (LinN., 1758) and Rasbora sp. were also examined, for comparative purposes.

The bulk of the ecological data stems from personal observations on live fish, either in nature or in aquaria, as well as from numerous gut content analyses. Complementary information was culled from various sources, e.g. Girgis (1952), Greenwood (1958), Fryer (1959), Daget (1954), Poll (1953; 1959), Boulenger (1901; 1907), etc. The osteology and musculature of the mouth and pharynx were studied from mounted skeletons, Alizarin preparations (for small species) and from careful dissections (also under the microscope).

A large series of pharyngeal bones from both African and European species was also examined and compared.

The nomenclature followed is essentially the same as that used by Gregory (1933) and RamaswamI (1955) for the bones and by EDcewortr (1935) for the muscles. Owing to the fact that muscle nomenclature was found to be rather confused, a table of the cranial muscles and their main function has been drawn up (Table I) enabling rapid comparison of the different names used by various authors. No attempt at establishing synonymies for these different terms was made. The names used in this paper are the ones which appear most appropriate, taking into account not only the muscle function but also its ontogeny.

In order to study the finer structure of the inner mouth and pharyngeal linings, histological sections of the head region of Barbus pleuropholis and of the lamellar vomero-palatine organ and pharyngeal pad 
("palatal organ") of Labeo lineatus were made. Staining was mostly done with Azan and HaematoxylinEosin. Numerous drawings and photographs have been included in order to illustrate all salient points.

\section{GENERAL INTRODUCTION}

The Cyprinidae form an extremely rich and diversified family and its numerous species have adapted to a broad variety of environments. This ecological diversity is directly related to their high morphological variability, and many remarkable trophic specialisations illustrate the close relationship between the morphology of their feeding mechanisms and their mode of life.

Feeding in Cyprinids can be subdivided into several distinct actions, i.e.: prehension, selection (filtering), mastication, deglutition and digestion. Accordingly, the following account of each genus studied has been subdivided thus:

1. General characters (brief diagnostic description of the genus), species studied and references to earlier work done.

2. Ecology of the species considered.

3. Functional morphology of the feeding mechanisms, subdivided into:

a) External features (rostrum, sense organs, lips, etc.)

b) Bucco-pharyngeal cavity, comprising:

i. The prehensile apparatus (mouth and buccal cavity).

ii. The selective apparatus (palate, branchial arches and anterior pharynx).

c) The masticatory apparatus (posterior pharynx).

d) The digestive tract.

4. Conclusions and discussion (adaptations, application of results obtained to other fields, further lines of research, etc.)

In order to simplify matters and avoid unnecessary repetition, a general introductory review is given here, broadly along these lines, relating all characteristics these fish were found to possess in common. Hence, in the individual accounts, only those features in which they differ significantly from the overall picture and from other species will be considered.

\section{GENERAL CHARACTERS}

In all fishes of this family the mouth is toothless and generally more or less strongly protractile, the important modifications of the posterior pharynx being in direct relation to the first character.

The upper jaw is bordered by the premaxillaries only, the maxillaries being completely excluded from the gape of the mouth. Lips and barbels are variously developed and may even be absent altogether. Paired nostrils, separated by a valvular flap, are situated on the snout, anterior to the eye; the sense of smell is known to be extremely well developed in Cyprinids (Brown, 1957, vol. II).

A membraneous valve is present along the inner side of the upper jaw only (maxillary valve). A true tongue is, with one remarkable exception, not developed, there only appearing a more or less distinctly raised hump in the mouth-floor, over the glossohyal. The inner lining of the bucco-pharyngeal cavity generally presents numerous more or less longitudinal plicae and the palatal epithelium may be modified in several ways, in relation to a particular feeding habit (e.g. vomero-palatine organ). Posteriorly, a thickened dorsal pharyngeal pad occupies most of the anterior pharyngeal cavity, leaving only a narrow passage for water and food particles; this "palatal organ" is covered with a stratified, strongly papillose, and/or plicated epithelium. Below this, the submucosa consists largely of collagen and elastic fibres in a matrix of connective tissue. The thick muscularis is composed of numerous muscle strands running in all directiors as well as collagen fibres, etc. A somewhat similar, but smaller and thinner, triangular ventral pad overlies the anterior pharynx floor, just in front of the pharyngeal teeth area. Investigations by several authors (Al-Hussain,, 1949; Dorier \& Bellon, 1952; MALTZAN, 1935; GrRGIs, 1952, etc.) have shown that cyprinid fishes possess numerous mucus cells in the bucco-pharyngeal mucosa, as well us well-developed taste buds, which are particularly numerous in the herbivorous species. These cells are more or less concentrated locally, for instance: the concentrations of taste buds on barbels or lips, as well as on the palate and pharyngeal pad; and the high concentrations of mucus glands (goblet cells) in the posterior pharynx, where they are ideally situated to ensure efficient lubrication of the food. The histological investigations carried out in connection with this subject gave results corroborating those obtained by these authors.

The gill arches are 4 in number, branchiostegal rays 3 , the gill membranes usually more or less extensively united to the isthmus ventrally. The development and functional importance of the gill-rakers varies greatly in the different species, ranging from the rudimentary stumps of Barilius to the highly specialised ,intricate sieve mechanism of Labeo. Pseudobranchiae, often of the enclosed type, are usually present, lying in the antero-superior part of the bran- 
chial cavity, against the posterior aspect of the upper hyomandibular.

The 5th branchial arches are modified into more or less falciform or triangular, paired pharyngeal bones, lying parallel and internal to the 4 th branchial arches and bearing a variable number of teeth internally, arranged in 1 to 3 rows. Rostrally, the anteroventral processes of the pharyngeal bones unite in a ligamentous symphysis and are prolonged forwards by a more or less strongly developed cartilage extending to the posterior basibranchials; the posteroventral processes also bend laterally outwards and the dorsal (ascending) ones reach up into the subtemporal fossae. The pharyngeal teeth are true teeth (HoPPE, 1894) and their form varies in close correlation with the feeding habit, consequently being often very specialised (Heckes, 1843). They are composed of an enamel-like crown, dentine, a pulp cavity containing the pulp nerves and blood vessels, which pass through the spongy, alveolar lateral surface of the pharyngeal bones, and the hollow root.

The teeth are regularly replaced by new ones (polyphyodont dentition), which are developed in the mucous coat between and alongside the functional ones and later become attached by a root to the underlying bony covering, just before becoming functional, the old teeth falling out.

They work against a sclerous plate attached to a ventral process of the basi-occipital which also extends backwards under the anterior vertebrae and represents the upper pharyngeal bones (pharyngeal process). The short muscular oesophagus leads directly into the intestine, from which it is separated by an oesophageal-intestinal sphincter; there is no stomach present and no pyloric caecae are developed, the digestive tract being thus greatly simplified. However, the anterior intestine usually presents a swollen wider portion which constitutes a "stomach" of sorts. The gut length varies in direct correlation to nutrition, being, for instance, extremely long in herbivorous species. The histology and physiology of the digestive tract of Cyprinids has already been intensively studied by various authors (e.g. Curry, 1939; Maltzan, 1935; McVay \& KaAn, 1940; Pictet, 1909; Sarbahi, 1940; etc.).

\section{OSTEOLOGY}

For a comprehensive, succinct account of the osteology of the cyprinid skull and the dynamics of its various parts, one can consult Gregory (1933). The general mechanism of moving bony parts related to feeding movements is explained further on (see: Mechanisms of mouth protrusion and mastication).
Where in any particular case this may show differences, these are described accordingly.

\section{MUSCULATURE}

In the following table, the cranial muscles and their principal function as well as the different names given them by various authors have been included. Since their origins and points of insertion often vary in different species, these will be described in the next section and, if necessary, in the individual accounts. All these muscles are essentially identical in the different cyprinid genera, but their development, relative positions and importance may vary considerably. Also, some secondary muscles may be absent in some species. Striate muscle occurs in the buccopharyngeal cavity, oesophagus and in the anterior portion of the intestine as well (partly); in the rest of the gut only smooth muscle is present. Muscles whose function has but little or no incidence on feeding movements shall not be further attended to here. Further detailed information on the cranial muscles of Cyprinoid fishes can be culled from TaxaHasI (1925).

\section{MECHANISM OF MOUTH PROTRUSION, DEGLU-} TITION AND MASTICATION

The mouth is opened through the action of the longgitudinal throat muscles, namely, the geniohyoideus and the posterior sternohyoideus, which pull down the lower jaw and simultaneously dilate the buccal cavity. These muscles originate respectively from the anterior extremities of the ceratohyal and le \& $2 e$ branchiostegals, and from the anterior dorso-rostrad surface of the cleithrum (and coracoid); they run forwards to insert respectively on the posterior edge of the anterior dentary branches and the dorsal surface of the urohyal and/or hypohyalia.

When the mouth opens, the ascending coronoid process of the dentary/angular swings forward, pushing the caudal extremity of the maxillary-to which it is connected through a ligament-forward. The premaxillary, which is joined to the maxillary through a ligament posteriorly, and antero-medially via a ligament and the rostral bone to the vomero-mesethmoid fork, is also carried forward. Wider opening of the mouth furthermore pulls the maxillary and premaxillary downwards, through action of the coronoid process and the membraneous ligament between the posterior extremities of the maxillary/premaxillary and dentary, at the corner of the mouth. The rocking action of the maxillaries as the mouth opens and closes is achieved through the rolling action of the maxillary condyles which articulate dorso-posteriorly 
TABLE I. The cranial muscles of Cyprinidae, their function an

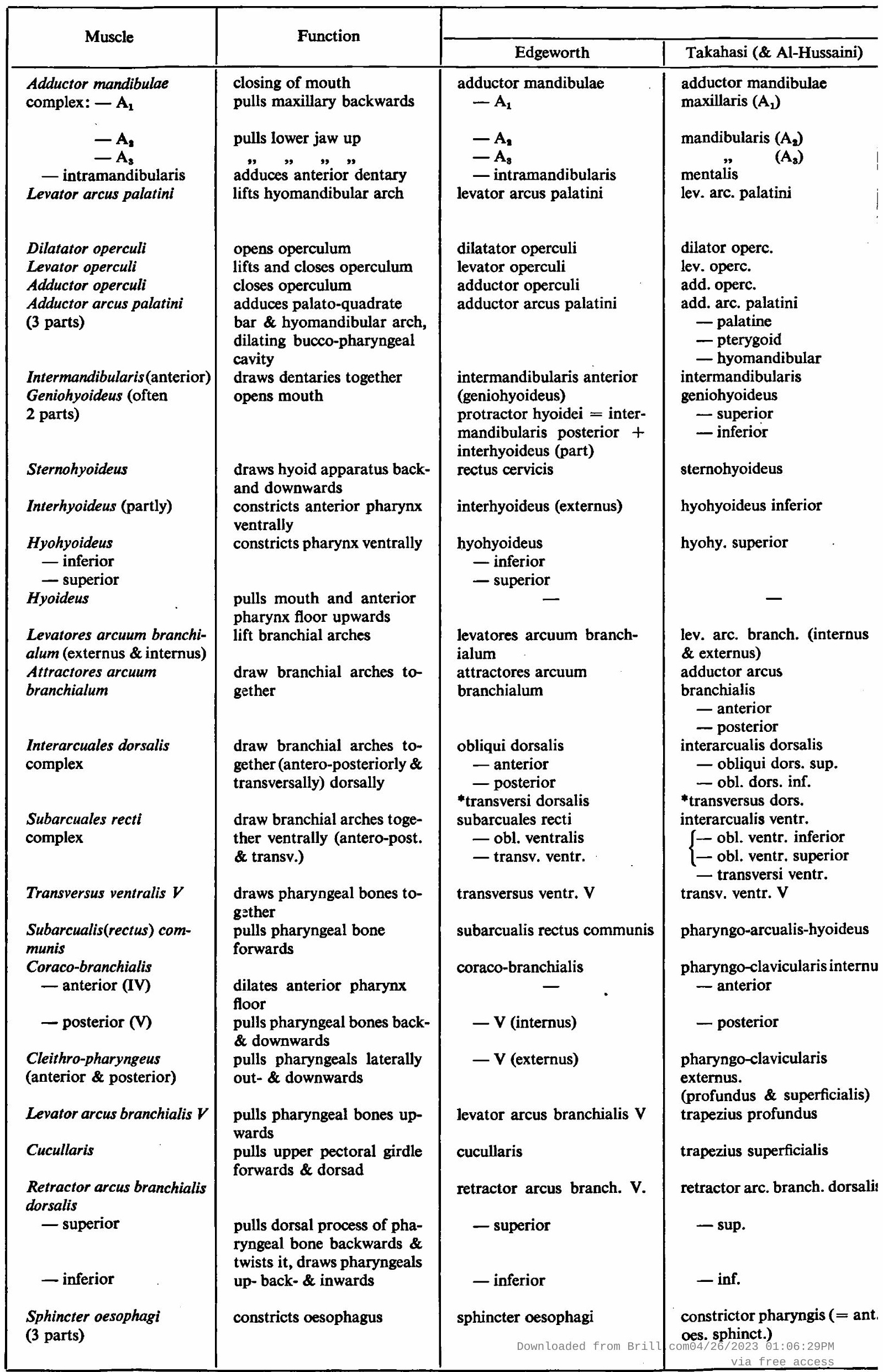

- absent in Cyprinidae. 
Named used by:

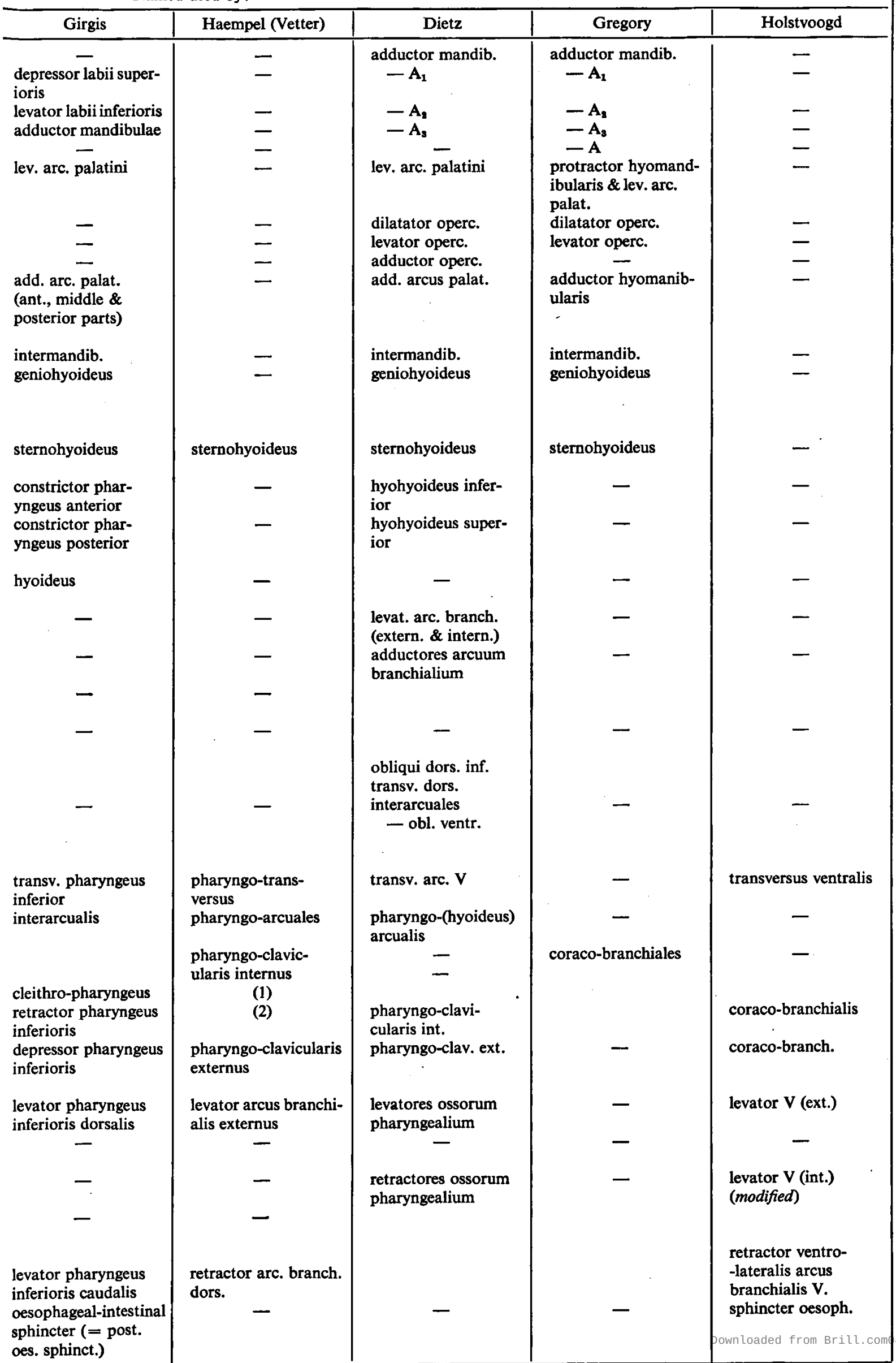


via cartilaginous caps (submaxillary cartilages) with rounded vomero-preethmoid projections. Excessive movement is checked by the sigmoid ligament (attached to the rostral bone), the membraneous ligament between the antero-dorsal border of the premaxillary and ventral border of the maxillary, and that between the dorso-anterior processes of the maxillaries. Protrusion of the upper jaw is also somewhat affected by contraction of the levator arcus palatini, which originates from the sphenotic, and runs downwards behind the orbit to insert on the upper external surface of the hyomandibular and pterygoid, lifting the hyomandibular arch.

Closing of the mouth takes place through contraction of the adductor mandibulae complex, the various parts of which lie on the cheek, external to the membrane bones. This muscle presents several interesting modifications in the different genera, according to their mode of prehension of food.

In most cases, the maxillaris $\left(A_{1}\right)$ originates from the preoperculum and quadrate and runs forward to insert on the antero-external aspect of the maxillary, thus pulling the latter backwards on contraction. The two parts of the mandibularis $\left(\mathrm{A}_{2} \mathrm{~A}_{3}\right)$ which lie under $A_{1}$, originate from the metapterygoid (in the orbit), sympletic, hyomandibular and upper preopercular, to run rostrad and ventrad and insert on the angular and coronoid process. Simultaneously with closing of the mouth, relaxation of the longitudinal throat muscles and the adductor arcus palatini, and contraction of the hyoideus, interhyoideus (partly) and hyohyoideus bring about constriction of the mouth cavity (and anterior pharynx), thus forcing water and food backwards. The adductor arcus palatini, which consists of three parts, arises from the cranium (pro-otic $\&$ parasphenoid) runs antero-laterally and somewhat ventrally to insert on the inner dorsal surfaces of the palatine, pterygoid and hyomandibular bones. The hyoideus is a thin, narrow muscle lying internal to the hyoid arch and more or less parallel to it, arising from the posterior basihyal region and inserting dorso-posteriorly on the caudad surface of the upper hyomandibular. The interhyoideus is a narrow muscle lying on the gullet, posterior and dorsal to the geniohyoideus, but ventral to the sternohyoideus and originates from the inner surface of the posterior part of the ceratohyal and/or epihyal, to run transversely towards its fellow from the opposite side, which it meets mesially.

Further back, dilatation of the pharyngeal (branchial) cavity is brought about by overall contraction of the pharyngeal pad and by the action of the coraco-branchialis anterior and sub-arcualis rectus com- munis (partly). The first arises from the anterior dorso-rostrad surface of the coracoid and/or cleithrum (between the inner and the outer fascia of the sternohyoideus) and runs forwards to insert on the anterior (medial) ends of the 4th ceratobranchial and/or 3rd-4th basibranchials; the second originates from the antero-ventral process of the pharyngeal bones to insert rostrally on the anterior (medial) ends of the hypobranchials (hypobranchial 3) or the inner posterior side of the hypohyal. Contraction of the anterior pharynx and dilatation of the pharyngeal pad forces water out through the gills, and food back into the posterior pharynx when this dilates after the water has been expelled (food particles having meanwhile been sifted out through the gill-raker sieve in some species). This contraction is mainly effected by the hyohyoideus and transversi ventrales; the levatores arcuum branchialum as well as the interarcuales (obliqui) also contributing somewhat to this movement. The hyohyoideus consists of a broad muscular sheet overlying the gullet (posterior to the interhyoideus), arising from the inner ventral edges of the opercular bones (interopercular, subopercular) and running antero-mesially to insert on the hypohyal and/or on a medial raphe to its fellow from the opposite side. The transversi ventrales run from the ventral parts of the branchial bars inwards to meet their opposite fellows medially, but the transversus ventralis IV inserts mesially on the anterior process of the pharyngeal bones.

The movements of the pharyngeal bones are commanded by a set of specialised muscles mainly derived from the musculature of the 5th gill arch and working antagonistically. Enlargement of the posterior pharynx cavity, mainly through contraction of the coraco-branchialis posterior and cleithro-pharyngeus muscles, admits food to the pharyngeal teeth area where it can be masticated. The first of these muscles arises from the mesial antero-dorsal surface of the coracoid (being also partly continuous with the body muscles) and inserts anteriorly on the ventral aspect of the rostrad ends of the pharyngeal bones. The second originates from the anterior dorsal surface of the ventral part of the cleithrum (external and posterior to the sterno-hyoideus), runs forward and medially over the latter to insert on the inner (ventral) lateral border of the pharyngeal bone; usually, it consists of an anterior and posterior part, the fasciae of which cross over each other.

Contraction of the posterior pharynx brings the pharyngeal teeth together and up against the dorsal plate; this is brought about by the action of the $L e$ vator arcus branchialis $V$ and retractor arcus branchi- 
alis dorsalis inferior muscles, the first of which originates in the subtemporal fossa (surrounded by the exoccipital, epiotic \& pterotic) and inserts ventrally on the tip and posterior edge of the ascending process of the pharyngeals. Interior (mesially) to the origin of this muscle arise 3 or 4 small, thin muscles which run ventrad to insert through a tendinous cauda on the dorso-lateral part of the upper pharynx wall (the 2 anterior muscles); the posterior muscular strands run along the hind edge of the ascending pharyngeal bone process to insert on the lateral pharynx wall. Upon contraction, they draw the posterior pharyngeal walls upwards, dilating the cavity. These muscles are evidently derived from the levator arcus branchialis V. The second is derived from the sphincter oesophagi, arises from the posterior aspect of the latero-ventral process of the pharyngeal bone and runs obliquely back-, in- and up-wards to insert mesially on the posterior part of the pharyngeal process (basi-occipital process). Some fibres also insert on the dorso-lateral walls of the pharynx, and contribute to its dilatation. The retractor arcus branchialis dorsalis superior is a small, narrow muscle originating from the pharyngeal process (anterior to the preceding muscle) and running forward mesial to the ascending process, to insert through a long tendinous cauda onto the rostrad (inner) edge of its upper part. Contraction of this muscle pulls the ascending pharyngeal process caudad and inwards, swinging the ventral part of the pharyngeals somewhat down, the particular anterior insertion of the muscle causing a torsion which twists the lower parts of the bones laterally outwards; hence, the action of this muscle also contributes towards enlargement of the posterior pharyngeal cavity.

Ventrally, below the pharyngeal teeth area, the transversus ventralis $\boldsymbol{V}$ arises from the inner edge of the posterior latero-ventral process and runs mesially to meet its fellow from the opposite side; contraction of this muscle draws the two pharyngeal bones together, also approximating the teeth. Behind the pharyngeals, a sphincter oesophagi surrounds the oesophagus; relaxation of this muscle whilst the (posterior) pharynx contracts, admits food to the oesophagus and hence to the intestine. This muscle, though continuous, may be divided into three parts, namely: an anterior constrictor pharyngis part surrounding the posterior pharyngeal chamber immediately behind the teeth; a median circular muscle part around the short oesophagus and a posterior oesophageal-intestinal sphincter part, at its junction with the intestine.

Alternating contractions of these muscles working as antagonistic pairs, enable the pharyngeal teeth to work in various ways against the upper sclerous plate and/or against each other, e.g.: crushing (up and down), grinding (rotatory), lacerating (lateral) and shearing (back- and forwards) movements. Mastication is the lengthiest process of the feeding actions, as can readily be observed on living fish; these movements can be effected while respiration is going on, thanks to the posterior position of the pharyngeal bones and teeth, so that there is no interference between deglution, mastication and respiration.

An important point to stress is that no cyprinid species has been observed to regularly pass sand, mud, or other debris through its gills, whilst retaining the larger organisms on which it feeds. This sorting or sifting action is the rule in silurids and quite common in other fish groups, but in Cyprinidae generally, the sorting-out process takes place inside the mouth and anterior pharynx cavities, rejected material being evacuated through the mouth.

This spitting movement is effected through contraction of the pharynx, bringing into action mainly the subarcuales, levatores arcuum branchialum, hyohyoideus, interhyoideus, and adductor arcus palatini muscles, simultaneously with relaxation of the coracobranchialis anterior, and sternohyoideus muscles, whilst the mandible is quickly depressed (through contraction of the geniohyoideus, this also assisting in raising the hyoid apparatus) and the whole protrusile mouth apparatus thrown forwards. Thus, the posterior constriction raising the pressure and the anterior protrusion (dilatation) of the mouth lowering it, a strong forwards current is set up, ejecting water and all loose particles. The absence of a mandibular valve in members of this family is clearly a character in relation to this habit.

Those species which feed mainly by a method of picking up mouthfuls of (bottom) sediments and vegetable matter, sorting out suitable food particles in the bucco-pharyngeal activity, characteristically have a strongly protrusile, inferior mouth, as well as a thick pharyngeal pad and well developed gill-rakers meshing closely to form a sieve or even to completely isolate the pharynx from the gill chambers.

Food particles, whether composed of vegetable or animal matter, are retained during the spitting out of rejected material in the following way:

1. In the bucco-pharyngeal cavity they become thoroughly mixed with and entangled in the mucus produced by the goblet cells.

2. When the mouth opens and the pharynx contracts during spitting, the papillae and plicae on the mucous lining, especially those on the pharyngeal 
pad, trap them in the anterior pharynx between the raised floor and dilated pharyngeal pad, the latter even acting as a press in the final stages of constriction, squeezing out the water (through the gill sieve in many species).

There probably exists some factor-e.g. pertaining to surface tension phenomena-which causes the mucus to adhere closely to organic matter (food), whereas inorganic particles will remain relatively unaffected, and can thus be easily rejected. That this process is far from infallible is evidenced by the quite considerable quantities of sand, mud, etc. which are nevertheless regularly present in the digestive tract of the bottom-feeding species.

\section{ECOLOGICAL CLASSIFICATION}

The African Cyprinidae can be divided ecologically into two major groups, i.e.:

Open-water forms: including most of the more specialised types.

Species belonging here are generally small and largely carnivorous, feeding on fish, insects, crustacea and other invertebrates, or plankton-eating (zooplankton mostly).

Morphologically, this group is characterised by large-mouthed, elongate (streamlined) species, which can also be considered ecologically as "sprinters" (see Boddeke, Slijper \& v. D. Stelt, 1959). The mouth is usually terminal and somewhat less protractile than in fishes belonging to the next group.

Species of the genera Leptocypris, Barilius, Chelaethiops, Engraulicypris, Coptostomabarbus and some of the large Barbus species (the predatory ones) can be classified here.

Bottom-living forms: This group also includes some highly specialised types as well as most of the more primitive members of the family. Fishes of this group are mainly herbivorous (algae, waterplants), omnivorous or even detritivorous. Some may be predominantly carnivorous, feeding on small bottom invertebrates (insect larvae). Most however, are characteristically facultative feeders.

Morphologically, members of this group consist of stocky forms with well-developed sense organs (taste, touch), e.g. barbels, fringed, papillose lips, etc., around the mouth, which is usually inferior. Their body-form also tends to be less compressed laterally. These fishes may be considered as "stayers" and "crawlers", as regards their mode of life.

The following genera are represented here: most Barbus species, Caecobarbus, Barbopsis, Phreatichthys, Varicorhinus, Garra and Labeo.
Labeo Cuvier, 1817.

Species studied: L. lineatus BLGR., 1891 (Congo basin)

L. variegatus PeLl., 1901 (StanleyPool, Congo)

L. annectens BLGR., 1903 (W. Africa:

Nigeria, Cameroun)

L. niloticus (ForsK., 1775) (Nile)

(See also Grigrs, 1952).

\section{General characters}

Carp-like species, usually large $(20-60 \mathrm{~cm}$.)

Two major groups can be clearly distinguished among the Labeo species; One is characterised by a compressed body form, relatively small head, lateral eyes, rather small, protractile, suckerlike, transverse, inferior mouth with thickened fringed lips, the inner surface of which bears no transverse plicae ( $P l$. I, a). The rostrum is weakly developed and there is a perfectly formed vomero-palatine organ.

e.g.: $L$. lineatus, $L$. niloticus, $L$. horie (studied by GIRGIS, l.c.).

The other group has a more distinctly cylindriform body, larger head, supero-lateral eyes, a wide, inferior, strongly protractile mouth, bordered by thick, fringed, papillose lips bearing transverse plicae, and a well developed rostrum ( $P l$. III, a), limited posteriorly by a deep transverse furrow across the snout. A vomero-palatine organ is present, but is irregular in form and poorly developed. Also, the barbels, when present, are better developed, as well as the horny cutting edge along the jaws. Moreover, the gill slits usually don't extend as far forward ventrally, the gill membranes being broadly united with the isthmus, and the posterior lobe of the air bladder is very small in some species ( $L$. variegatus) but quite normal in others (L. annectens).

\section{Ecology}

Members of the first group as defined above, live mostly in large, more or less muddy streams, quiet backwaters and lakes, where they feed on diatoms, microscopic algae (e.g. Desmids), filamentous algae, and on animal micro-organisms and higher waterplants as well. The food is obtained largely from the (muddy) bottom and banks, but also from submerged vegetation, tree-trunks, rocks, etc. Though they generally live on or near the bottom, they are nevertheless good swimmers and can easily surmount strong currents.

In the second group, $L$. variegatus is a small species living in the rapids of the lower Congo (near Leopoldville) and has adapted to a more torrenticolous life, as is evidenced by its more cylindrical body- 
form, more or less horizontally placed paired fins, the reduction of the air bladder, etc. (see also Hora, 1930). It feeds mainly on the algal growth covering the rocks, and more particularly on the microscopic algae and diatoms which it sucks out from between the algal filaments. It is also a very able swimmer.

$L$. annectens and other members of the second group usually live in the upper reaches of rivers where the water is clearer and more turbulent; they also tend to be more microphytophageous than those of the first one.

Some species not studied here have an exceedingly developed rostrum, for instance; $L$. cylindricus, $L$. sorex, etc., which evidently serves to stir up the bottom sediments and detritus. In the latter species the eyes are greatly reduced in size, indicating a preference for a practically lightless habitat (deep, muddy river stretches).

\section{Functional morphology}

External features: The rostrum consists largely of thickened connective tissue and fat overlying the upper jaw bones and forming a rostral flap anteriorly, which partly overhangs the upper lip when the mouth is closed. It is covered by tough skin and usually bears numerous horny tubercles, particularly apparent in the $\delta$. The rostral flap is fringed, bearing 2 or 3 alternating rows of small sensory papillae along its lower edge.

A single pair of barbels is present in L. variegatus; they are absent, or represented by a rudimentary pair hidden in the folds at the side of the mouth, in the 3 other species considered. The fleshy lips are strongly fringed by 2 or 3 rows of small papillae of various size. Transverse ridges (5-8) of confluent papillae are present on the inner side of the lips in some species, greatly increasing the sensory surface (Pl. I, c).

Laterally and ventrally, a deep post-labial groove separates the lower lip from the isthmus or "chin"; the caudad parts of the premaxillaries and maxillaries also fit laterally into this groove when the mouth is closed ( $P l$. I, a; $P l$. III, a). The maxillaries are visible laterally when the mouth is protruded.

Taste buds and some mucus cells are present on the lips, particularly on the papillose plicae, as well as on the barbels (Gincis, l.c.). Numerous nerve endings are also apparent in these structures.

Bucco-pharyngeal cavity:

a) The prehensile apparatus: In this genus it is more of a sucking and scraping apparatus formed by the thick, continuous lips surrounding the sharp cutting edges of the jaws, behind which lies the enlarged buccal cavity ( $P l$. I, b \& c). The premaxillaries have no ascending process (premax. pedicel), their anteromesial ends being directly connected to the sigmoid ligament and hence, through the rostral bone lying more or less horizontally between the anterior ascending processes of the maxillaries, to the vomeromesethmoid fork (Pl. III, b). Right and left premaxillaries are joined anteriorly by a membraneous ligament. The lower jaw halves join antero-mesially through an interdentary cartilage. WEBER \& DE BEAUFORT (1916, pp. 212-213, figs. 82-83) mention a large inner fold, running transversely along the entire lip circumference in Labeo erythropterus C. \& V., 1842 (Java). None of the African species examined however, shows this feature. When the mouth is protruded, the lips draw back and spread outwards, exposing the cutting jaw edges, thus enabling the fish to "graze" on, or scrape loose the biological covering of the substrate and subsequently suck in the loosened material through dilatation of the buccal cavity. These horny cutting edges consist of hardened epithelial cells (stratum corneum) formed by the specialised underlying epithelium (stratum germinativum). This stratum corneum forms a deciduous horny sheath along the jaw edges (Girgis, l.c.). The maxillary valve, bordering the upper jaw internally and which often also bears tiny papillae, moves forward and comes into contact with the mouth floor, effectively closing the mouth aperture, when the internal water pressure is raised during contraction of the buccopharyngeal cavity.

As is the rule in Cyprinids, the mouth floor over the "tongue" area bears numerous, parallel plicae, which run obliquely outwards and backwards from the median line and become deepened posteriorly. The epithelium between the lower jaw halves, in front of the "tongue", however, is entirely smooth (Pl. I, c).

Musculature of the mouth: (Pl. III, b \& c). The short geniohyoideus originates from the anteroventral extremities of the interopercle and the $1 \mathrm{e}$ and $2 \mathrm{e}$ branchiostegals to insert anteriorly on the caudad inner edge of the dentaries and interdentary cartilage. The posterior sternohyoideus, which pulls the hyoid apparatus down- and back-wards, dilating the buccal cavity, inserts rostrally into the urohyal fossa and onto the median urohyal spine (anterior part). Part of the abdominal musculature, which inserts anteriorly on the inner (caudad) surface of the urohyal also assists in depressing the hyoid apparatus.

The adductor mandibulae complex, closing the 
mouth, consists of three distinct muscles, namely: the maxillaris $\left(\mathrm{A}_{1}\right)$, which consists of a broad muscular sheet originating from the preopercular and quadrate and inserts anteriorly through a tendinous cauda on the external rostral side of the maxillary in species of the first group ( $L$. lineatus, etc.), depresses the snout and pulls upper lip and maxillary backwards. The mandibularis consists of two parts $\left(\mathrm{A}_{2} \&\right.$ $A_{3}$ ) lying under $A_{1}$; in species of the first group, $A_{2}$ comprises two fasciae $\left(\mathrm{A}_{2}^{\prime} \& \mathrm{~A}_{2}^{\prime \prime}\right)$ of which the upper $\left(A_{2}^{\prime}\right)$ has two capita, the anterior one originating in the orbit, mainly on the metapterygoid; the posterior from the hyomandibular and upper preopercular, partly internal and partly external to the levator arcus palatini. Beneath the eye, just before fusing with the anterior caput, it is greatly narrowed and tendinous. This fascia inserts rostrally on the anterior inner edge of the mandible and dorsally sends a tendinous cauda to the caudad part of the maxillary in L. lineatus, but not in the other two species studied. The lower fascia $\left(A_{2}{ }_{2}\right)$ is flat, originates from the preopercular, lower hyomandibular and the surface of $A_{3}$ and runs rostro-ventrally, joining $A_{2}^{\prime}$, to insert on the mandible just behind it. $A_{3}$ originates in the orbit from the metapterygoid and hyomandibular behind $A_{2}^{\prime}$, and runs ventrad under $A_{2}$ to insert on the posterior inner edge of the mandible. Contraction of $A_{2} \& A_{3}$ lifts the lower jaw, closing the mouth. Furthermore, contraction of $A_{3}$ will also tend to raise the mouth floor, constricting the buccal cavity.

In species of the second group on the other hand, $A_{1}$ possesses an upper fascia which originates in the orbit anterior to the head of $A_{2}^{\prime}$, and joins the main muscular mass anteriorly ( $P l$. III, c); it probably represents the anterior caput of $A_{2}^{\prime} . A_{2}$ also has two fasciae, the upper one $\left(A_{2}^{\prime}\right)$ originating in the orbit only and joining the lower $\left(\mathrm{A}_{2}{ }_{2}\right)$ to insert on the mandible ventrally. The thin $A_{3}$ muscle does not differ substantially from that in members of the first group, which seem to possess a more specialised type of musculature.

There is no intramandibularis and no intermandibularis muscle present.

The levator arcus palatini, besides raising the hyomandibular arch, also causes an outward swing of the whole suspensorium, thus enlarging the bucco-pharyngeal cavity.

b) The selective apparatus: This shows some extremely specialised and interesting features. The roof of the buccal cavity curves strongly upwards behind the jaw region, forming an oval depression from which a lamellar vomero-palatine organ hangs down.
Posteriorly, the thick pharyngeal pad (palatal organ) overhangs the anterior pharynx floor, reducing the pharyngeal cavity to a broad, narrow slit (Pl. I, b).

The remarkable vomero-palatine organ is ovoid and consists of two parallel rows of broad, thick, papillose lamellae medially, bordered laterally by an external row of long, thin, irregularly shaped lamellar projections, partly lying in a groove ( $\mathrm{Pl}$. II, a). It lies under the vomer anteriorly, the parasphenoid posteriorly, the palatines and mesopterygoids laterally. The palatal epithelium adjacent to the lamellae is finely plicated longitudinally. The number and development of the lamellae varies from one species to another and they are also less developed in the young; usually, they number 6-10. The lateral row is very variable, and may even be absent altogether or reduced to a ridge ( $L$. niloticus). Though the vomero-palatine organ may differ in minor details, it is however quite constant in form and size in species of the first group but in those of the second group, it shows a much more primitive state.

In $L$. variegatus ( $P l$. I, d) only two lamellar, crenulated folds running obliquely backwards and several irregular, serial papillose projections are developed medially in the oval depression of the mouth roof. The two lamellar folds apparently correspond to the external row of lamellar projections in fishes of the first group, whereas the few large median projections represent a draft of the median lamellar series.

In young specimens of $L$. annectens the oblong depression of the mouth roof is bordered by a membraneous ridge and a double series of large, rounded papillae are separated by a deep median groove.

Posteriorly, the palate curves down sharply, and a semicircular, feebly papillose ridge marks the separation between vomero-palatine organ and pharyngeal pad. The latter, or "palatal organ" as it is often called, is a thick cushion-like papillose pad lying under the parasphenoid and metapterygoid anteriorly, the basisphenoid, basioccipital and pharyngobranchials posteriorly. It is divided medially by a shallow longitudinal groove into right and left lobes and bears varishaped papillae, long anteriorly, smaller, but more numerous posteriorly, which project into the narrow pharyngeal cavity (Pl. I, b \& Pl. II, c). Thus food particles, entangled in mucus, will get snagged between the papillae when the mouth closes and the entire pharyngeal apparatus contracts, expelling water through the gill filter.

The anterior pharynx floor is more or less triangular, with the apex pointing backwards and a plicated, slightly convex surface which becomes concave posteriorly and laterally over the branchial arches. The 
caudad portion of the pharynx floor, overlying the anterior pharyngeal bone process, rises sharply towards the pharyngeal teeth area, following the upward curvature of the pharyngeal pad. This triangular portion has a forwardly directed apex and is also somewhat thickened, forming a small ventral pharyngeal pad which bears small plicae running antero-laterally from the median line ( $P l$. III, d). The curvature of the pharynx floor is such that it fits exactly onto the pharyngeal pad surface.

Histological investigation (see also Gircis, l.c.) shows that the mucosa of the bucco-pharyngeal cavity consists of stratified epithelium with numerous mucus cells (goblet cells) and taste buds (particularly on the crests of the folds). These specialised cells are everywhere present, on the vomero-palatine organ, the pharyngeal pad, as well as on the maxillary valve. The goblet cells (mostly situated on the sides of the folds) increase in number posteriorly. The numerous taste buds denote a highly developed gustatory sense, which again is typical for plant-eating species as well as for those which engulf much inorganic matter along with food particles. The epithelium is usually more or less stratified and in some places even becomes cornified and can be desquamated.

The submucosa consists of areolar tissue and collagen fibres with capillaries, nerves, connective tissue and fat cells. Though a few striate muscle strands are present in the vomero-palatine organ, no true muscularis layer is developed there $(P l . \mathrm{V}, \mathrm{a})$, though it is present laterally, under the palatal epithelium. In the pharyngeal pad, striate muscle fibres run in all directions, but areolar connective tissue, fat cells, elastic and collagen fibres make up most of its mass. Posteriorly, the dorsal pharynx epithelium becomes more and more stratified and horny untill it abuts the horny pad against which the pharyngeal teeth work.

The regular form of the vomero-palatine organ suggests some specialised function in relation to feeding; however, no voluntary muscle being present, any active function is excluded. Girgis (1952) studied the nerve endings by silver impregnation and found that they were no different from those in the adjacent epithelium. Therefore, the primary function of the organ seems to be the great increase in surface of the mucous membrane brought about by its lamellar structure. Another passive function can be suggested however, namely that of ensuring thorough mixing of tiny food particles (e.g. diatoms), suspended in the water, with mucus before they are passed backwards and the water is fitered out through the gill-raker sieve. This mixing can be brought about by alternate dilatation and contraction of the anterior mouth cavi- ty and the posterior mouth and anterior pharyngeal cavities, while the mouth remains closed and the pharyngeal pad expanded, closing off the pharynx over the gill area. These mouvements will set up back and forth water currents with corresponding movements of the lamellae. Lowering and raising of the mouth floor through action of the sternohyoideus and hyoideus will also contribute considerably to the mixing movements and even action of the epithelial muscularis may not be negligible. Thus small water currents will pass over and between the lamellae; the suspended food particles passing closely over the epithelial surface will become entangled in mucus before being passed backwards to the pharynx. It would be interesting to obtain experimental confirmation of this hypothesis which is mechanically feasible and further supported by the observation of small, rapid munching movements in live specimens, with mouth closed, alternate raising and lowering of the hyoid apparatus, and no apparent expulsion of water through the gills while this takes place.

The branchial arches support on the ceratobranchials and the distal part of the epibranchials the gill lamellae externally and the gill-rakers internally to the pharyngeal cavity. The latter are long, slender, closely set parallel to each other, numerous, varying from 50 to 100 in adult fish, and inserted in two rows laterally along each arch. Those in the outer row of the first branchial arch are distinctly longer than those of the inner rows, more or less setiform, and rest against the inner opercle wall, thus completely closing off the anterior pharynx from the gill chamber. Each gill-raker is free at its distal end only in the inner rows, and is joined by a membraneous, lamellar connection to a median ridge running along the length of the arch. The gill-rakers of adjoining arches mesh at their distal halves only, but each bears tiny lateral projections along the inner lamellar ridge, which mesh in turn with similar projections from its neighbour ( $\mathrm{Pl}$. II, b). This whole apparatus forms a very efficient sieve, allowing water to flow through towards the gills whilst retaining all other particles (food, sand, mud, etc.).

No distinctly formed micro-gill-rakers like those of Tilapia nilotica (L., 1758) or Citharinus congicus BLGR., 1897, all microphytophageous and pelophageous species (Gosse, 1956), have been found in Labeo. However, numerous tiny papillae are to be seen, dispersed on the epithelium of the gill arches, and may in some cases (e.g. L. niloticus, $L$. variegatus) form a regular row of micro-papillae along the bases of the gill-rakers. Even the epithelium covering the inner surface of the opercula may bear tiny 
papillae, particularly apparent in $L$. variegatus.

The gill lamellae often show numerous small transverse ridges, giving them a serrated appearance, as well as a tendency to become feathery at their extremities, a feature which is very prominent in Garra spp. (Pl. IV, c), and which probably has nothing to do with feeding, but serves essentially to increase the respiratory surface, a character which is evidently of survival value for bottom-living species where oxygen deficiencies in the environment are common. It is therefore surprising to observe that this particularity of the gills is most developed in fishes like $L$. variegatus and Garra which live in rapids, where the water is theoretically always well oxygenated. It could be a feature developed in connection with mechanical breathing difficulties in violent water currents.

The epithelial covering of the gill arches and gillrakers is thin and contains taste buds and mucus cells, the gill-rakers having tastebuds on their inner edge (lamellar ridge) and a row of goblet cells along each side.

Musculature of the anterior pharynx: The narrow hyoideus muscle lies internal to the hyoid arch and originates on the surface of the caudad portion of the basihyal to run cranially, backwards and laterally (along the lateral border of the pharyngeal pad) to insert on the caudad surface of the proximal part of the hyomandibular. It raises the posterior mouth- and anterior pharynx floor. The large, flat adductor arcus palatini is largely situated dorsal to the pharyngeal pad and brings about lateral constriction of the bucco-pharyngeal cavity. In the throat region, constriction of the pharynx is effected by the transverse interhyoideus and hyohyoideus muscles, which form a thin, broad muscular sheet lying under the branchial arches, between the sternohyoideus and the broad urohyal and the branchiostegals. The subarcualis communis also, by raising the pharynx floor, contributes to constrict the pharynx due to its posterior part lying higher than the anterior $(P l . I V, b)$.

Dilatation of the pharynx is effected by contraction of the muscular pharyngeal pad, the levator arcus palatini, levator operculum and coraco-branchialis an terior, which inserts rostrally on the ventral aspect of the 4th ceratobranchial and 3rd basibranchial and partly on the anterior cartilage of the pharyngeal bones ( $P l$. IV, a), and dilates the anterior pharynx floor.

The masticatory apparatus:

The pharyngeal bones ( $P l$. II, d), each of which is more or less triangular in shape, meet antero-mesially at an angle of about 80 to $90^{\circ}$; they are relatively small compared with those of other African Cyprinids and so positioned that the pharyngeal teeth can practically only work up and down against the dorsal horny pad. A long, thin cartilage originates from the antero-dorsal part of the anterior processes, above their symphysis, and runs forwards to the posterior tip of the basi-branchials. The posterior ventral processes curve sharply downwards and but little outwards laterally; the dorsal processes are quite straight, curving somewhat outwards at their tips. The three processes form a striated bony border surrounding the spongy part which projects medially and bears the teeth.

The pharyngeal teeth (Pl. II, d) are homodont and placed in three rows, the teeth formula being: 2-3; $3-4 ; 5$ - 5; 4-3; 3-2. They have flattened, \pm compressed crowns, some being slightly excavated and more or less spoonshaped, lying close together and forming a \pm oval grinding surface which projects into the posterior pharyngeal cavity and works against the upper horny plate.

The horny plate is a \pm heart-shaped, hard, cornified, deciduous, brown-coloured structure composed of dense connective tissue and numerous collagenous fibres, which is attached dorsally to the laterally broadened masticatory process of the upper pharyngeal bone and is covered by a two-layered epithelium composed of basal columnar cells and a horny layer of enucleate cells forming a stratum corneum (Girgis, l.c.). This horny layer bears short longitudinal grooves or striae anteriorly and two diverging series of grooves postero-laterally. The lateral wall of the posterior pharynx is muscular, has deep, anastomosing longitudinal folds, which are continued into the oesophagus, and numerous goblet cells to ensure efficient lubrication of the food. The teeth area is bordered anteriorly by a narrow strip of smooth stratified epithelium, laterally and posteriorly by a crescentic pad of hardened (stratified) epithelium, bearing transverse ridges (Pl. III, d).

The masticatory musculature: (Pl. III, c \& $P l$. IV, a \& b).

Contraction of the coraco-branchialis posterior and cleithro-pharyngeus muscles dilates the posterior pharynx, admitting food to the pharyngeal teeth area. The latter muscle is simple and consists of a thin, broad muscular sheet overlying the sternohyoideus and running obliquely caudad, ventrad and laterally; it pulls the pharyngeal bone down and outwards. Contraction of the subarcualis communis, besides raising the anterior pharynx floor, also acts antagonistically to 
the coraco-branchialis posterior, pulling the pharyngeal bones forwards and somewhat down, thus contributing to dilate the posterior pharyngeal chamber behind the teeth.

Constriction of the posterior pharynx is effected by the action of the levator arcus branchialis $V$, retractor arcus branchialis dorsalis inferior and transversus ventralis $\mathbf{V}$ muscles, the first of which has two fasciae a narrow upper one and a broad, posterior, lower fascia which originates partly in the subtemporal fossa and partly (the posterior portion) from the ventrad surface of the opisthotic and posttemporal; ventrally, it inserts along the greater length of the convex caudad border of the ascending pharyngeal bone process. It draws the pharyngeals up and slightly forwards, bringing the teeth up against the horny plate. The second runs obliquely dorsad, caudad and mesially, to insert mainly on the lateral flange of the posterior part of the pharyngeal process (upper pharyngeal bone); this muscle retracts the pharyngeals dorsad, inwards and caudad, bringing the teeth upwards and towards each other. The transversus ventralis acts antagonistically to the cleithro-pharyngeus, drawing the pharyngeals together.

The role of the thin retractor arcus branchialis dorsalis superior ( $P l$. III, c) lies mainly in pulling the ascending process backwards and inwards, this twisting movement causing a corresponding downward and outward movement of the caudad ventral pharyngeal bone parts, separating the teeth and dilating the posterior pharynx chamber. When the oesophagus dilates, relaxation of this muscle, coupled with contraction of the levator $\mathrm{V}$, retractor inferior and the pharyngeal wall muscles, will drive the finely ground food into it and hence to the intestine.

\section{The digestive tract}

The short, muscular oesophagus has large mucosal folds running longitudinally and continuous poste- riorly with those of the anterior intestine; its lumen is narrow, mucus cells are very numerous and taste buds gradually disappear; the muscularis is composed of a thin inner layer of longitudinal fibres and a thick outer one of circular fibres, all striate.

The intestine has an anterior swelling, the intestinal bulb, which serves as "stomach", followed by an extremely long, coiled, undifferentiated intestine. There is no anal sphincter. The mucosal folds are \pm longitudinal and few in number anteriorly (in the intestinal bulb), becoming more numerous, anostomosing and wavy further back, finally forming zigzag lines and becoming transverse posteriorly. The muscularis is mainly composed of smooth circular fibres, some striate and considerably more longitudinal fibres being present in the anterior bulb part, where goblet cells are also still present. All that need be said here about the other organs related to digestion is that the pancreas is diffuse, being scattered about in the omenta which hold the intestinal coils together, and the liver, thin, elongate and poorly developed, lying dorsally, with the relatively large, elongate gall bladder medially beneath it.

An important character of the digestive tract in relation to the nature of the food is the relative length of the intestine; this is expressed by the ratio intestine length/standard length (body). The following table shows the ratios found for the species studied.

Taking into consideration that relative gut length increases with body size (this being in relation to the condition factor, a greater bulk necessitating a proportionally much greater absorption surface) and that the examined specimens are small-sized, $L$. variegatus has a longer intestine than the other species, which is to be expected in connection with its more purely microphytophageous habit. There is, however, considerable individual variation in the intestinal lengths. A comparison of these ratios with those given for the

TABLE II

\begin{tabular}{|l|c|c|c|c|}
\hline \multicolumn{1}{|c|}{ Species } & $\begin{array}{c}\text { Number of specimens } \\
\text { examined }\end{array}$ & $\begin{array}{c}\text { Size range of spec. } \\
\text { examined } \\
(\mathrm{cm})\end{array}$ & $\begin{array}{c}\text { Gut length/standard } \\
\text { length } \\
\text { (variability) }\end{array}$ & Mean ratio \\
\hline Labeo horie* & 33 & $2-58,5$ & $14-21$ & $\pm 15,5$ \\
L. lineatus & 5 & $9,1-31,0$ & $12,4-19,9$ & 16,1 \\
L. niloticus & 1 & 16,2 & 16,9 & $(16,9)$ \\
L. variegatus & 2 & $8,7-9,0$ & $16,8-17,1$ & 16,95 \\
\hline
\end{tabular}

*From Girgis (1.c.) 
Carp (AL-HussainI, 1949), i.e. 1,8-1,9, gives a good idea of the great gut length in Labeo.

Another interesting feature concerns the lining of the abdominal cavity, which is strongly blackened by numerous melanophore cells in L. lineatus and L. niloticus. This black lining is typical of phytophageous fish, particularly in open-water forms, as well as of many pelagic species, and it is thought to be a protection against ultra-violet radiation which may destroy the digestive enzymes (HuBBs, 1941). In L. variegatus and $L$. annectens (juveniles), this blackening is much less apparent, presumably owing to their more benthic mode of life, less exposed to penetrating solar radiation. It is also possible, however, that this pigmentation is merely a consequence of the deposition of metabolic waste products in the peritoneum which cannot be gotten rid of in other ways (excretion). These would be present in greater quantity in planteating species.

\section{Conclusion}

The remarkable feeding mechanisms developed in this genus show it to be one of the most highly specialised among the African Cyprinidae, presenting some unique morphological adaptations to a phytophageous, pelophageous and/or a microphageous diet. It is interesting to note that the $L$. variegatus group, though better adapted to a benthic mode of life, and in spite of a more microphageous diet, shows less specialisation in apparently important features like the vomero-palatine organ or the gill-raker sieve.

\section{Garra Hamilton Buchanan, 1822.}

Species studied: G. dembeensis (RüpP., 1837) (Nile, East Africa, N. E. Congo)

G. congoensis PoLl, 1959 (Congo: Stanley-Pool rapids)

\section{General characters}

Small species $(7-15 \mathrm{~cm}$.) with an elongate, more or less cylindrical body, often somewhat depressed, especially anteriorly. The paired fins are also nearly horizontally placed. The protractile mouth is inferior, transverse, the sharp cutting edges of the jaws forming a crescentic slit. The lips are more or less developed, continuous laterally, the posterior part of the lower lip modified into a labial suctorial disc bordered anteriorly by a labial fold. A rostral flap is absent or but poorly developed, but the upper lip, which is quite stiff, overhangs the upper jaw and has a crenulated edge ( $P l . \mathrm{V}, \mathrm{b})$. A transverse rostral furrow, usually bearing tubercles, is often present across the snout. One or two pairs of barbels (rostral and maxil- lary) are present, but small. The gill slits are restricted to the sides and the air bladder is small, lying far forwards, the posterior lobe poorly developed.

\section{Ecology}

Species of this genus are typical torrenticolous, bottom-living forms, as is clearly shown by their various characteristic adaptations, i.e.: the body-form, horizontal fins, restricted gill openings, adhesive disc, reduced swimbladder, etc.

They are omnivorous, feeding mainly on the filamentous algae and associated micro-organisms forming the biological covering of the rocks, logs, etc., of their habitat, as well as on the small invertebrates which find refuge there. The food is scraped off the substrate by the sharp jaw edges and then sucked in through alternating dilatations and contractions of the bucco-pharyngeal cavity.

\section{Functional morphology}

External features: As in Labeo, the fringed upper lip-on the external surface of which small papillae may also be present-, the papillose areas of the lower lip, and the barbels have a sensory (gustatory) function. Small papillae are particularly apparent along the lower lip fold as well as on the soft margins of the suctorial disc.

\section{Bucco-pharyngeal cavity:}

a) The prehensile apparatus: This shows many similarities with that of Labeo; the jaws are covered with a deciduous horny sheath forming a cutting edge; the premaxillaries also have no anterior ascending process, but the dentaries meet in a median symphysis and no interdentary cartilage is present. The suspension of the lower jaw is quite complex, the articular bone articulating posteriorly with the quadrate above (mostly) and the preopercular below (slightly); ventrally, the angular articulates with a facet onto the interopercular and the 1st branchiostegal; a ligament also runs from the latter to the angle between the caudad processes of the angular ( $P l$. IV, d).

The mechanism for protrusion of the jaws is basically identical in the two genera, particularly with the species of the $L$. lineatus group.

Musculature of the mouth: This shows several interesting and previously undescribed features in relation to the mode of life of these fishes. Anterior to and parallel to the geniohyoideus-which originates from the rostral extremities of the 2nd branchiostegal and the ceratohyal to run obliquely forwards and dorsad, and inserts on the inner border 
of the mandible, just behind and below the coronoid process-lies a more superficial muscle, which has been named the adductor discus suctorius anterior (Pl. IV, d).

This muscle originates from the fleshy cushion in the middle of the adhesive disc and runs laterally, dorsad and rostrad to insert on the inner dentary border just anterior to the insertion of the geniohyoideus. On contracting, it pulls the fleshy cushion upwards, thus creating a strong suction when the disc is pressed against the substrate; it also assists in depressing the mandible, so that the fish can open its mouth even when it is attached to the substrate. Behind this muscle and ventral to the anterior part of the hyohyoideus, another, smaller adhesive disc muscle, the adductor discus suctorius posterior, originates from the anterior ventral extremities of the 2 nd and 3 rd branchiostegals and runs transversely to insert on the postero-mesial part of the disc, meeting its fellow from the opposite side medially. On contraction, it pulls the fleshy cushion up and laterally outwards.

Hora (1922) describes a median tendon running from the centre of the disc (callous portion) towards the anterior urohyal in Asiatic Garra species; lifting of the urohyal would then exert the necessary suction for attachment. No trace of this was found, however, in the spp. studied, not even in G. lamta HAM. Buch., 1822, an Asian species which was also examined, though there are connective tissue attachments anteriorly, to the short, rounded glossohyal. Hora also seems to have missed the particular muscular arrangement, though he describes and figures (p. 47) a single muscle, the "muscle joining the two sides of the anterior jaw", which appears to represent both the geniohyoideus and the posterior adductor. Moreover, the arrangement as described by him would have a definite drawback, namely, that while remaining attached, the fish must keep the urohyal (and hyoid apparatus) lifted-through contraction of the geniohyoideus, hyoideus and hyohyoideus mainly -which will also keep the bucco-pharyngeal cavity constricted and probably seriously interfere with respiration.

The anterior suctorial disc adductor appears at first sight to be a modification of the geniohyoideus, but it could as well represent a modified intermandibularis. However, the fact that it is paired and that a thin muscular strand, lying transversely along the caudad dentary margin was found in a carefully dissected specimen of Garra dembeensis, probably representing a degenerate intermandibularis, weigh against it. If, as in Barbus, the geniohyoideus is composed of an intermandibularis posterior part (sensu, EDGEWORTH,
1935) and part of the interhyoideus, forming a protractor hyoidei, the anterior disc adductor could represent its intermandibularis part and the geniohyoideus its interhyoideus part. The absence of a distinct interhyoideus in the species studied suggests that it has probably been entirely modified in this manner. Similarly, the posterior adductor may have been derived either from superficial skin muscle or from the geniohyoideus, or rather part of the interhyoideus. Only further research on the ontogeny of these muscles will give an unambiguous answer to this problem.

The abdominal muscle fasciae which insert posteriorly on the dorsal surface of the broad, flattened urohyal also contribute to depress and pull back the hyoid apparatus, enlarging the bucco-pharyngeal cavity.

The following differences from Labeo lineatus may be noted in connection with the adductor mandibulae:

1. The maxillaris $\left(\mathrm{A}_{1}\right)$ has two fasciae, an upper $\left(A_{1} \beta\right)$ lying internal to a lower one $\left(A_{1} \alpha\right)$ and originating on the quadrate and lower preopercular to run dorsad and rostrad, inserting on the upper part of the anterior maxillary immediately above the tendinous insertion of $A_{1}$ a.

2. The mandibularis $\left(\mathrm{A}_{2}\right)$ much resembles the condition in Labeo niloticus and $L$. horie, but the median (tendinous) narrowing of the upper fascia $\left(\mathrm{A}_{2}^{\prime}\right)$ beneath the orbit is not as marked. Besides, the anterior caput originating in the lower orbit is hardly apparent. The lower fascia $\left(\mathrm{A}_{2}{ }_{2}\right)$ is also double-lobed, but with the lower one more developed and broader.

$A_{3}$ is also more fan-shaped than in Labeo.

All other muscles show no significant differences from the state of affairs as described for Labeo.

b) The selective apparatus: In a median oblong depression of the mouth roof, just behind the maxillary valve, lies a rudimentary vomero-palatine organ ( $P l$. $\mathrm{V}, \mathrm{b})$ consisting of a central elevation from which radiate several epithelial ridges, which are longest parallel to the longitudinal axis of the fish. Anterior to this and partly hidden under the maxillary valve, is a median series of 6-7 papillae. The oblong depression is bordered laterally by two strong ridges, parallel to which run several large plicae exteriorly. In $G$. congoensis however, this organ is still less developed and the plicae are shallower, all running more or less parallel longitudinally.

Posteriorly, the plicae diverge, branching out into smaller and shallower ones, which bend laterally out- 
wards and gradually pass over into a well developed pharyngeal pad. This differs from that of Labeo in that it bears much less and smaller papillose projections and has numerous anastomosing small plicae in its surface, running generally in an obliquely backwards direction. The semicircular ridge separating the buccal palate from the pharyngeal pad is also absent here. The mouth and anterior pharynx floor, as well as the lateral walls of the buccal cavity, are plicated longitudinally, more or less as in Labeo. Tiny papillae are everywhere present, but not in great number. It is evident from these characters that the palate of Garra spp. is not called upon to fulfill a selective function anywhere as finely specialised as in the preceding genus.

The gill-rakers ( $P l$. IV, c) number 10 to 20 and are stubbier and more widely spaced along the sides of the branchial arches than in Labeo. They alternate with those on the next arch so that they can mesh closely, effectively closing off the anterior pharynx, e.g. during spitting movements. Nevertheless, the species of this genus possess only a rough branchial filter fit for retaining larger particles. Tiny papillae are present on the branchial arches, particularly at the base of the gill lamellae and on the small inner epithelial lamellae joining the proximal part of the gill-rakers to the middle of the arch, thus giving them a finely serrated appearance.

A curious feature is the feathery aspect of the gills $(P l . \mathrm{IV}, \mathrm{c})$, the small, parallel transverse ridges along the lamellae already apparent in some Labeo species being much deeper here and also becoming larger distally, giving the gill lamellae a feathery or clublike appearance.

Musculature of the anterior pharynx: This is practically identical to that of Labeo, but the hyohyoideus lies ventrally over the broad, flattened, \pm triangular urohyal; an interhyoideus is absent; the subarcualis communis, due to its horizontal position, hardly contributes to dilate the pharynx, its major task being the forward traction of the pharyngeal bones. The coraco-branchialis anterior also inserts far forwards, near the tip of the cartilage prolonging the pharyngeals anteriorly, and partly onto it.

\section{The masticatory apparatus:}

The lower pharyngeal bones ( $P l . \mathrm{V}, \mathrm{c}$ ) are of a distinctly different type than those of Labeo; each is more or less falciform in shape, with a latero-posterior broadening, which has a rounded posterior edge. The central area of the external surface of the pharyngeals is strongly hollowed, with only a few very small al- veolar cavities. The anterior processes join at their ends in a median ligamentous symphysis and are prolonged rostrally by a long slender cartilage. The angle at which they neet is about 100 to $110^{\circ}$. The ascending processes curve forwards and bend sharply inwards at their upper part, thus coming to lie almost horizontally in the subtemporal fossa. This, especially the latter feature, is not the case in G. congoensis, where they point quite straight up. The pharyngeal teeth ( $\mathrm{Pl}$. V. c) arise from the internal (mesial) side of the broadened lateral face and point transversally inwards as well as slightly up- and backwards. They are arranged in three rows, according to the formula: $2 ; 3-4 ; 5-5 ; 4-3 ; 2$. Their crown is more or less spoonshaped or uncinate, with a sharp backwardly directed point and they can work transversely against each other as well as up against the horny plate. The latter $(P l . \mathrm{V}, \mathrm{b})$ hardly differs in form and structure from that of Labeo, though it is softer and less distinctly grooved, probably owing to the fact that the teeth work more against each other than against it.

The masticatory musculature: This differ from that of Labeo in the following points:

1. The coraco-branchialis posterior is more developed (thicker).

2. The cleithro-pharyngeus has two fasciae crossing over each other, as in Barbus, and all other African genera studied. An anterior one originating on the cranial surface of the ventral part of the cleithrum, behind and mesially to the origin of the posterior fascia, which lies just behind and external to that of the sternohyoideus. It passes cranially up and forwards under the posterior part, to insert on the anterior ventral edge of the pharyngeal bone, external to the origin of the coraco-branchialis. On contracting, it pulls the anterior part of the pharyngeal bone down,- back- and laterally outwards, enlarging the posterior pharynx cavity. The posterior, superficial fascia, which originates more anteriorly than in $\mathrm{La}$ beo, runs mesially and somewhat dorsad and caudad, to insert just behind the anterior one on the lateral ventral edge of the pharyngeal bone. Its action pulls the lower pharyngeals outwards, separating the teeth, and slightly downwards.

3. The levator arcus branchialis $V$, inserts higher up on the ascending pharyngeal process, as in Barbus.

4. The retractor arcus branchialis dorsalis inferior runs nearly transversally inwards. and but slightly back- and upwards; therefore, its main action consists in pulling the pharyngeals together, bringing 
the teeth against each other. The dilacerating action of the pharyngeal teeth when they work against each other takes place as follows: after the posterior pharynx has dilated, admitting food (small invertebrates, filamentous algae) to the teeth area, contraction of the levator $\mathrm{V}$, retractor inferior and transversus ventralis muscles bring the teeth together, as well as up against the horny plate, crushing the food particles. Subsequent relaxation of these muscles and contraction of the subarcualis communis, cleithro-pharyngeus posterior and retractor arcus branchialis dorsalis superior muscles, pulls the teeth down and apart, their hooked crowns, which have pierced large food particles or become entangled in algal masses, tearing these to pieces.

\section{The digestive tract:}

This differs essentially from that of Labeo in the length of the intestine, which is very much shorter in relation to body length. The mean ratio for 3 specimens examined ( 2 of G. dembeensis and 1 of G. congoensis) of 74 to $90 \mathrm{~mm}$. standard length, is roughly 4,5. This is of course in direct correlation with the more omnivorous nature of the diet. The liver is better developed in this genus and the lining of the abdominal cavity is but slightly blackened.

\section{Conclusion}

Garra species show distinct specialisation to a torrenticolous, benthic mode of life, which expresses itself as well in general form and the development of an adhesive organ as in their feeding mechanisms, which are specifically adapted to the obtention of food from a hard substrate. This study of their feeding mechanisms, also reveals some interesting facts concerning the taxonomic relationships between them and genera like Labeo and Barbus, to both of which it appears related in several characters. Many of these, including some osteological characters, point to affinities with Labeo, though others, like those of the masticatory apparatus for instance, indicate a definite relationship with Barbus and Varicorhinus. Garra therefore, occupies an intermediate position in many respects in relation to these genera, but seems closest to Varicorhinus.

Barbus Cuvier \& Cloquet, 1816.

Species studied: B. altianalis BLGr., 1900 (East Africa \& E. Congo)

B. tropidolepis BLGR., 1900 (lake

Tanganyika)

B. urundensis DAvid, 1937 (RuandaUrundi)
B. squamosissimus STDR., 1913 (Central Congo)

B. holotaenia BLGR., 1904 (Equatorial West Africa)

B. kersteni Peters, 1868 (East Africa \& Congo)

B. lineomaculatus BLGR., 1903 (East \& South Africa, E. Congo)

B. pleuropholis BLGR., 1899 (Central Congo)

(DAvid, 1937 -osteology of the snout region of Barbus stappersi BLGR., 1916-).

\section{General characters}

This large, extremely variable, ill-defined genus can be divided taxonomically as well as ecologically into several groups, which, however, don't coincide. The large majority of species though, are carp-like, with well-developed lips and barbels (2 pairs, generally) surrounding a protractile mouth which may be terminal to inferior ( $P l$. V. d). The edges of the jaws are usually rounded and covered with a \pm hardened, stratified epithelium (stratum corneum). African Barbus spp. range in size from $2,5 \mathrm{~cm}$. to 1 metre.

\section{Ecology}

Most Barbus species are characteristically facultative feeders, being able to adopt almost any diet, as circumstances require. But essentially they are omnivorous, with a distinct predominance of the carnivorous habit. They usually prefer strongly flowing streams, where they often congregate in large shoals, especially during the breeding season (upstream migrations). Some large species have become predatory and have acquired a large, terminal mouth, some even with a projecting lower jaw. Species with a tendency towards a herbivorous habit show a more inferior mouth and acquire a horny cutting edge on the lower jaw. Several of the small spp. have become planktonophageous.

Among the species considered here, $B$. altianalis is large, more or less omnivorous, but mainly feeding on bottom-living invertebrates, in rivers; populations living in mountain streams where the bottom consists largely of pebbles and rock fragments, often develop oversize, lobed lips ("rubberlip") ( $P l$. IX, a) which greatly facilitate the grasping of prey between the bottom rubble. B. urundensis is another large omnivorous species which feeds mostly on filamentous algae and water plants however, and consequently possesses a horny cutting edge on the lower jaw, the lower lip being often poorly developed as well. $B$. tropidolepis, a large, endemic species of lake Tangan- 
yika, feeds mainly on molluscs and crabs; the barbels are poorly developed (1 pair) or absent altogether, which may be a consequence of life in clear waters and hunting its relatively large prey by sight. Also, the pharyngeal bones bear large, molariform crushing teeth ( $P l$. VIII, a).

B. squamosissimus, B. holotaenia, B. kersteni and $B$. lineomaculatus are small species, principally feeding on small benthic invertebrates (insect larvae), but often on vegetable matter as well. They live in small streams and possess well-developed barbels; the firstnamed species is predominantly carnivorous and has a terminal, rather large mouth.

B. pleuropholis is a tiny $(3-4 \mathrm{~cm}$.), semi-pelagic species living in lakes and large rivers, where it feeds mainly on zooplankton and benthic Entomostraca.

\section{Functional morphology}

External features: Except in B. tropidolepis and $B$. pleuropholis, the sensory barbels are well developed and point forwards and downwards during the search for food, as well as when the mouth is protruded. The lips are variably developed, even within the same species, but lip size seems to be quite constant in the small species and in B. tropidolepis. $B$. urundensis and $B$. squamosissimus often have reduced lips, the lower being restricted to the sides of the jaw. In others (e.g. B. altianalis) "rubberlips" frequently occur. A post-labial groove is more or less apparent, especially in the large spp., into which fit the posterior parts of the maxillary and premaxillary, and the lip corners.

A curious feature in B. pleuropholis are the numerous sensory pore canals on the head, which are in relation to the lateral line system, but the function of which is not yet clearly understood. Papillae are rarely present externally, on lips, etc.; horny tubercles on the snout are also unusual, though they are a prominent feature of $B$. pleuropholis $\delta \hat{\delta}$. There is no distinct rostral flap and no transverse groove on the snout.

Bucco-pharyngeal cavity:

a. The prehensile apparatus: The general picture of the mouth and pharynx in Barbus is nearly identical with that of the carp (Cyprinus carpio) which has been studied by many authors (TAKAHASI, 1925; vaN Dobben, 1935; Fiebiger, 1931; Haempel, 1909; Curry, 1939; Dorier \& Bellon, 1952; Maltzan, 1935; ZANDER, 1903; etc.).

The premaxillary pedicels are well-developed, being joined through the sigmoid ligament, bearing the small rounded rostral bone in its middle, to the vomero-mesethmoid fork. The lower jaw edge is sometimes horny and sharp, but usually the stratified epithelium covering the jaws is more or less smooth or finely plicated transversely to the jaw axis, these ridges usually continuous with the buccal cavity plicae and giving the jaws a ribbed appearance (e.g. B. squamosissimus). There is no tongue, but the mouth floor overlying the glossohyal region is thickened, slightly raised and bears numerous more or less longitudinal plicae radiating outwards from the median line. The maxillary valve often has a row of tiny papillae along its base and these can also be found along the inner edge of the lower jaw, in front of the "tongue" area (e.g. 2 rows in B. squamosissimus); numerous taste buds are present on these papillae (Pl. VIII, b).

Musculature of the mouth: (Pl. VI, a; Pl. IX, b).

The geniohyoideus, which originates on the ceratohyal (and epihyal), 1st \& 2nd branchiostegals, and sometimes the interopercular (the external part of the fascia in B. altianalis), consists of two parts: a geniohyoideus superior, above and behind a geniohyoideus inferior, lying ventral and anterior to the former and connected to it posteriorly through an aponeurotic striation. The geniohyoideus superior is derived from part of the interhyoideus, and the whole forms a protractor hyoidei (sensu EDGEworTH, 1935).

An intermandibularis (anterior) lies between the dorsal (ghy. sup.) and ventral (ghy. inf.) fibres of the geniohyoideus, joining the anterior dentary branches. Just behind the aponeurotic striation, a pair of small, thin muscles arises from the tough connective tissue septum separating the left and right geniohyoidei, and run transversely outwards to insert on the skin laterally, against the posterior mandible edges. A modification of these muscles may have given rise to the posterior adhesive disc adductor in Garra.

The adductor mandibulae complex differs from that of the Carp (van Dobben, 1935) in one important respect, i.e.: $A_{1}$ shows no distinct upper and lower fascia and there is no muscle fibre originating from the posterior branch of the mandible. Moreover, the upper part of the anterior tendinous cauda inserts far forwards on the maxillary. The fan-shaped $A_{3}$ has two capita, one external $\left(A_{3}^{\prime}\right)$, the other $\left(A^{\prime \prime}{ }_{3}\right)$ internal to the levator arcus palatini. Antero-ventrally, it inserts through a tendinous cauda onto the inner surface of the mandible, below the coronoid process. A poorly developed intramandibularis originates from the inner anterior surface of the mandible (above Meckel's cartilage), inserting posteriorly on the tendinous por- 
tion of $\mathrm{A}_{3}$. In small Barbus species and young specimens (smaller than $5 \mathrm{~cm}$.) no intramandibularis is present, though in some (e.g. B. pleuropholis) it is well developed, as an offshoot of $A_{2}$. Moreover, in small Barbus, $A_{2}$ and $A_{3}$ are fused, $A_{3}$ being represented by an anterior fascia, internal to the levator arcus palatini; $A_{2}$ is also constricted in its upper fascia $\left(A_{2}^{\prime}\right)$. This situation is similar to that in Varicorhinus, except for the fusion of $A_{2}$ and $A_{3}$. Protrusion of the mouth is effected in much the same way as in the Carp, the mouth remaining half open during the search for food and quickly protruded fully when food is grabbed.

b. The selective apparatus: Anteriorly, the palate has a striate appearance due to the numerous longitudinal plicae, often bearing small papillae, especially posteriorly. These plicae usually form an anostomosing network at the anterior extremity of the palate; also, the lateral ones diverge posteriorly and the large median plicae converge somewhat, before diverging again just in front of the pharyngeal pad ( $P l$. VI, b). This pattern seems to be quite common in Cyprinids, for AL-Hussaini (1949) also describes and figures it for Rutilus. In B. pleuropholis (Pl. VII, d), these mucosal folds are few in number, but large and very deep, bearing numerous tiny papillae in longitudinal series as well as mucus cells and taste buds (Pl. VIII, a). In this case, the folds hanging down from the palate evidently greatly increase the gustatory surface.

The thick pharyngeal pad mainly consists of loosely bound connective tissue, collagen and elastic fibres, and numerous striate muscle fibres running in all directions, though mostly transversely and longitudinally ( $P l$. VIII, c \& X, a). The thick, stratified epithelium bears numerous, vari-sized papillose projections which hang down into the pharynx and are particularly well developed in the large species. These papillae, with those on the branchial arches, form a sort of intricate maze in which food particles become trapped when the expanded pharyngeal pad presses out water (through the gills), prior to passing the food backwards to the masticatory apparatus. Taste buds and goblet cells are also quite numerous on the pharyngeal pad, which is better developed (more muscular) than in Labeo.

The gill-rakers are variously developed in the different species, ranging in number from \pm 5 (in small, carnivorous spp.) to \pm 25 (B. urundensis). They are placed in two rows on the sides of the branchial arches and connected transversely through a thick, papillose (serrated) epithelial ridge to a shallow median groove running the length of the $\operatorname{arch}(P l . V I, d)$.
Those in the outer row of the 1st gill arch are usually less numerous, more widely spaced and stubbier. The free ends of the gill-rakers mesh with those from the adjacent arch, thus forming a rough but efficient filter ( $P l$. VI, c).

When the gill arches are pulled together (adduced) and the gill covers closed, the rakers can mesh completely, fitting tightly against each other (ZANDER, 1903); those of the outer row bend forwards against the operculum, also touching each other. Thus, the anterior pharynx can be entirely closed off so that even tiny particles can be spat out or trapped-the median groove on the gill arches also serving as a collector for food and mucus-and forced back into the posterior pharynx when this dilates. Many Barbus species thus have a more or less adjustable branchial filter. This seems to be generally better developed in the large species, whereas in the small ones the gill-rakers are reduced and irregularly disposed. In $B$. pleuropholis, however, they are large, very stout, conical and papillose, numbering 10 (external row) to 20, meshing closely; this is not surprising for a plankton-eating species.

The anterior pharynx floor between the gill arches is narrow and bears longitudinal, sinuose, papillose plicae. Tiny papillae may be present also on the gill arches and some species (B. holotaenia) have fine plicae on the inside of their gill covers.

Musculature of the anterior pharynx: The broad, thin hyoideus appears as an offshoot of the posterior part of the adductor arcus palatini and runs down from the caudad aspect of the hyomandibular to insert on the lateral wall of the bucco-pharyngeal cavity, overlying the metapterygoid. The posterior part of the interhyoideus is distinct, but narrow. Both this muscle and the broad hyohyoideus lie ventral to the urohyal, which is strongly keeled. The subarcualis communis lies more or less horizontally in this genus and in related genera, and pulls the lower pharyngeal bones forwards, but does not contribute appreciably to raise the pharynx floor. It inserts anteriorly on the thin, small, nearly vertical 3rd hypobranchials, which join mesially below the 3rd basibranchial to form a stirrup-like bone. The thin coraco-branchialis anterior lies relatively further back than in Labeo and inserts antero-mesially largely onto the strong, thick anterior cartilage, just in front of the anterior pharyngeal bone processes ( $P l$. IX,c).

\section{The masticatory apparatus:}

The pharyngeal bones ( $P l$. VII, a \& b) are more or less falciform with a long, downward curved anterior 
process which meets the opposite one mesially in a broad symphysis at an angle of $\pm 70^{\circ}$. From the posterior part of this symphysis, a median cartilaginous rod, which represents the modified basibranchials IV and V, extends horizontally forwards, overlying the basibranchials, to the 2nd (1st) basibranchial. Laterally and posteriorly, the bones widen out into a more or less developed lateral flange, which bears large and small alveolar depressions running through to the bases of the teeth on the inner side. The ascending processes curve forwards dorsally and more or less strongly inwards.

In the small species the pharyngeals are quite constant in form, but in the large ones, their detailed structure and the relative development of the various parts can vary considerably, as may readily be observed on comparing the pharyngeals of $B$. altianalis and B. tropidolepis (Pl. VII, a \& b) specimens of more or less the same size.

The pharyngeal teeth are usually heterodont, placed in 3 rows, the teeth formula being: $2(3) ; 3 ; 5$ $5 ; 3 ;(3) 2$. However, in B. tropidolepis the anterior tooth of the inner row is absent in adult specimens; present, but very small in the young. Tooth size and form varies greatly in correlation with the ecological (trophic) diversity of the members of this genus. Generally, the 2nd and 3rd teeth of the inner row are much larger, at least in the big species. Their crowns are placed quite close together in each dental area, but the two areas are separated mesially by a considerable space, especially posteriorly. Their form is mostly spoon-shaped with a backwardly directed hook at their extremity (B. altianalis), but mamilliform (especially the enlarged median teeth) (B. urundensis), molariform (B. tropidolepis), conical (caniniform) or more or less incisor-like, with flat crowns and sharp edges (shearing teeth) like the posterior teeth of $B$. squamosissimus, are also frequently found.

The horny plate (Pl. VII, c) is saddle-shaped, with a posteriorly directed apex and an undulated masticatory surface which fits quite precisely against the teeth; posteriorly, it ends in a hard, rounded, knob-like outgrowth, projecting into the pharynx medially above the hindermost portion of the teeth area. It is a very hard, stratified structure, partly calcified in the large species, whereas in the small ones it is more purely sclerous, being covered with a brown, deciduous horny sheath.

The masticatory musculature: (Pl. IX, c). This differs from that of Labeo in several respects: the coraco-branchialis posterior is much stronger, also originating partly on the exterior flange of the cleithrum; the cleithro-pharyngeus consists of two distinct parts, namely: an anterior cleithro-pharyngeus profundus and a posterior cleithro-pharyngeus superficialis crossing over each other, as in Garra. The levator arcus branchialis $V$ consists of 3 fasciae; a superior, a posterior and an antero-internal which passes behind the other two and inserts anteriorly, through a tendinous cauda, on the external aspect of the ascending pharyngeal bone process; this muscle fascia pulls the ascending process up-, inwards and somewhat forewards, also imparting a torsion to the pharyngeal bone. The insertion of the other fasciae along the posterior (inner) edge of the pharyngeals is considerably smaller and lies higher than in Labeo, probably as a consequence of the more vertical (standing) position of the pharyngeals in situ and the stronger forward curvature of the ascending processes. The superior and inferior retractores arcuum branchialium dorsalis originate from the strong vertical keel of the pharyngeal process of the basioccipital and not on the narrow lateral flanges of this bone. The first muscle inserts through a tendon on the rostral aspect of the ascending process (in the angle of its forwards curvature) and also has a small ventral fascia arising from the dorso-lateral posterior pharynx wall, contributing to dilate it. A small upper fascia of the inferior retractor muscle is affixed to the lateral wall of the posterior pharyngeal chamber, dilating it; another originates from the pharyngeal process (basioccipital) and runs to the lateral pharynx wall, mesial to the ascending process; 3 or 4 thin, tendinous muscle strands run from the subtemporal fossa to insert also on the dorso-lateral pharynx wall.

The transversus ventralis $V$ is also larger and stronger than in Labeo, which is to be expected since the teeth here work as well against each other as up against the horny plate. There is no appreciable difference in muscular arrangement between the Barbus spp. studied.

\section{The digestive tract:}

When the food has been fully chewed, a wave of contraction passes backwards from the posterior pharynx, forcing it through the muscular oesophagus down into the gut. The intestine differs from that of Labeo essentially in length (much shorter) and in the somewhat larger intestinal bulb, which-especially in carnivorous species-is relatively better developed.

The ratio of intestine length to standard length varies from 1,0 (in carnivorous spp.) to 3,5 (in the omnivorous spp., like $B$. altianalis), though it may even be still longer in predominantly herbivorous spp., like $B$. urundensis. These ratios are comparable 
with those found for the european Carp (1,8-1,9) and in Rutilus $(0,9-1,9)$ by AL-HussainI (1949).

The peritoneum is often quite strongly blackened in omnivores and herbivores, but hardly so in carnivores.

The liver is better developed than in Labeo, consisting of 3 lobes, two short lateral ones and a greatly elongate, rather diffuse, median lobe extending to the posterior end of the abdominal cavity, where it becomes reduced to a stringy connection bending ventrally and widening out again, overlying the intestine.

\section{Conclusion}

The members of this genus show a range of variation in feeding habits which appears out of proportion to the relatively minor differences in morphological features related to feeding. It must be kept in mind however, that Barbus is one of the more primitive living cyprinid genera (a generalised form), a fact which is further confirmed by its many generalised anatomical characters. One corollary of this is that its members are characteristically "facultative feeders", i.e.: the species may have a very distinct preferential diet under normal circumstances, but should these change, readily adapt to another, which may be very different.

Therefore, Barbus species are extremely adaptable and this genus has speciated explosively whenever the environment was suitable. The numerous species actually referred to it can, however, be split subgenerically into several distinct groups, but further investigation of their morphology in connection with feeding is necessary, in order to check whether some differences observed in the species studied are constant or not and whether they would lend support to further taxonomic splitting.

Varicorhinus RüPPEL, 1837.

Species studied: V. tanganicae BLGR., 1900 (lake Tanganyika).

\section{General characters}

This genus includes large species $(25-50 \mathrm{~cm}$.) very much like large Barbus spp. in most characters and in form, the principal distinguishing feature being the sharp, horny cutting edges on the jaws, especially the lower.

\section{Ecology}

Varicorhinus tanganicae lives mainly in biotopes with a rocky bottom, e.g. along rocky lake shores and in small, strongly flowing rivers. Massive seasonal mi- grations take place in order to spawn in cold, clear mountain streams. Feeding is done by scraping algae, etc., off the bottom, and these, as well as (epiphytic) diatoms, constitute the main part of its diet. Higher plants, insect larvae, etc., are also eaten occasionally.

\section{Functional morphology}

External features: The mouth is large, transverse, inferior, moderately protractile; a thin rostral flap partly overhangs the upper jaw; the lower lip is absent, giving a shovel-like appearance to the lower jaw. The barbels are generally reduced in size as well as in number. Characteristically, horny tubercles are present on snout and rostrum, especially in $\hat{\delta} \hat{\delta}$.

In $V$. tanganicae, the barbels are much reduced in size; the lower lip is represented by two small folds at the mouth corners and the horny cutting edge is strongly developed on the lower jaw only. The upper lip is thin; the premaxillaries, as in Labeo, lack a pedicel or ascending process antero-mesially; the coronoid process of the mandible is large, as in Barbus, and there is no interdentary cartilage.

\section{Bucco-pharyngeal cavity:}

a. The prehensile apparatus: The mouth floor and lateral walls show no particular features, the epithelium being plicated in much the same pattern as in Barbus, but much less distinctly. The palate, however, $(P l . \mathrm{X}, \mathrm{b})$, is divided into two lateral depressions separated by a broad median ridge of finely papillose epithelial and connective tissue. The lateral plicae and papillae here are also weakly developed, but tend to become deeper posteriorly. In young specimens, the palatal plicae are relatively deeper and the median ridge is only apparent anteriorly, so that it evidently grows backwards with age.

Musculature of the mouth: This differs little from that of Barbus, but the intermandibularis lies under the strongly developed geniohyoideus; the mandibularis $\left(\mathrm{A}_{2}\right)$ inserts more anteriorly on the mandible, i.e. only on the posterior border of the coronoid process, and presents two fasciae: an upper one $\left(\mathrm{A}_{2}^{\prime}\right)$ which is constricted in its middle part, somewhat as in Labeo, whereas the lower $\left(\mathrm{A}_{2}{ }_{2}\right)$ is broad and flat, extending back and more or less downwards to its origin on the quadrate, preopercular and symplectic. $A_{3}$ is distinct from $A_{2}$ and has a small inner fascia which does not extend so far back into the orbit (behind the levator arcus palatini). A very small intramandibularis is present. The paired superficial muscles overlying the geniohyoideus behind the aponeu- 
rotic striation are broader than in Barbus and met in a median raphe.

b. The selective apparatus: The pharyngeal pad is strongly papillose, but rather poorly developed. The gill-rakers are short, but numerous: 17 (in the exterior row) to 35; they are compressed (lamellar) and placed along the lateral edges of the gill arch, leaving a shallow, longitudinal groove medially. Tiny papillae are present on the epithelium of the branchial arches as well as on the inner side of the gill-rakers. The latter can mesh very closely, forming an adjustable, fine branchial filter, which is intermediate in structure to the rough filter of Barbus and the extremely fine one of Labeo.

In spite of the thin pharyngeal pad, the pharynx is very narrow dorso-ventrally and can easily be closed completely through contraction of the anterior pharynx muscles, whose arrangement does not differ from that in Barbus.

The masticatory apparatus:

The pharyngeal bones ( $P l . \mathrm{X}, \mathrm{c}$ ) are of the Barbus type, though their ascending processes do not bend so sharply inwards. They meet in a long anterior symphysis, at an angle of about $60^{\circ}$. The pharyngeal teeth are placed in three rows, the formula being: $2 ; 3 ; 4-5-5-4 ; 3 ; 2$. Those of the innermost row are larger, with but slightly excavated crowns, the other teeth having more or less spoon-shaped crowns which lie close together, forming a grinding surface comparable to that of Labeo. The teeth also come into contact medially and work mostly up against the horny plate. The masticatory surface formed by them lies quite free from the interstitial and adjacent plicated epithelium, and not, as generally in Barbus, more or less embedded in it.

The horny plate $(P l . \mathrm{X}, \mathrm{b})$ is identical to that of the large Barbus species and also shows a strong degree of calcification.

The musculature of the pharyngeal bones hardly differs in any respect from that of Barbus, the only noteworthy difference lying in the lesser development of the cleithro-pharyngeus, which is relatively thinner.

Prehension, deglution and mastication:

$V$. tanganicae has been observed (in aquarium) to swim obliquely and rapidly towards the bottom with mouth open, the lower jaw scraping along the surface of stones as the fish reaches them, often leaving a distinct track several $\mathrm{cm}$. long in the algal covering. During this scraping-off process, the mouth begins to close, staying half-open till the fish tilts up again, completely closing it. Meanwhile, the bucco-pharyngeal cavity has expanded, sucking in water and loosened material. As soon as the mouth has closed, a wave of contraction passes backwards from the buccal cavity towards the anterior pharynx; the water is strained out through the gill-raker sieve, the expanded pharyngeal pad acting as a press, and food particles-which are by now becoming well mixed with mucus-are sucked into the posterior pharynx which dilates through the action of the masticatory and pharyngeal wall musculature. Admission of food (plus mucus) is probably also facilitated by the pressure of the water which has been subsequently drawn into the bucco-pharyngeal cavity during respiratory movements; when the anterior pharynx constricts to expell water through the gills, the posterior pharynx may briefly dilate somewhat and so allow food to be washed in. After being thoroughly masticated-movements which can clearly be observed in living specimens-the oesophagus dilates while the posterior pharynx constricts, admitting food to the gut.

\section{The digestive tract:}

This shows no difference from that of Barbus, but the intestine is distinctly longer, being comparable in relative length to that of Garra, which has a very similar diet. The ratio intestine length/standard length is 3,2 (young) $-5,0$, as determined on 5 specimens. The gut also shows more circonvolutions than in Barbus and the peritoneum is strongly blackened.

\section{Conclusion}

Though V.tanganicae has a diet very akin to that of Garra spp., it leads a much more free-swimming life, to which it shows definite adaptations. Morphologically, Varicorhinus appears most closely related to Barbus, though it also shares some features with $\mathrm{La}$ beo and particularly with Garra. Only further research can determine whether characters like, for instance, the absence of premaxillary pedicels, are indicative of any direct relationship with the latter two genera, or only secondarily and independently acquired, as is probably the case.

Barbobsis Di Caporiacco, 1926.

Species studied: B. devechii Dr CAP., 1926. (Somaliland)

\section{General characters}

Small species $(6-10 \mathrm{~cm}$.) very much like Barbus, but body not compressed, scales absent or reduced (small, under the skin) and eye very small. Colour light, the 
back scarcely darker (more or less depigmented).

\section{Ecology}

Fishes of this species are known from small streams, springs and wells of Somaliland, where they live on the bottom, preferably in dark places, probably even burrowing into the mud at times (during dry periods). This can be deduced from their morphological aspect, the reductions in scalation, eye, pigmentation, etc. The single specimen examined had mostly fresh, herbaceous plant material in its gut (water-plants?) as well as some filamentous algae, sand grains and small invertebrates.

\section{Functional morphology}

There are two pairs of well-developed barbels present; the anterior nostril consists of a short tube ( $1 / 2$ $\mathrm{mm}$.); numerous parallel sensory lines (pits) are present on the head, as in some small Barbus spp. The mouth is inferior, large, with normally developed lips, the lower separated from the "chin" by a post-labial groove which is deeper laterally. The ascending process of the premaxillary is short.

The musculature of the mouth and anterior pharynx does not differ appreciably from that of Barbus, except that $A_{3}$, which is not completely separated from $A_{2}$, inserts further back on the mandible (as in Labeo).

An intermandibular is apparently not developed. The adductor mandibulae muscles are overlain on the cheek by fatty tissue in which lie the sensory pores, which are well innervated by the hyomandibular ramus of the nervus facialis (VII).

The lining of the bucco-pharyngeal cavity is distinctly plicated longitudinally and papillose; on the palate, a central group of 5-6 very large and long projections, hanging down into the mouth cavity, form a sort of vomero-palatine organ. Numerous welldeveloped papillae are present on the pharyngeal pad which is similar to that of Barbus. The gill-rakers number 8-10 in the external row, 13-15 internally; they are relatively large, well developed, strongly papillose (micro-papillae), meshing closely, as in Barbus altianalis.

The pharyngeal bones and musculature are also of the Barbus type, though more simplified (more primitive?). The pharyngeal teeth resemble those of small Barbus spp., with spoon-shaped, hooked crowns, 2-3 of the innermost row enlarged, and they can work against each other as well as upwards. However, there are only two rows of teeth on each pharyngeal bone, the formula being: $2 ; 5-5 ; 2$. The horny plate is sclerous, uncalcified, like in the small Barbus spp.
The intestine is quite long (intestine length/standard length $=4,2$ ), with a short, wide anterior bulb, and is bent back upon itself and thrown into 3-4 coils. The liver is as in Barbus and the abdominal lining quite strongly blackened.

\section{Conclusion}

This genus is clearly derived from a primitive Barbus type, but has acquired some special characters of its own in relation to its habitat and feeding. The particular features concerning feeding show typical adaptations to a phytophageous diet (strongly plicated, papillose bucco-pharyngeal lining, increasing the sensory surface, probably well developed taste sense, longer intestine, etc.), which is rather surprising in a fish with cavernicolous tendencies, a polyphageous or even a detritiphageous diet being the rule in species living in such an environment. Another noteworthy characteristic is the unspecialised nature of the masticatory apparatus, especially the teeth, which are of a very generalised type.

Coptostomabarbus David \& Polx, 1937.

Species studied: C. wittei Dav. \& Polx, 1937 (upper Congo).

(see Davm, 1937.)

\section{General characters}

This tiny species is distinguished from Barbus-to which it is related-mainly by its supero-terminal, nearly vertical mouth. The osteology and dynamics of the mouth and head region of Coptostomabarbus has been studied by DAvID (l.c.) and its close relationship to Barbus confirmed. The main osteological differences concerning the prehensile mechanism are:

1. The long premaxillary pedicels.

2. A longer, more slender maxillary.

3. The mandibular only articulating with the quadrate.

4. A feebly developed rostrum, mainly consisting of (elastic) connective tissue, and a weakly ossified rostral bone.

5. The absence of the superior part (posterior to the rostral bone) of the sigmoid ligament.

6. A cylindrical cavity in the anterior mesethmoid, into which fits the rostral bone dorsally.

7. The mobile sub-maxillary cartilages.

These characteristics permit a very strong forward protrusion of the mouth (especially the lower jaw), thus forming a sucking tube of sorts. Barbels are absent, the lips are thin, the nostrils situated close up against the orbit. 


\section{Ecology}

This fish lives in quiet, open back-waters of large rivers and feeds on zooplankton (mostly crustacea) which it sucks in though its tube-like mouth. Occasionally, planktonic algae are also ingested.

\section{Functional morphology}

The most prominent feature of the buccal cavity is, surprisingly, a well developed, rod-like tongue ( $P l$. $\mathrm{X}, \mathrm{d})$. This feature was apparently missed by DAVID, though it shows quite clearly on a micrograph of a transverse section of the snout region (page 15), where it lies in a deep fold of the mouth epithelium between the left and right geniohyoidei muscles. This tongue is formed by the long glossohyal which is lined with epithelium and completely free anteriorly.

Through contraction mainly of the geniohyoideus and probably also the anterior pharyngeal muscles (hyoideus, interhyoideus) adducing the hyoid apparatus, it can be lifted clear of the mouth floor. On the anterior palate, two ventral projections of the palatine bones appear, between which the point of the tongue fits when the mouth is closed. The action of the tongue is largely passive apparently, though it may aid in holding food particles and then in pushing them backwards when the mouth closes. Its close resemblance to the tongue of plankton-eating Clupeids provides an interesting example of convergent adaptive evolution.

The bucco-pharyngeal epithelium shows small longitudinal plicae and a papillose pharyngeal pad is present, overlying the gill arches. The gill-rakers, numbering 9 (ext. row) to 15, are quite long, lamellar, forming a fine sieve.

The musculature of the mouth and pharynx has not been studied, as this would have involved complete dissection of one of the few type specimens. A superficial examination, however, showed the $A_{1}$ part of the adductor mandibulae to insert through a tendinous cauda on the widened medial portion of the maxillary, and the mandibularis $\left(\mathrm{A}_{2} \mathrm{~A}_{3}\right)$ to insert largely on the posterior border of the coronoid process.

The pharyngeal bones are very similar to those of Barbus, though on a much smaller scale; the lateral ventral flanges are relatively much better developed (even more so than in B. tropidolepis), with a strong ventral extension posteriorly; the ascending processes are quite straight, only bending slightly inwards at their upper ends. The dorsal horny plate is rather soft, though it possesses a distinct sclerous covering.

The teeth are usually in 2 rows, sometimes 3 , the formula being: $0(1) ; 2(3) ; 4(5)-(5) 4 ;(3) 2 ;(1) 0$. They are more or less straight, rather obtusely pointed, with sometimes a slightly hooked point anteriorly, and all roughly the same size. They can work against each other as well as against the horny plate.

The masticatory musculature is essentially similar to that in Barbus, but some differences are apparent, the cleithro-pharyngeus, for instance, does not show a separation into deep and superficial parts.

The intestine is exceedingly short and only coils back upon itself once; the ratio intestine length/ standard length $=0,7-0,85$ ( 3 specimens measured). The peritoneum is distinctly blackened.

\section{Conclusion}

This species is especially interesting in that it has developed a very specialised prehensile mechanism, which through convergence, has given rise to a clupeoid type of mouth. Also the development of a tongue constitutes a unique feature among Cyprinidae. These characters have evolved in connection with its mode of feeding, and its ancestors probably resembled closely some of the small Barbus spp. like B. pleuropholis, B. mocoensis TREw., 1937, etc.

\section{Barilius Hamilton Buchanan, 1822.}

Species studied: B. moorei BLGR., 1900 (lake Tanganyika)

B. christyi BLGR., 1920 (Congo
basin)

\section{General characters}

Barilius species range in size from 10 to $50 \mathrm{~cm}$.; the body is elongate, streamlined, the mouth moderate to very large, terminal, often slightly oblique, without lips. The sub-orbitals are large, covering the cheek; barbels are absent, the nostrils close to the orbit, the eye is large, the gill-slits extend further forwards ventrally than in Barbus; the tailfin is deeply forked, the colour silvery.

\section{Ecology}

These fishes are carnivorous, open-water forms, which feed on free-swimming insect larvae and adult insects (falling into the water), crustacea (shrimps), fish, etc. They are fast, strong swimmers, can jump like trout, to which they show a superficial resemblance, and are often seen jumping after low-flying insects. They live mostly in clear lakes and fast-flowing streams, usually in small groups.

\section{Functional morphology}

External features: The dentary symphysis often forms a knob ( $P l$. XI, a) which fits into a cor- 
responding median notch in the upper jaw when the mouth is closed; this structure aids in the retention of large prey, also crushing it. The premaxillaries are not very protrusile, both premaxillaries and maxillaries sliding under the sub-orbitals laterally, when the mouth closes. The premaxillary pedicels are long, passing back- and upwards under the median ligament joining the rostrad ends of the maxillaries. The rostral bone and sigmoid ligament fit posteriorly into a median depression of the mesethmoid, between and dorsal to the antero-lateral preethmoid projections. This arrangement shows similarities with that in Coptostomabarbus. Horny tubercles are characteristically present on the snout in $\hat{\delta} \hat{\delta}$.

\section{Bucco-pharyngeal cavity:}

a. The prehensile apparatus: The symphysial knob is poorly developed in B. moorei, which also shows less extreme backwards extension of the mouth which extends to behind the orbit in $B$. christyi ( $P l$. XI, a). The long mandible articulates with the quadrate only, and connects through a stout ligament with the preopercular and the interopercular.

Numerous small, parallel ridges $(P l . \mathrm{XI}, \mathrm{b})$ run transversely across the jaws which are covered with more or less cornified, stratified epithelium. The mouth floor of the narrow lower jaw is strongly convex, bearing numerous parallel plicae which run more or less transversely, gradually curving backwards laterally. Rows of tiny sharp papillae usually occur everywhere in the bucco-pharyngeal cavity on the crests of the folds, even on the "lips" externally. A row of rounded papillae ( $P l$. XI, b) appears laterally between the hind edge of the upper jaw and the base of the maxillary valve, as well as all along the inner border of the lower jaw. Like similar papillae in some Barbus species, these are probably also gustatory.

The palate bears longitudinal plicae, the sharp papillae on their crests becoming larger and more numerous posteriorly, where the plicae gradually diverge before passing over into the pharyngeal pad. The 2 or 3 median plicae are distinctly deeper. At its extreme anterior end, partly below the maxillary valve, the palate shows a small median pad which is usually strongly papillose, often with one or two large papillose (arborescent) projections (B. moorei). This structure, which also probably has a predominantly gustatory function, is very poorly developed in B. christyi.

Musculature of the mouth: (Pl. XII). The long geniohyoideus originates from the cerato- hyal and the anterior ends of the 1st \& 2nd branchiostegals and is composite, as in Barbus, forming a protractor hyoidei, but an aponeurotic striation is barely apparent or even absent (B. christyi). An intermandibularis (anterior) is present, lying entirely under the geniohyoideus, between the anterior dentary extremities.

The adductor mandibulae complex (Pl. XII, b \& c) shows some particular features, namely: the maxillaris $\left(A_{1}\right)$ consists of two distinct portions, i.e.: $A_{1} \alpha$, originating from the quadrate and preopercular, and inserting on the median, external aspect of the maxillary through a tendinous cauda; it is itself divided into an upper $\left(\mathrm{A}_{1}^{\prime} \alpha\right)$ and lower $\left(\mathrm{A}^{\prime \prime}{ }_{1} \alpha\right)$ fascia. $\mathrm{A}_{1} \beta$, is a thin, narrow muscle overlying the maxillary and originating on the median, widened portion of the latter, just dorsal to the insertion of $A_{1} \alpha$; it runs caudoventrally to insert on the quadrate just above its articulation with the mandible. Contraction of this muscle when the mouth is already open, pulls the quadrate (and posterior mandible) up and the maxillary down, thus further widening the gape of the mouth.

The mandibularis $\left(A_{2}\right)$ is large, flat, fanshaped, extending far upwards behind the orbit and originating from the preopercular, the hyomandibular, the external surface of the levator arcus palatini (which extends downwards to below the level of the orbit) and from the cranium (sphenotic). It inserts on the posterior inner surface of the well-developed coronoid process and also comprises two fasciae $\left(\mathrm{A}_{2}^{\prime} \& \mathrm{~A}_{2}{ }_{2}\right)$. $A_{3}$ is a thin muscle, not very distinct from $A_{2}$, lying under its anterior portion and originating from the metapterygoid in the posterior orbit (internal to the lev. arc. palat.); it inserts on the coronoid process anteriorly to $\mathrm{A}_{2}$. A feebly developed intramandibularis is present.

\section{b. The selective apparatus:}

As such, this is generally poorly developed in Barilius and in related genera. The thin, very poorly developed pharyngeal pad, resembles that of (small) carnivorous Barbus species and bears numerous, sinuose, more or less longitudinal plicae with pointed papillae which become deep, sinuose, lamellar ridges with crenulated crests posteriorly. On the pharynx floor, the space between the gill arches is wider than in Barbus and bears a few large, sinuose, longitudinal plicae to which others are added postero-laterally, all converging towards the teeth area in the posterior pharynx.

The gill-rakers are degenerate, irregular in size and form (more or less conical) and reduced in number (6-12). They alternate in adjacent rows, but cannot 
mesh closely and shut off the pharynx from the gill chamber. This, however, is unnecessary in openwater forms which feed on relatively large prey, and don't have to spit out or strain off small particles. A considerable number of tiny, sharp papillae are also present on the branchial arches, particularly apparent in B. moorei. The small, sharp papillae, as well as the posterior lamellar ridges, mainly serve a mechanical function, namely, that of retention of the prey.

Musculature of the anterior pharynx: An interhyoideus is absent; the hyohyoideus (Pl. XII, a) is a broad muscle sheet lying on the gullet, ventral to the urohyal, and runs obliquely forwards and mesially from its origin on the inner surface of the branchiostegals and ventral edge of the subopercular. Its anterior fibres also insert on the hypohyal mesially. The flat hyoideus originates from the lower hyomandibular and upper preopercular and runs ventrad between the membrane bones of the cheek and the epi- and cerato-hyals to insert on the lateral mouth floor and basihyal. The coraco-branchialis anterior runs from the cleithrum upwards and rostrad, passing laterally against the anterior extremity of the pharyngeal bones, to insert mesially on a vestigial cartilaginous 4th hypobranchial, lying in the pharynx floor, just in front of and dorsad to the anterior extremity of the pharyngeals.

The short sternohyoideus originates from the dorsad surface of the antero-ventral extension of the cleithrum and inserts mesially on the anterior half of the large, triangular keel of the urohyal, which is but slightly flattened laterally. Part of the abdominal musculature inserts on the posterior half of the urohyal keel and also contributes to lower the hyoid apparatus.

\section{The masticatory apparatus:}

The pharyngeal bones ( $P l$. XI, c) are falciform and slender, with long anterior processes meeting at an angle of $\pm 50^{\circ}$ and rather loosely united in a short ligamentous symphysis, prolonged anteriorly by a poorly developed, thin, more or less ligamentous cartilage, which is even absent altogether in small specimens.

The alveolar lateral area is much reduced; the ascending processes bend sharply inwards and slightly forwards at their upper ends. The pharyngeals are more of the type found in european Cyprinids of the genus Leuciscus than like those of Barbus. Compared to Leuciscus cephalus, Barilius has smaller teeth, a less developed alveolar area and lacks a postero-ventral process on the pharyngeal bones.

The pharyngeal teeth are arranged in two rows, the formula being: $2(3) ; 5-5 ;(3) 2$. They are more or less of equal size, homodont (conical with a backwardly directed point) and they work mostly against each other (dilacerating action). The masticatory plate has a form more or less like a camel-saddle, is scarcely cornified and bears small, sharp projections.

Both teeth and masticatory plate are largely hidden in the deep lamellar ridges and the papillose, crenulated projections of the posterior pharyngeal wall. These ridges are continuous with the large, smooth longitudinal ones in the oesophagus.

The masticatory musculature: This differs from that of Barbus only in some minor respects, the cleithro-pharyngeus (especially the posterior superficial fascium) being relatively better developed and the antero-internal fascium of the levator arcus branchialis $\mathrm{V}$ inserting more towards the tip of the ascending pharyngeal process. A subarcualis communis inserts anteriorly, as in Barbus, on the caudad aspect of the vertically placed, slender, curved 3rd hypobranchial, which is relatively much stronger in this genus. A thin cucullaris muscle is present, running from the cranium (pterotic) to the upper cleithrum, externally to the pharyngeal bone. The retractor arcus branchialis dorsalis superior is strongly developed, somewhat as in the predominantly carnivorous Barbus spp. (B. holotaenia), where it also appears relatively larger (thicker) in contrast to most species. As already mentioned, the action of the masticatory muscles tends to bring the teeth against each other in a transverse motion more than up towards the masticatory plate.

\section{The digestive tract:}

The intestine is exceedingly short, nearly straight, the ratio intestine length/standard length being 0,6 0,75 (measured on 4 specimens). This is comparable to the ratio for Gobio $(0,65-0,85)$, a bottom-living, carnivorous species (insects and other invertebrates), as given by AL-Hussain (l.c.); also, the intestinal bulb is large and well-developed. The pancreas is diffuse, as in all Cyprinidae studied, and the liver is large, consisting of two dorso-lateral, elongate lobes. The abdominal cavity is lined by silvery epithelium bearing large, scattered melanophores, giving it a spotted appearance.

\section{Conclusion}

Barilius and related genera form a different group altogether among the African Cyprinids, especially ecologically (belonging to the first group as outlined in the ecological classification). They show characteristic specialisations towards a predatory mode of life with 
a corresponding great simplification of the selective mechanism as opposed to specialisation of the prehensile apparatus. Their prey being generally quite large and captured in open water, it does not have to be separated from other material (detritus, bottom sediments) and consequently a selective apparatus becomes unnessary. Selection as such takes place in the mouth itself, where most taste buds are situated, rejected objects being immediately spat out (aquarium observations on $B$. moorei). They must be able to catch elusive prey, hence the large mouth, strongly protractile lower jaw and specialised mandibular articulation and musculature. This type of specialisation has been carried further in $B$. christy $i$ than in $B$. moorei.

\section{Engraulicypris GüNTHER, 1893.}

Species studied: E. minutus (BLGR., 1906) (lake Tanganyika).

\section{General characters}

Small fishes (5-12 cm.) mostly elongate "pelagic" forms, closely resembling Barilius. The terminal mouth is large, oblique, lipless; barbels are absent.

\section{Ecology}

Open-water forms living in lakes and large rivers where they generally occur in shoals, feeding on zooplankton and on small insects, near the surface. They look very much like small pelagic Clupeids of the genus Engraulis, from which their generic name is derived. The lacustrine species show no seasonal spawing migrations up-river.

\section{Functional morphology}

The symphysial knob is pointed, fitting as in Barilius into a notch of the upper jaw; the premaxillaries are also somewhat more protractile. The mucosa of the bucco-pharyngeal cavity is finely plicated longitudinally, the plicae becoming deeper posteriorly. Tiny papillae are also present, more numerous and larger posteriorly, but not as pointed as in Barilius. The pharyngeal pad is somewhat better developed and more strongly papillose.

The gill-rakers are well developed, numbering 12 (on inner side of the 4 th arch) to 33 ; they are long and pointed (especially in the external row), slightly compressed (lamellar), smooth, and mesh closely, forming a relatively fine branchial sieve.

The masticatory apparatus is practically identical to that of Barilius; the slender pharyngeal bones bear 2-3 rows of proportionally large, conical, hooked teeth, the formula being: $0-1 ; 3 ; 5-5 ; 3 ; 1-0$.

The teeth are embedded in the strongly plicated and papillose epithelial tissues, but the soft mastica- tory plate is not largely hidden by the surrounding papillose projections.

The musculature only shows some minor differences from that of the preceding genus, the mandibularis $\left(\mathrm{A}_{2} \mathrm{~A}_{3}\right)$ consisting of a single muscular mass in which the division into various fasciae is very indistinct. Also, the coraco-branchialis anterior has a somewhat more anterior insertion.

The digestive tract differs only from that of Barilius in that the abdominal lining is distinctly blackened and the short intestine coils back once upon itself. The anterior intestinal bulb is very large; the ratio intestine length/standard length is about 0,7 .

\section{Conclusion}

Engraulicypris, which is apparently directly derived from Barilius, appearing in fact to be a sort of pigmy form of it, nevertheless shows some distinctive characters which are also in correlation with its mode of life; the well-developed gill-rakers, for instance, being an adaptation towards a plankton-eating diet.

\section{Chelaethiops BouLENGER, 1899.}

Species studied: C. elongatus BLGR., 1899 (Congo, Nile, West Africa: Niger).

\section{General characters}

Very like the preceding genus, but with keeled scales on the mid-ventral line, anterior to the pelvic fins, and gill-membranes narrowly united to the isthmus anteriorly, the gill-slits extending far forwards ventrally; body strongly compressed. This small species strongly resembles some of the Asiatic Chela spp.

\section{Ecology}

Open-water forms (in large rivers), feeding on zooplankton, small insects, etc., near the surface.

\section{Functional morphology}

In most of its features it is identical to Engraulicypris, but the symphysial knob is small, indistinct; the gillrakers are short, but stubby, not quite as poorly developed as in Barilius, and can mesh to form a very rough, more or less adjustable filter, as in Barbus.

The bucco-pharyngeal lining is plicated, with rows of small papillae everywhere on the crests of the folds, exactly as in Barilius. There is, however, no small, papillose pad on the anterior palate and the plicae are proportionally larger, but this seems to be the case in all small (young) specimens of every species, and therefore cannot strictly be considered as an adaptive character. 
The masticatory apparatus is identical to that of Engraulicypris. The pharyngeal teeth being set in $2-3$ rows according to the formula: $0-1 ; 3 ; 5-5 ; 3 ; 1-0$. The cranial musculature shows no differences from that of Barilius.

The short gut coils back once upon itself, the ratio intestine length/standard length is $\pm 0,75$. The peritoneum is only weakly blackened.

\section{Conclusion}

Like the preceding genus, Chelaethiops is probably derived from Barilius and has adapted to a more or less pelagic mode of life, but its specific morphological adaptions are less marked than in Engraulicypris.

Leptocypris BouLENGER, 1900.

Species studied: L. modestus BLGR., 1900 (Central Congo basin).

\section{General characters}

Small, silvery fishes $(6-12 \mathrm{~cm}$.) very much like Barilius, but with a smaller, more or less sub-inferior mouth ( $P l . \mathrm{XI}, \mathrm{d})$ and the anterior and posterior borders of the eye covered with translucent fatty tissue, forming an adipose eyelid of sorts.

\section{Ecology}

These fishes live in shoals in the open-water reaches of large, generally muddy, rivers and feed mainly on small crustacea (Ostracods), insect larvae and adults (caught near the surface). Vegetable matter (herbaceous) and sand, etc., is also regularly ingested, probably accidentally, when they come to feed on the banks or bottom.

\section{Functional morphology}

The dentary symphysis is simple, no symphysial knob being developed; the mouth is more protractile than in Barilius, especially the upper jaw; the premaxillary pedicels are shorter; the mandibular articulation is exactly as in Barilius.

The epithelial lining of the jaw just inside the mouth shows transverse ridges, but on the upper jaw it is nearly smooth. The mucosa of the bucco-pharyngeal cavity presents relatively few, but well developed, deep plicae and numerous rounded, large papillae are everywhere present, often (especially on the palate and pharyngeal pad) appearing as rows of large, more or less flattened patches or pads of papillose tissue. A row of rounded papillae borders the lower jaw internally and the maxillary valve is also papillose, bearing 2-3 rows of small papillae along its base. These probably serve a predominantly gustatory function, as in Barbus. There is no median papillose pad on the anterior palate.

The pharyngeal pad is poorly developed, as in $\mathrm{Ba}$ rilius, but more papillose; the gill-rakers are rudimentary, being reduced to short, widely spaced, finely papillose stumps, 5-12 in number. Therefore, they cannot mesh closely to form a functional sieve.

The musculature of the mouth and pharynx is very similar to that of Barilius, but the geniohyoideus shows a distinct aponeurotic striation; the intermandibularis is absent or vestigial; the fasciae of $\mathrm{A}_{1} \alpha$ insert through a long, tendinous cauda on the more rostral part of the maxillary. $A_{2}$ and $A_{3}$ are not, or but indistinctly subdivided and appear as a single muscular mass. The hyohyoideus is relatively thinner and also lies ventral to the urohyal, which has the same form as in Barilius and Barbus.

The masticatory apparatus does not differ much from that of Barilius; the pharyngeal teeth are arranged in two rows, the formula being: $3 ; 5-5 ; 3$; however, the pharyngeal bones are stockier, the anterior processes shorter, meeting at an angle of $\pm 70^{\circ}$, and the upper ascending processes dont bend as strongly forwards.

The masticatory plate has a proportionally larger area than in Barilius, of irregular form, with a mamillated, finely papillose, uncornified working surface; it is not embedded in the surrounding papillose epithelium.

The pharyngeal musculature only shows a few minor differences from that of Barilius, the subarcualis communis inserting via a long tendinous cauda on the basihyal and the retractor arcus branchialis dorsalis superior being tendinous and very thin.

The digestive tract closely resembles that of Barilius, but the intestine is somewhat longer, the ratio intestine length/standard length being: 0,85-1,0 (3 specimens) and coiled back once upon itself. The intestinal bulb is also less developed and the two liver lobes are less elongate. The abdominal lining bears scattered melanophores.

\section{Conclusion}

Leptocypris species have apparently reverted to a wider range of foods and also to feeding on the bottom, though remaining essentially carnivorous. This is evidenced by the more protractile mouth, the more strongly papillose bucco-pharyngeal lining with its increased surface area for greater mucus production and better taste sense, a longer gut, etc. However, an efficient selective apparatus has not developed and therefore much detritus and indigestible material (vegetable matter, sand, etc.) is also found in the gut. 
Leptocypris seems to be a more generalised genus, showing considerably less extreme specialisation than Barilius to a predaceous habit, but nevertheless probably derived from Barilius-like ancestors and it is not necessarily a primitive form.

\section{GENERAL CONCLUSIONS AND DISCUSSION}

Some interesting conclusions can be drawn from this study, not only concerning the diversity of feeding mechanisms and their relative development in the different genera, but also concerning the systematics of the African Cyprinidae. The question arises as to which types of feeding mechanisms are primitive in Cyprinids and consequently, which genera are primitive systematically.

The African Cyprinids can be broadly classified into 3 fundamental types, i.e.: a Labeo type, a Barbus type (including Barbus, Caecobarbus, Barbopsis, Phreatichthys, Varicorhinus, Garra, Xenobarbus, Coptostomabarbus) and a Barilius type (Barilius, Chelaethiops, Engraulicypris, Leptocypris). To a certain extent, this classification is also in accordance with ecological distinctions. Rasbora, of which two species have been described as African (though of very doubtful origin) is apparently close to the Barilius type, but has not been studied further here. The following table (Table III) summarises most of the major charactersas well those pertaining to feeding, as of systematic and ecological nature-distinguishing the three types as defined above.

According to Schaeffer \& Rosen (1961), the feeding mechanisms of early Teleosts of the Elopid type, to which the Cyprinid type is related, were fundamentally predaceous and it seems reasonable to infer that this was indeed so in early Cyprinids. In fact, the Cyprinidae, like most Teleosts possess a highly kinetic prehensile apparatus which shows some typical specialisations-e.g. the absence of the ligament patterns characteristic of most other teleost typesand has been independently derived, probably from sub-acanthopterygian ancestors, according to these authors. The primitive forms presumably had strongly protractile mouths, and though this character has been retained in most recent types, it is reduced in some of the more specialised forms (e.g. Labeo, Gar$\mathrm{ra}$, Barilius) and strongly modified in others (Coptostomabarbus). Certainly the most typical character of this family is the absence of teeth and consequent development of a post-branchial masticatory apparatus. This is well developed in all the species studied, the dentition showing most specialisation, in close accordance with the type of food. The teeth are also reduced in number and of a more simple type (primitive) in the carnivorous members of the family, especially the Barilius group.

Some species-especially the smaller ones-and genera show characters which appear to be of neotenic nature. The reduction in number of pharyngeal teeth, various simplifications in tooth form, bone development and in the musculature provide positive evidence of this. For instance, small genera like Barbopsis, Coptostomabarbus, Engraulicypris, etc., present osteological and muscular features which also appear in small Barbus and Barilius species, as well as in young specimens of the larger species.

The well-developed coronoid process is an important element in forms with a strong biting power (higher torque about the jaw articulation) and is in relation to the mode of prehension rather than to the type of food, being almost equally well developed in forms with cutting and scraping jaws (Garra, Labeo) as in predaceous species. The insertion of the adductor mandibulae $\left(A_{2} A_{3}\right)$ on the coronoid process only, is, however, a characteristic of predatory types.

The development of premaxillary pedicels, which allies strong protrusibility with greater rigidity, is also a necessary development in predaceous forms. The post-orbital jaw articulation which is developed in some Barilius species, would be a primitive character (see Schaeffer \& Rosen, l.c.); but it is not allied here to a vertical jaw suspension (hyomandibular) and has evidently been secondarily acquired.

Ecologically, the Labeo type is highly specialised towards a phytophageous (microphytophageous) diet; of the Barbus group, many are facultative feeders, their specialisations not having been carried so far, in the large majority of cases, as to restrict them to a particular diet. Finally, the Barilius type is entirely carnivorous (predaceous) with corresponding specialisation of the prehensile mechanism opposed to simplification of the selective apparatus.

As regards the taxonomy of the genera studied, the findings entirely confirm their validity and besides, reveal other characters on which further sub-division may be based, at least sub-generically, in some of them (e.g. Labeo, Barbus). A number of features, as well of osteological nature as concerning muscular arrangement, reveal that Labeo stands quite apart from all other African genera (see also Table III); the Barbus and Barilius types share many characteristics which are indicative of close phylogenetical affinities. Even though a genus like Garra shows a number of Labeo-like characters, these are probably only due to convergent evolution and its closest affinities are quite definitely with fishes of the Barbus group. 
TABLE III. Characteristics distinguishing the three fundamental types of African Cyprinidae.

\begin{tabular}{|c|c|c|}
\hline Labeo type & Barbus type & Barilius type \\
\hline $\begin{array}{l}\text { Stocky forms } \\
\text { Well-developed rostrum and rostral } \\
\text { groove } \\
\text { Mouth moderately protrusile, inferior, } \\
\text { transverse } \\
\text { Lips thick, papillose } \\
\text { Barbels usually reduced } \\
\text { Horny cutting edge on jaws } \\
\text { No premaxillary pedicels } \\
\text { Interdentary cartilage developed } \\
\text { Mandibular articulation with quadrate, } \\
\text { preopercular (\& interopercular) } \\
\text { Vomero-palatine organ } \\
\text { Pharyngeal pad well-developed, papill- } \\
\text { ose } \\
\text { Gill-rakers numerous, forming fine sieve } \\
\text { Gill slits largely united to the isthmus, } \\
\pm \text { restricted } \\
\text { Urohyal flat, broad, not strongly keeled } \\
\text { Pharyngeal bones relatively small, } \\
\text { stocky, } \pm \text { triangular } \\
\text { Pharyngeal teeth molariform, close-set }\end{array}$ & $\begin{array}{l}\text { variable forms } \\
\text { rostrum in some (Garra) } \\
\text { mouth strongly protrusile general- } \\
\text { ly, inferior to terminal. } \\
\text { lips variable } \\
\text { barbels mostly well developed } \\
\text { horny edge in some (Garra) } \\
\text { premax. pedicels usually moderate- } \\
\text { ly developed } \\
\text { dentary symphysis generally simple } \\
\text { mandibular artic. variable, usually } \\
\text { with quadrate and preopercular } \\
\text { generally only } \pm \text { longitudinal pli- } \\
\text { cae on palate, but rudimentary } \\
\text { organ in some (Barbopsis, Garra) } \\
\text { pharyngeal pad variably developed } \\
\text { gill-raker development variable; } \\
\text { usually rough, } \pm \text { adjustable filter } \\
\text { gill slits variable in development } \\
\text { urohyal strongly keeled, not much } \\
\text { flattened laterally, except in Garra } \\
\text { pharyngeals falciform, relatively } \\
\text { large and strong } \\
\text { pharyn. teeth variable, mostly } \\
\text { spoon-shaped, with a backwardly } \\
\text { directed point } \\
\text { mastic. plate horny or calcified } \\
\text { air-bladder reduced in some (Garra) } \\
\text { intestine moderate } \\
\text { adduct. mandib. of a general type, } \\
\text { insertion of } A_{2} \text { \& As more anterior } \\
\text { crawlers, some sprinters } \\
\text { omnivorous/carnivorous } \\
\text { intermandibularis usually present } \\
\text { geniohy. modified into a protractor } \\
\text { hyoidei } \\
\text { interhy. poorly developed or absent } \\
\text { hyohy. lies ventrad to urohyal } \\
\text { cleithro-pharyn. prof. present } \\
\text { antero-int. fascium of lev. V present } \\
\text { usully bottom-living; stayers, }\end{array}$ & 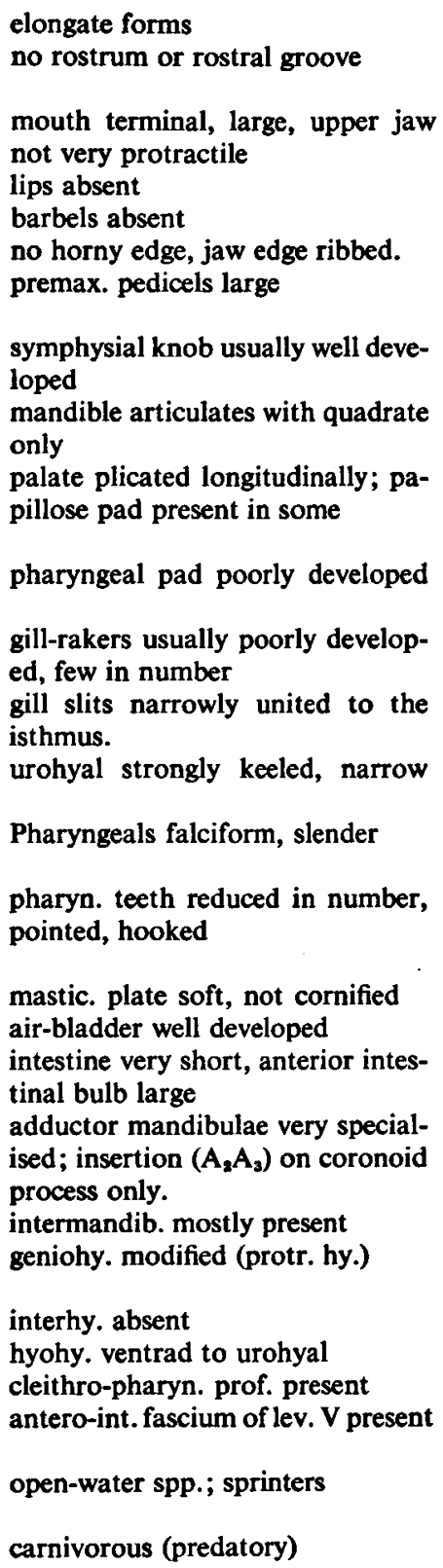 \\
\hline
\end{tabular}

More detailed research, especially on the anatomy, physiology and ontogeny of the head region of these fish, will certainly answer many questions as regards the finer structure and functioning of their feeding mechanisms and of their taxonomical relationships as well.
Lack of time and particularly lack of adequate material (as well fresh material for histological investigation and for dissection, as live specimens with which to experiment) imposed limitations on the scope of this work, which will nevertheless, I hope, prove to be of value. 


\section{LIST OF ABBREVIATIONS}

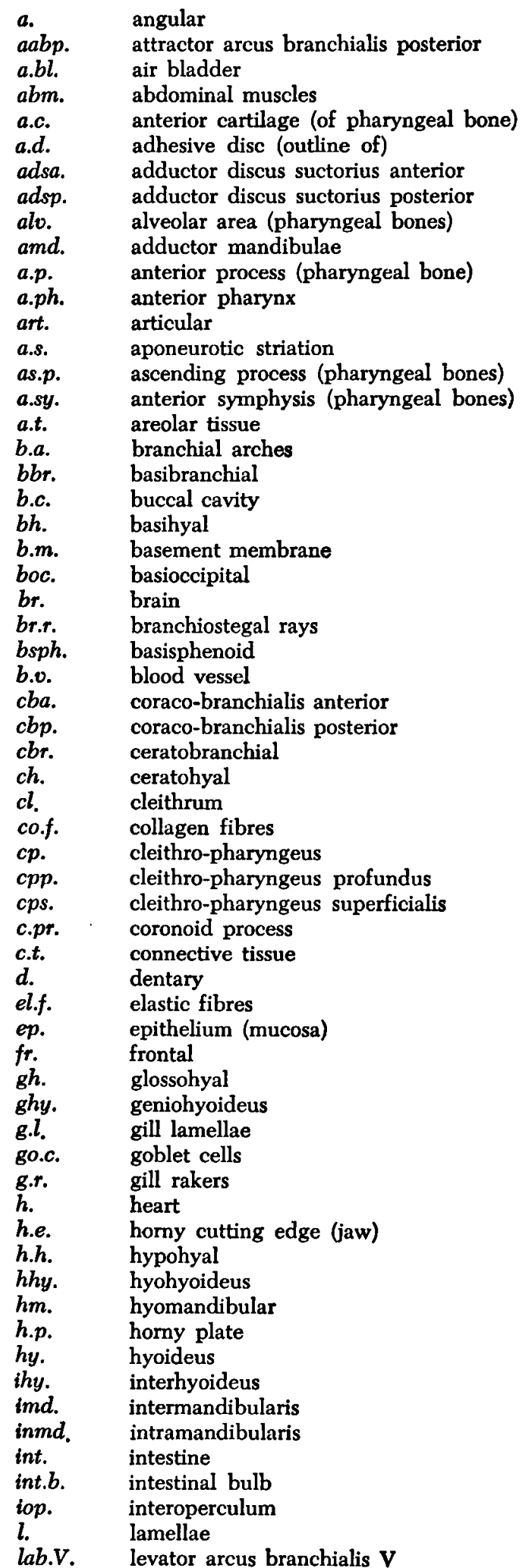

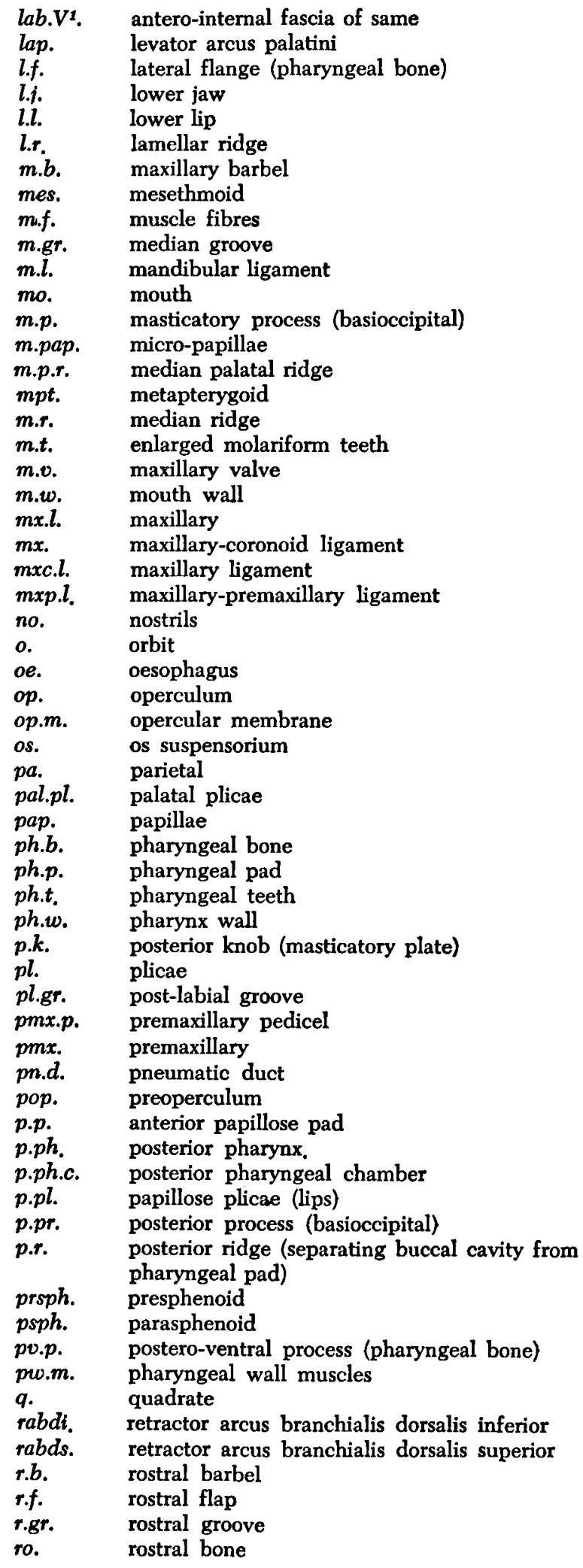


s.e. smooth epithelium (mouth floor)

sig.l. sigmoid ligament

sk.m. superficial skin muscle

smx.c. sub-maxillary cartilage

so. sub-orbitals

soc. supraoccipital

soc.p. supraoccipital process

sop. suboperculum

sph.o. sphincter oesophagi

src. subarcualis rectus communis

st.e. stratified epithelium

sthy. sternohyoideus

sy.k. $\quad$ symphysial knob

$\begin{array}{ll}\text { t.b. } & \text { taste bud } \\ \text { to. } & \text { tongue } \\ \text { tv. }(\mathrm{IV}, \mathrm{V}) & \text { transversus ventralis (IV \& V) } \\ \text { tv.r. } & \text { transverse ridges } \\ \text { tu. } & \text { tubercles } \\ \text { uh. } & \text { urohyal } \\ \text { u.j. } & \text { upper jaw } \\ \text { u.l. } & \text { upper lip } \\ \text { v. } & \text { vertebrae } \\ \text { v.a. } & \text { ventral aorta } \\ \text { vo. } & \text { vomer } \\ \text { v.ph.p. } & \text { ventral pharyngeal pad } \\ \text { vpo. } & \text { vomero-palatine organ }\end{array}$

BIBLIOGRAPHY
Al-Hussaini, A. H., 1949: On the functional morphology of the alimentary tract of some fish in relation to differences in their feeding. Quart. J. micr. Sc. (London), 90, 109-139 \& 323-354.

BERG, L. S., 1948: Freshwater fishes of the U.S.S.R. II, Acad. of Sc. Press, Moscow (4th ed.), 493-846.

Boddeke, R., Slijper, E. J. and v. D. Stelt, A., 1959: Histological characteristics of the body musculature of fishes in connection with their mode of life. Koninkl. Nederl. Akad. Wetensch., (C) Zool., 62, 5, 576-588.

Boulenger, G. A., 1901: Poissons du bassin du Congo. Publ. de l'Etat Indép. du Congo, Bruxelles.

- 1907: The Fishes of the Nile, in "Zoology of Egypt". Publ. Egypt. Gov., London.

Brown, M. E., 1957: The Physiology of Fishes. Acad. Press, New York, vol. I, 109-154; vol. II, 187-207.

Carrí, M., 1937: Note sur l'appareil digestif et la digestion de la tanche (Tinca tinca), Bull. Soc. Zool. Fr., 62, 277-280.

Chu, Y. T., 1935: Comparative studies on the scales and on the pharyngeals and their teeth in chinese Cyprinids ... Biol. Bull. St. Johns Univ., Shanghai, 2, 1-225.

Curry, E., 1939: The Histology of the digestive tube of the Carp. J. Morph., 65, 53-78.

Daget, J., 1954: Les poissons du Niger supérieur. Mém. I.F.A.N., 36, 174-218.

Davm, L., 1937: La conformation du museau chez un petit Cyprinide africain. Coptostomabarbus wittei Davm \& Poll. Rev. Zool. Bot. Afr., 30, 1, 1-18.

DAY, F., 1889: Fishes (I and II), in: Fauna of British India. TAYLoR \& Francis (London), 213-367.

DiErz, P. A., 1912: Vergelijkende anatomie van de kaak en kieuwboogspieren der Teleostei. (Proefschrift). Uitg. E. YDo, Leiden.

Dobben, W. H. van, 1935: Uber den Kiefermechanismus der Knochenfische. Arch. Néerl. Zool., II, 1, 27-31.

Dorier, A. \& BELON, G., 1952: Sur l'organe palatin des Cyprinidés. Trav. Lab. Hydrob. Pisc. Grenoble, 44, 47-60.

Dotrrens, E., 1951: Les poissons d'eau douce. I, Paris, 17-70.
Edgeworth, F. H., 1935: The cranial muscles of vertebrates. Cambridge Univ. Press.

Evans, H. E. \& Deubler, E. E., 1955: Pharyngeal tooth replacement... Copeia, 1, 31-43.

Fiebiger, J., 1931: Uber den Bau und die Mechanik des Karpfenrüssels. Zeitschr. mikr. anat. Forschg., 27.

Fryer, G., 1959: The tropic relationships and ecology of some littoral communities of lake Nyassa. Proc. Zool. Soc. London, 132, III, 153-281.

GiRgIS, S., 1952: The bucco-pharyngeal feeding mechanism in an herbivorous bottom-feeding Cyprinid Labeo horie (Cuv.). J. Morph., 90, 281-315.

- On the anatomy and histology of the alimentary tract of an herbivorous bottom-feeding Cyprinid ... J. Morph., $90,317-362$.

Gosse, J. P., 1956: Dispositions spéciales de l'appareil branchial des Tilapia et des Citharinus. Ann. Soc. R. Zool. Belg., LXXXVI, 2, 303-308.

Grasse, P. P., 1958: Traité de Zoologie. XIII, (2), pp. 929-934 and 1248-1302; (3), 2295-2300.

Greenwood, H. Ph., 1958: The fishes of Uganda. Uganda Soc. Publ., Kampala, 49-70.

Grecory, W. K., 1933: Fish skulls. Trans. Am. Phil. Soc. Philad., XXIII, 2, 189-194.

HAEmpel, O., 1909: Die Schlundknochenmusculatur der Cypriniden und ihre Function. Zool. Jahrb. (Abt. Anat.), 27, 95-101.

Heckel, J. J., 1843: Die fische Syriens. Schweizerbartsche Verlagshandlung, Stuttgart.

Heurs, M. J., 1951: Ecology, variation and adaptations of the blind african cave fish Caecobarbus ... Ann. Soc. Roy. Zool. Belge, 82, 2, 155-230.

HoLstroocd, C., 1961: The importance of the Retractores Arcuum Branchialium for the Classification of teleostean Fishes. Bull. Aq. Biol., 2, 15, 49-50.

Hoppe, R., 1894: Untersuchungen über den Kauapparat der Cyprinoiden (Dissertation). A.Th. Engelhardt Ed., Leipzig, 35 pp.

Hora, S. L., 1922: Structural modifications in the fishes of mountain torrents. Rec. Ind. Mus., 24, 1, 31-61.

- 1930: Ecology, bionomics and evolution of the torren- 
tial fauna with special reference to the organs of attachment. Phil. Trans., B., 218.

HuBBs, C. L., 1941: The relation of hydrological conditions to speciation in Fishes. (Symp. Hydrob.). Univ. of Wisconsin Press, 182-195.

Martzan, Grafnn v. R., 1935: Zur Emährungsbiologie und Physiologie des Karpfens. Zool. Zentr. Abt., 3, 55, 191-218.

Mcvax, J. A. \& KAAN, H. W., 1940: On the digestive tract of Carassius auratus. Biol. Bull., 78, 53-67.

Prcrer, A., 1909: Contributions à l'étude histologique du tube digestif des poissons Cyprinoides. Rev. Suisse Zool., 17, 1-76.

PIessis, S. S. DU, 1956: Some adaptations of the genera Barbus and Varicorhinus, 2nd Symposium Afr. Hydr. \& Inland Fisheries, CSA/CCTA, Publ. 25, 85-87.

Poll, M., 1953: Poissons non-Cichlidae. Expl. Hydrob. L. Tang., I. R. Sc. N. B., III, 5A, 74-116.

- 1959: Recherches sur la faune ichthyologique de la région du Stanley-Pool. Ann. Mus. R. C.B., $\left(8^{\circ}\right)$, Zool. $71,150-171$.

Ramaswami, L. S., 1955: The skeleton of Cyprinoid fishes in relation to phylogenetic studies. Part VII, (Cyprininae), Acta Zool., 36, 199-242.

SARBAHI, D. S., 1940: The alimentary canal of Labeo rohita (HАм.). J. Roy. As. Soc. Bengal, (Sc) 5, 2, 87-116.

Schaeffer, B. \& Rosen, D. E., 1961: Major adaptive levels in the evolution of the actinopterygian feeding mechanisms. Am. Zool., I, 2, 187-204.

Suvorov, E. K., 1959: Algemeine Fischkunde. Veb. Deutsch. Verl. Wiss., Berlin, 128-131.

SuYkHiro, Y., 1942: A study on the digestive system and feeding habits of fish. Japan. J. Zool., 10, 1-303.

Takahasi, N., 1925: On the homology of the cranial muscles of the Cypriniform fishes. J. Morph. \& Physiol., 40, 1-109.

Trin.o, O., 1920: Das Maulspitzen der Fische, Biol. Zentralbl., 40, 216-238.

Weber, M. \& DE Beaufort, L. F., 1916: The fishes of the Indo-Australian Archipelago, (Cyprinoidea). III, Leiden, 43-235.

ZaNDER, E., 1903: Studien über das Kiemenfilter bei Süsswasserfischen. Zeitschr. wiss. Zool., Leipzig, 75, 233-257. 
Plate 1.

a. Head of Labeo lineatus (lateral view) showing rostral flap and retracted inferior mouth bordered by thick lips. ( $x$ 2)

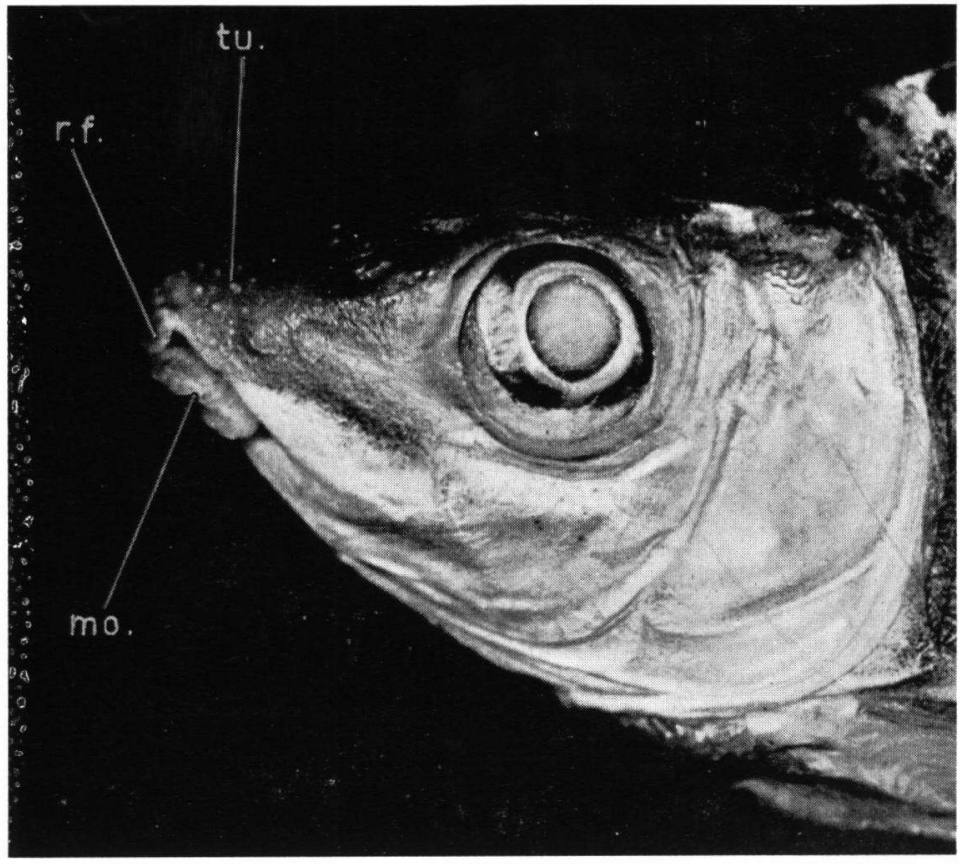

b. Head of Labeo niloticus (median longitudinal section) showing the course of the bucco-pharyngeal cavity. ( $x$ 2)

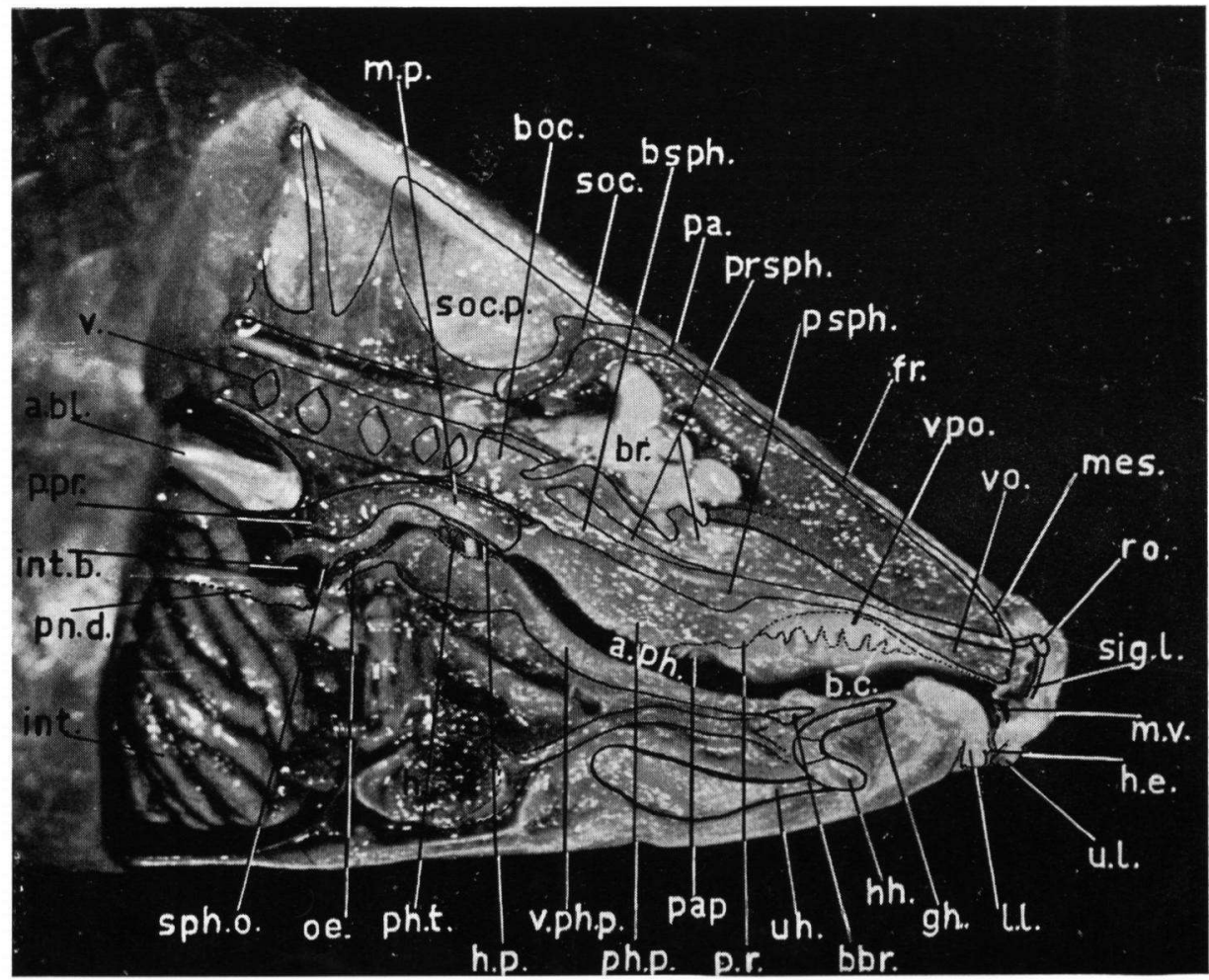


c. Mouth of Labeo variegatus (ventral view) cut open to show lower jaw, horny cutting edges and papillose plicae on lips. (x 4)
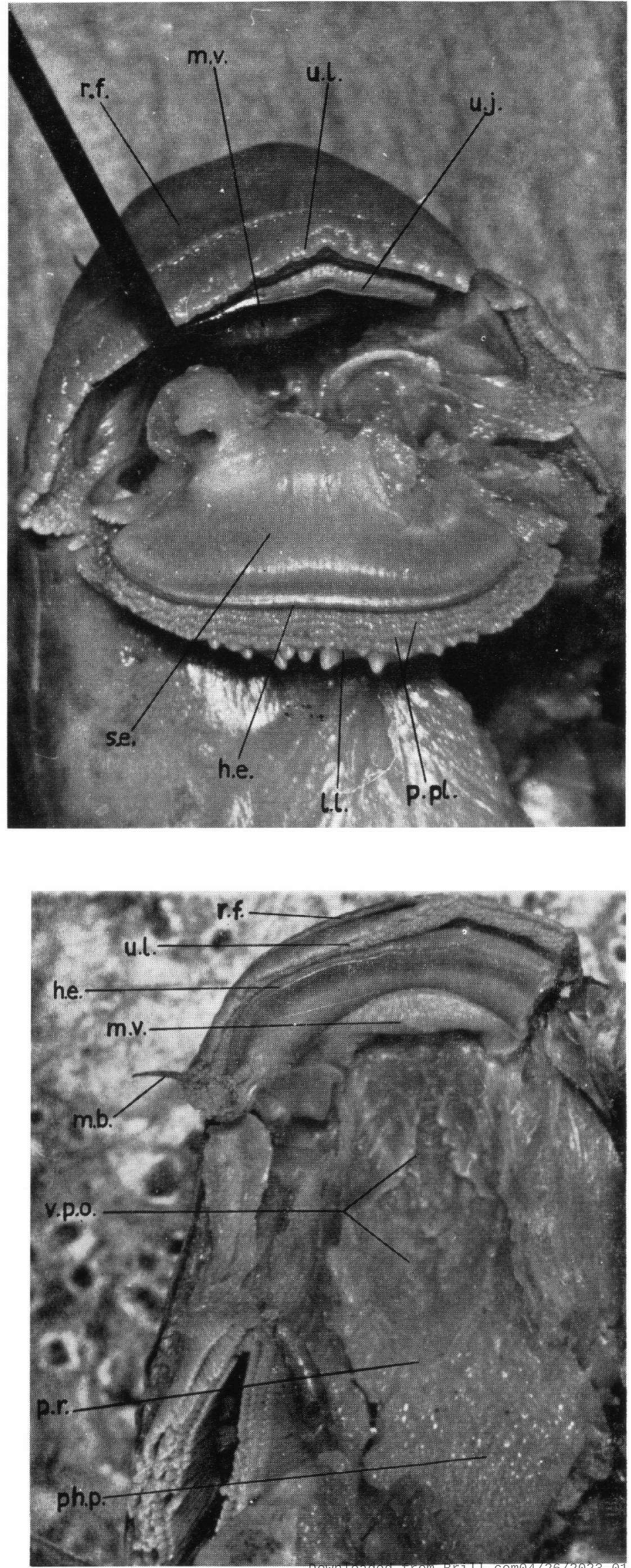
palatine organ and pharyngeal pad. (x 4) 
Plate II.

a. Vomero-palatine organ of Labeo lineatus on anterior palate (ventral view). (x 6)

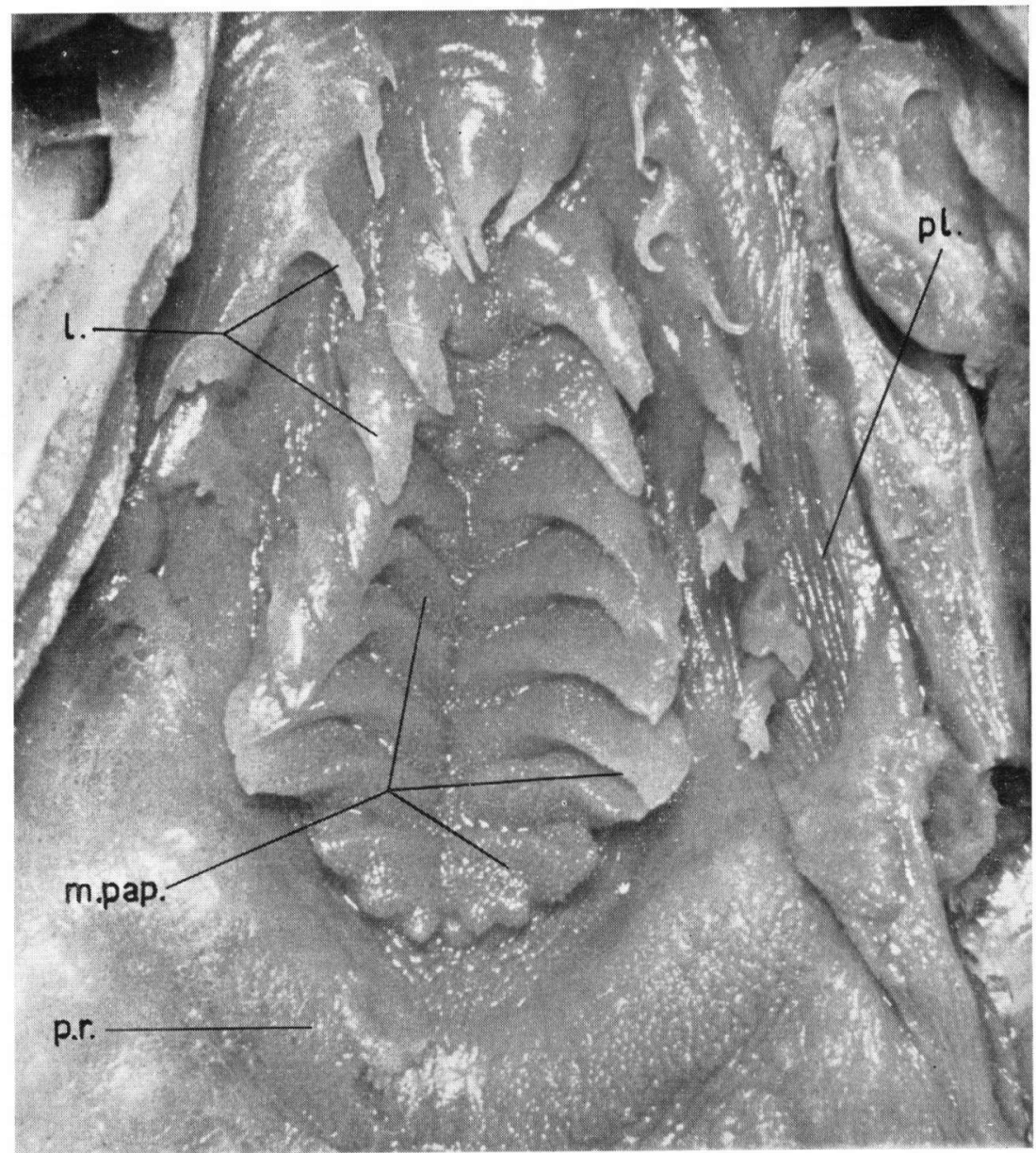

c. Dorsal pharyngeal pad of $L$. lineatus (ventral view) showing papillae, anterior ridge and median groove. (x 6)

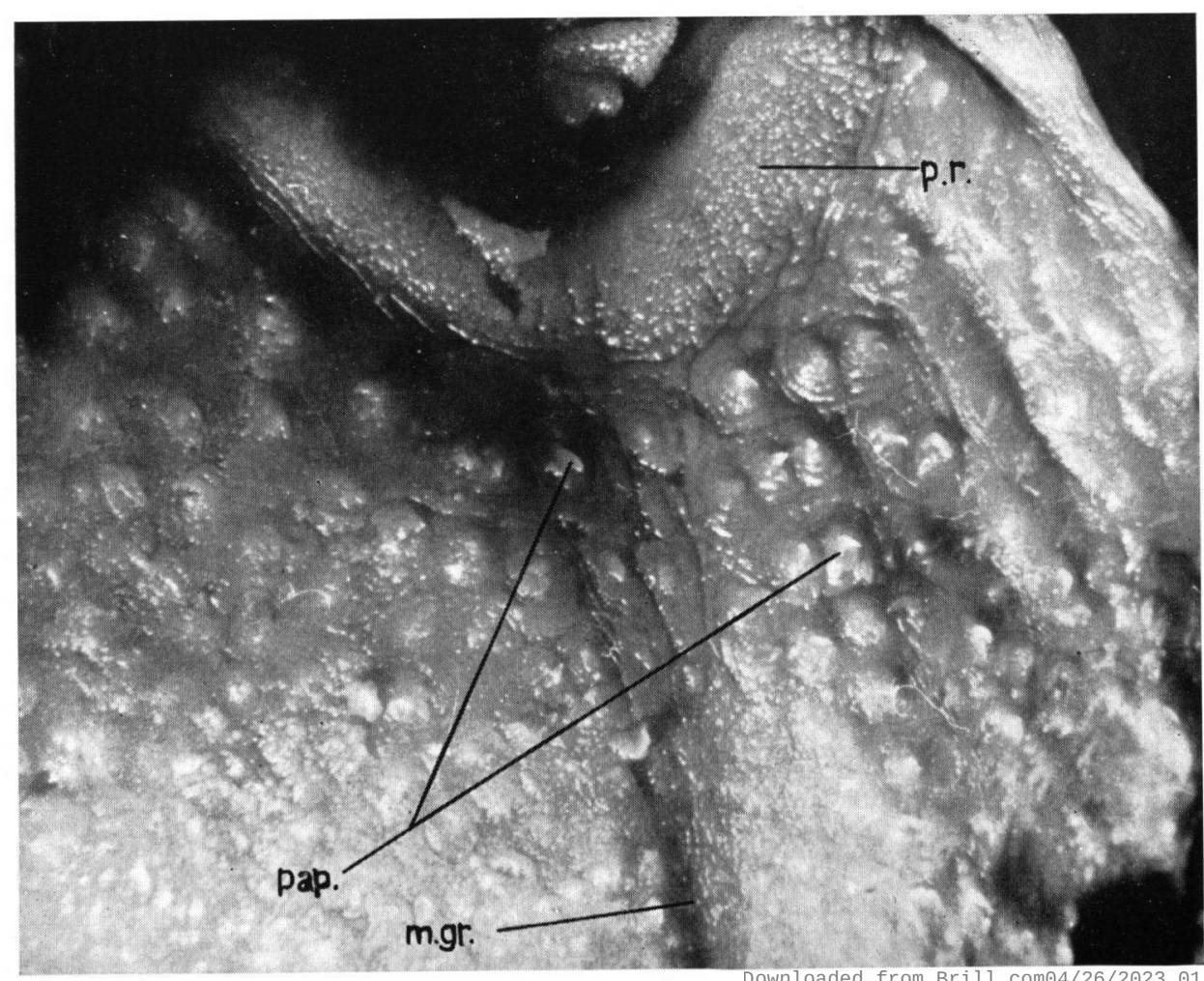


$b$. 2nd branchial arch of $L$. lineatus (superior view) showing gill-rakers and tiny lateral projections. ( $x$ 6)

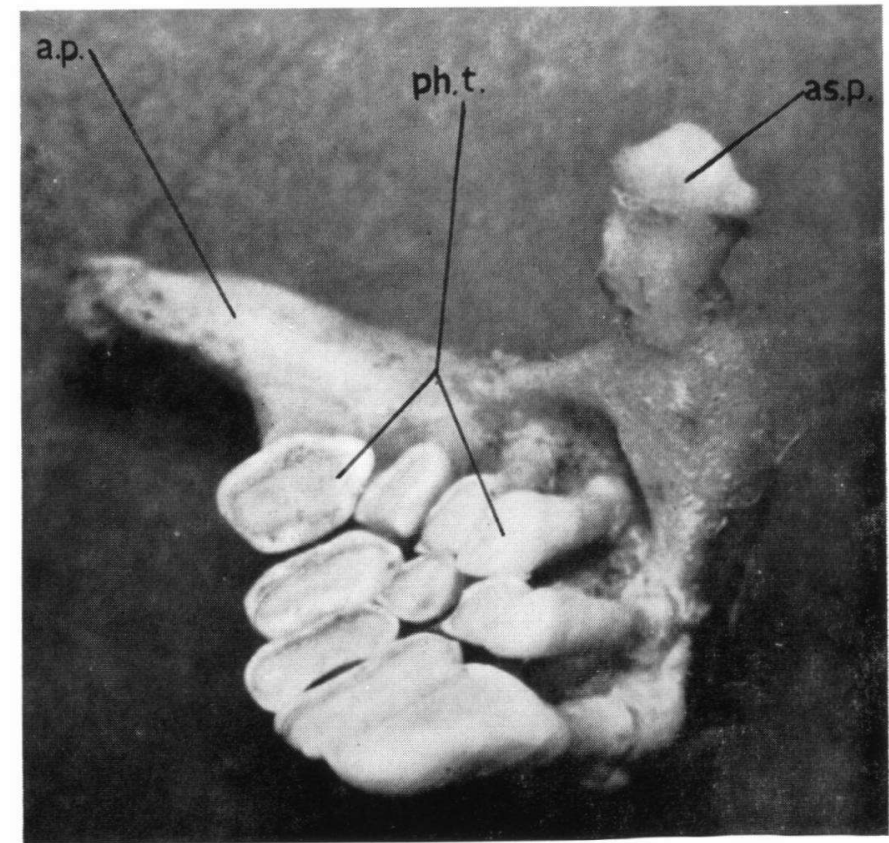

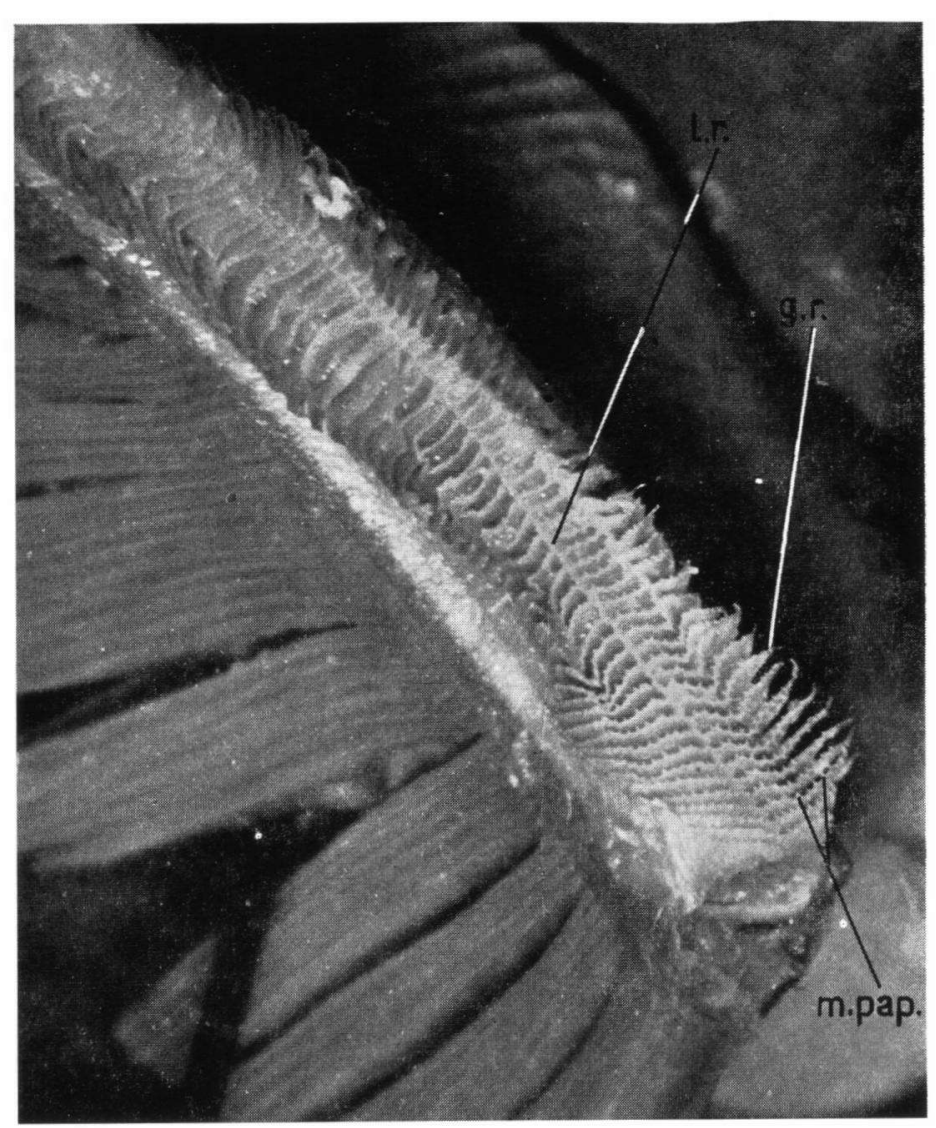

d. Right pharyngeal bone of L. lineatus (superior view) showing molariform grinding dentition. (x 6) 
Plate III.

a. Head of Labeo variegatus with mouth protruded, showing papillose lips and rostrum.

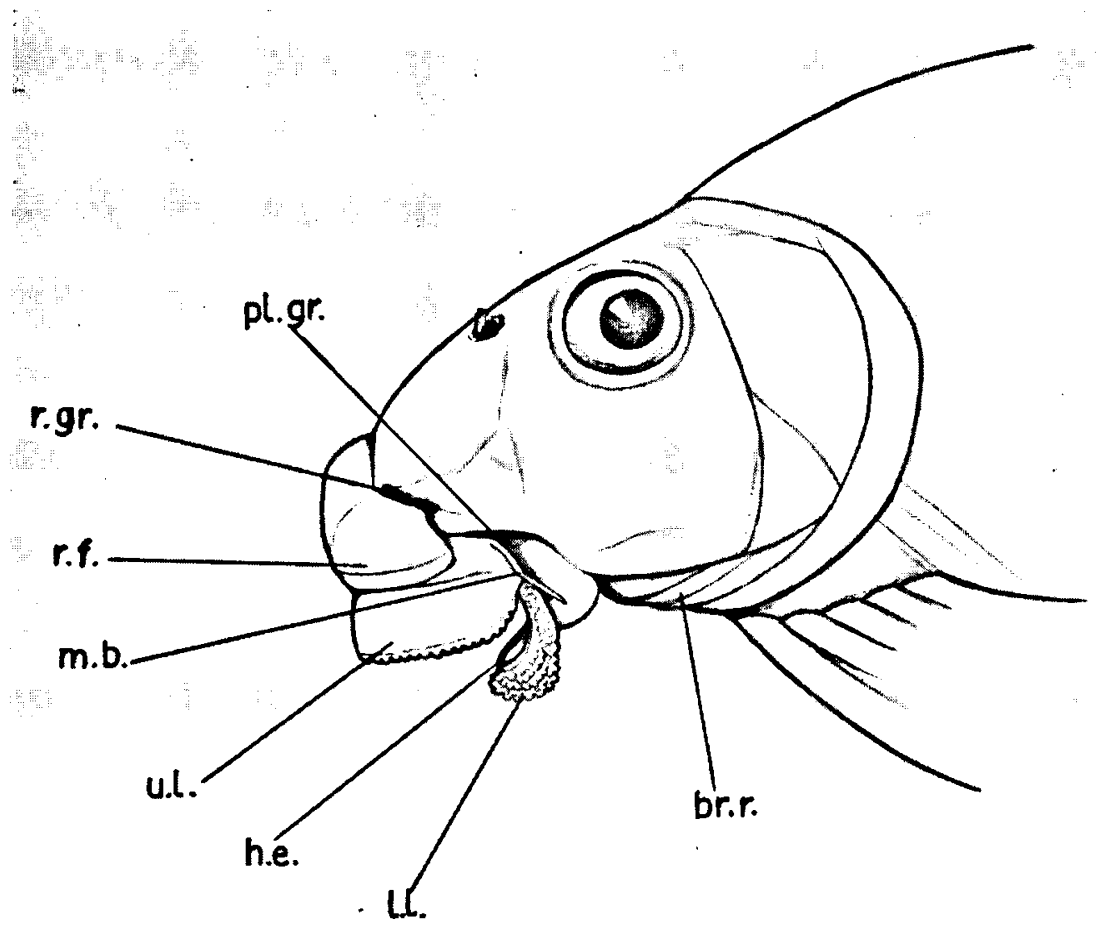

b. Head of Labeo lineatus, showing bones and musculature of the mouth (semidiagrammatic).

outline of bones, cartilage, etc.

outline of $A_{2}$ lying under $A_{1}$.

outline of $A_{3}$ lying under $A_{2}$ and $A_{1}$.

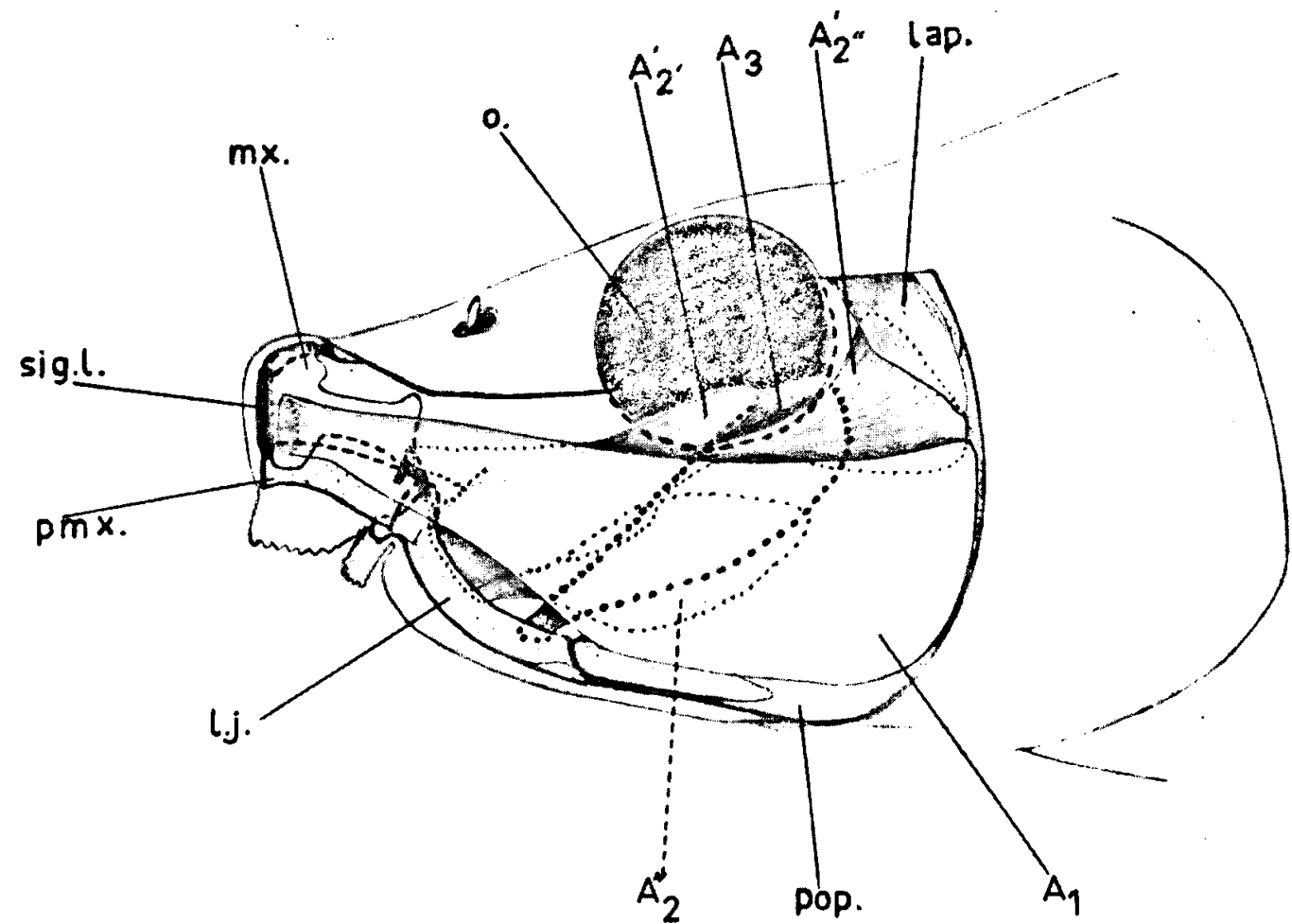




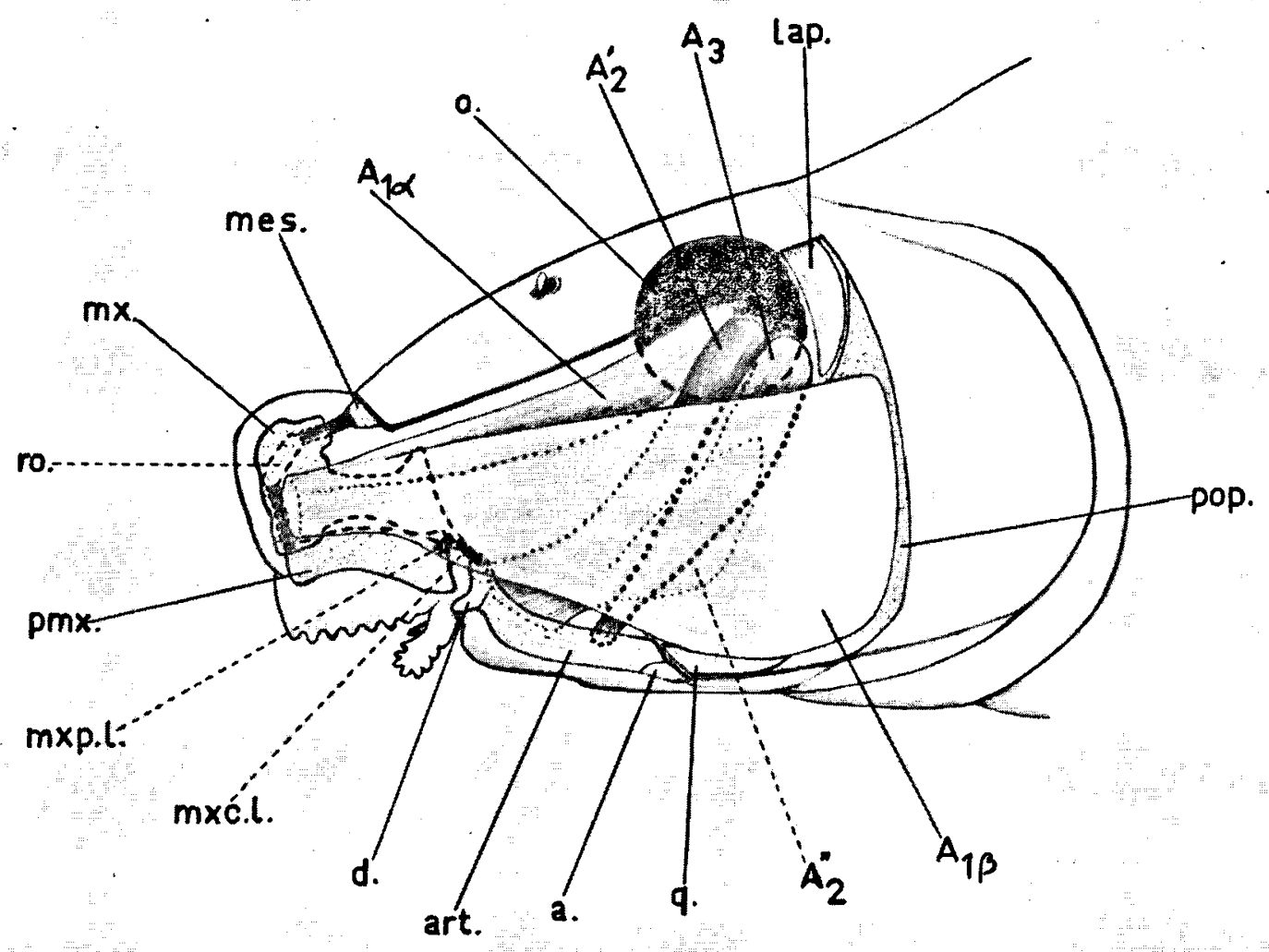

c. Head of L. variegatus, showing bones and musculature of the mouth.

d. Lower pharyngeals of $L$. lineatus (supero-posterior view) showing teath, left half of upper pharyngeal bone and masticatory musculature (semi-diagrammatic).

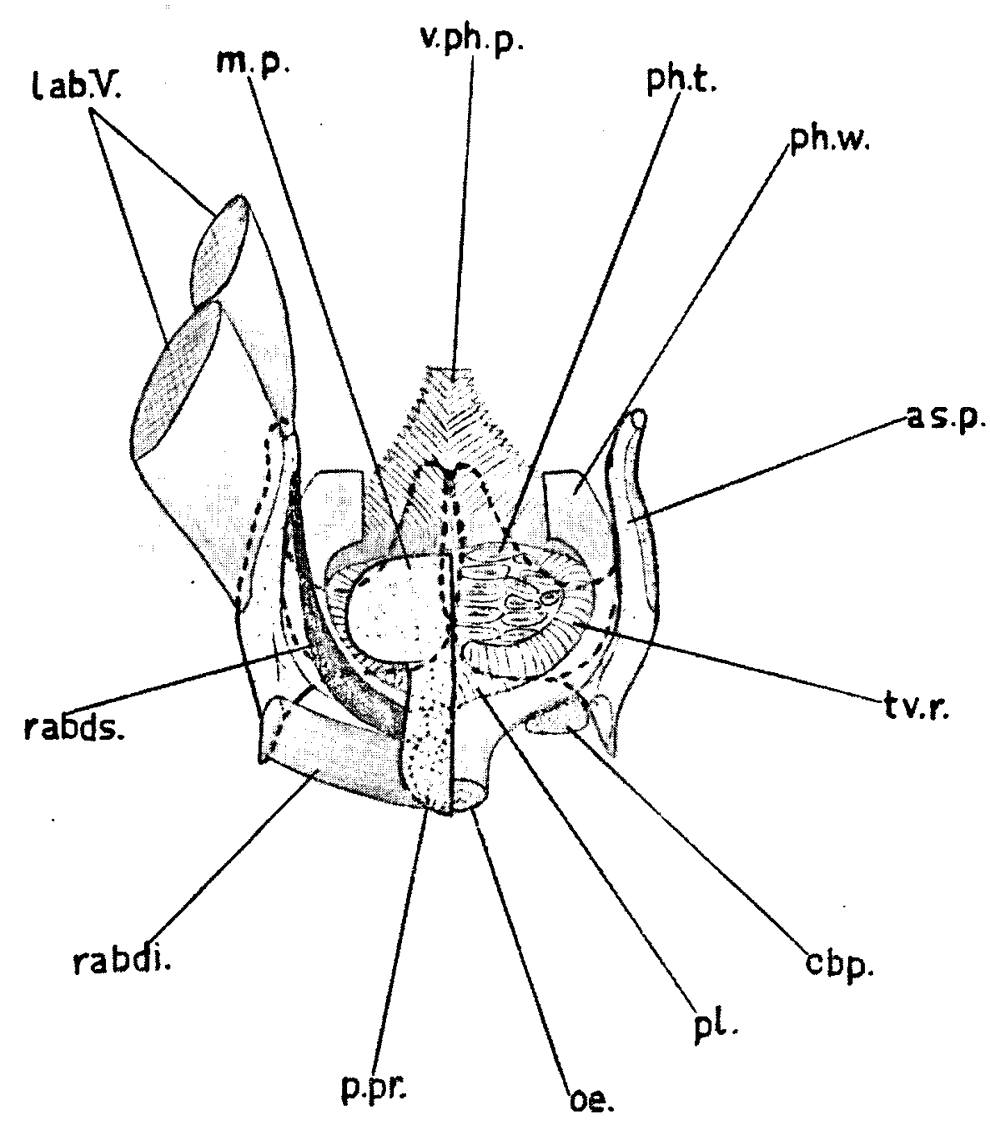


Plate IV.

a. Lower pharyngeals of Labeo lineatus (ventral view) showing masticatory muscles.

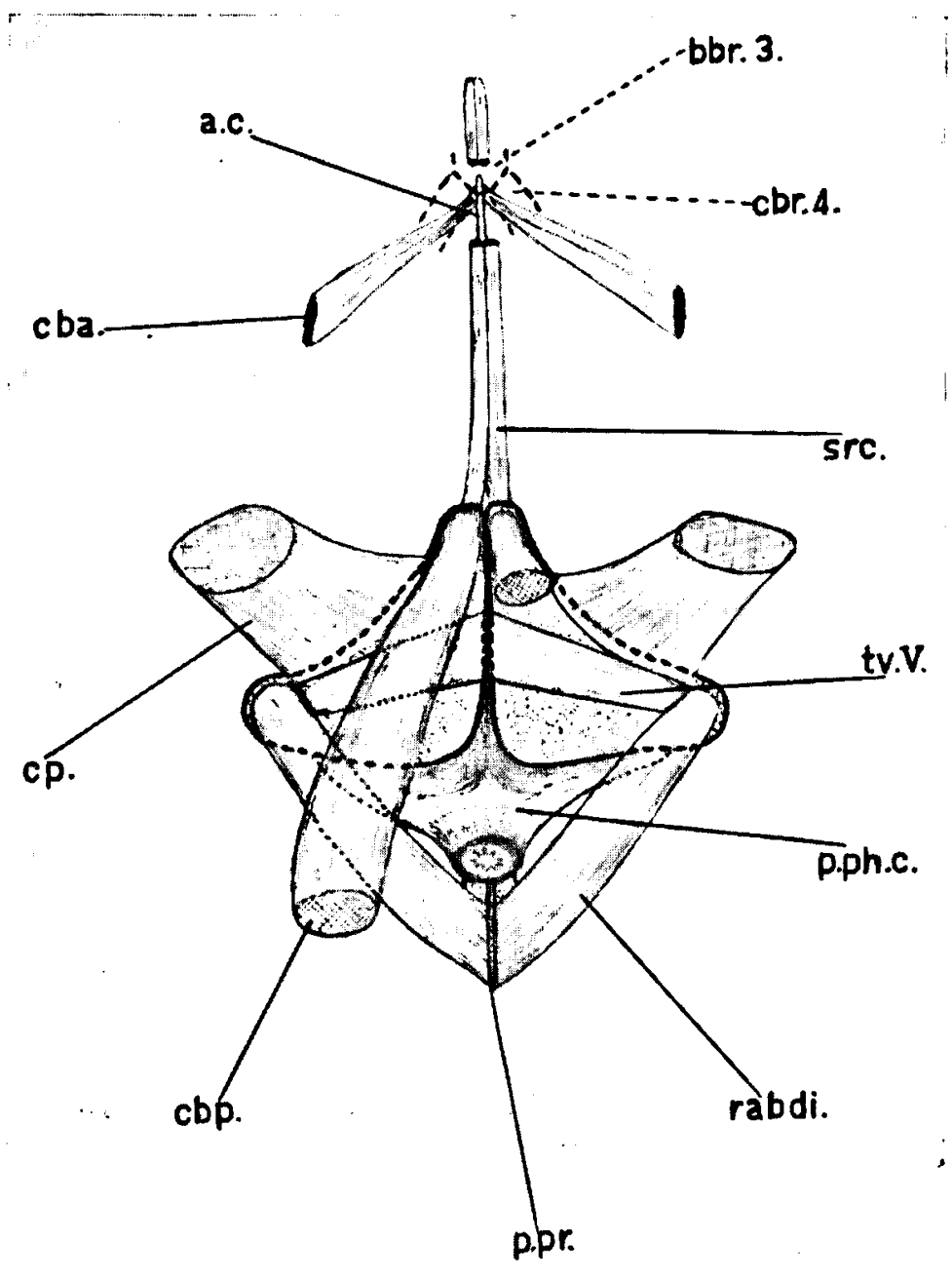

b. Left pharyngeal bone of $L$. lineatus (lateral view) showing musculature, outline of pharyngeal pad and upper pharyngeal bone.

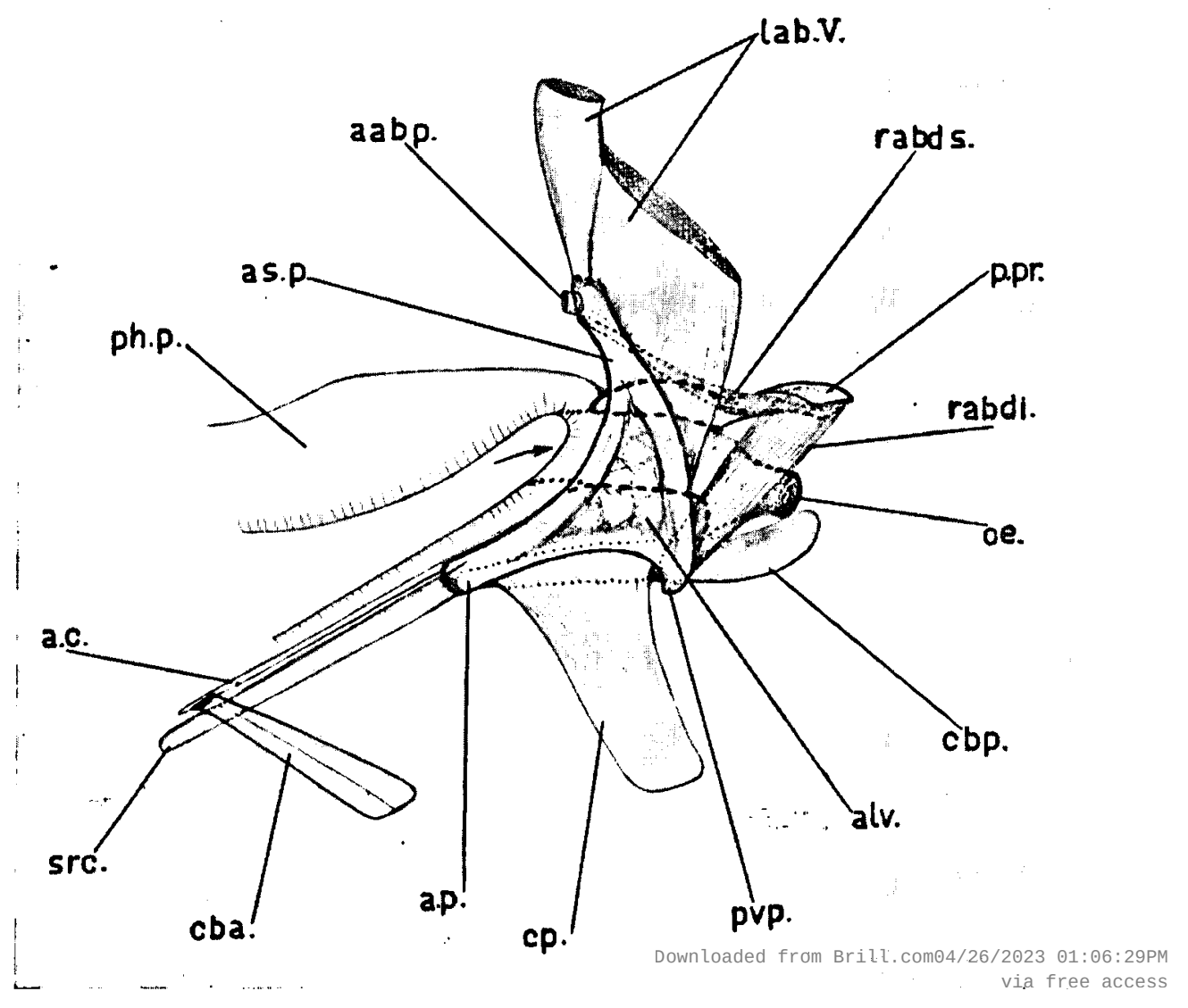


c. Portion of left gill arch of Garra congoensis, show-

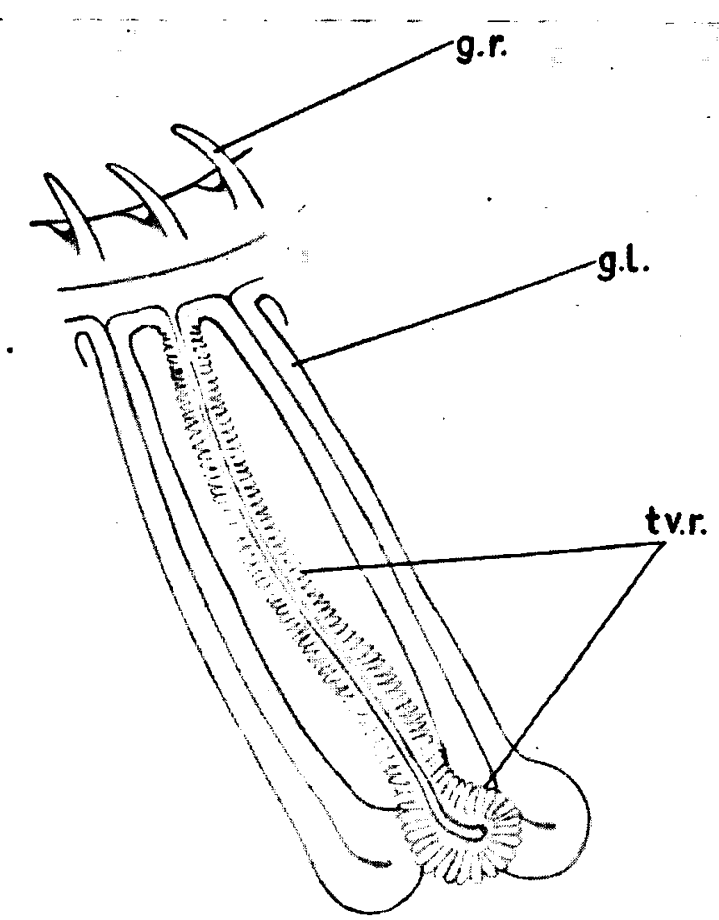
ing gill-rakers and transverse ridges of the gill lamellae.

d. Mouth of Garra dembeensis (ventral view) showing the lower jaw articulation and the adhesive disc muscles.

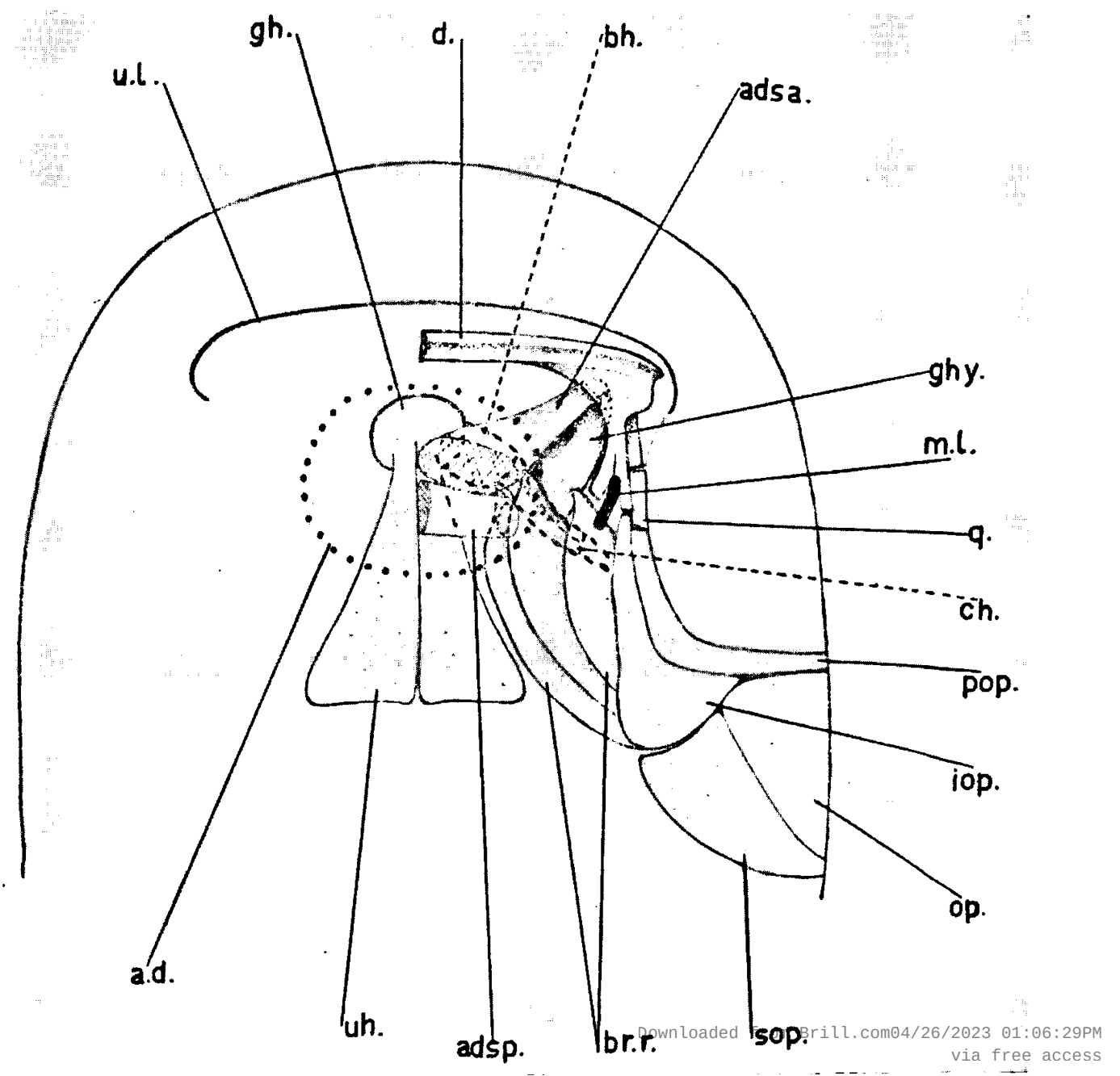




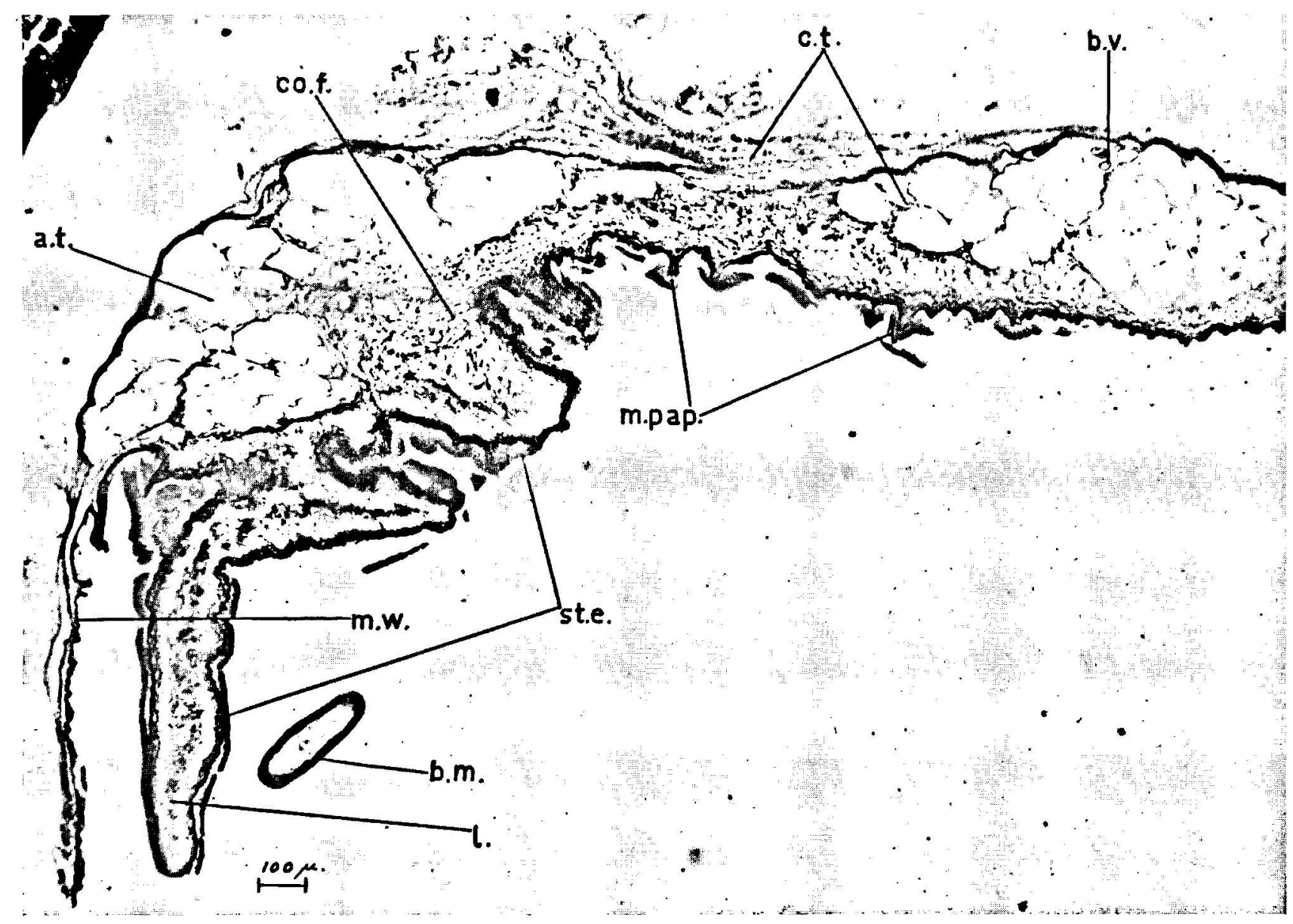

a. Vomeropalatine organ of Labeo lineatus (transverse section) showing its finer structure. (10 $\mu$, Azan)

b. Palate of Garra dembeensis, showing fringed upper lip, palatal plicae, pharyngeal pad and horny masticatory plate. ( $x$ 4)

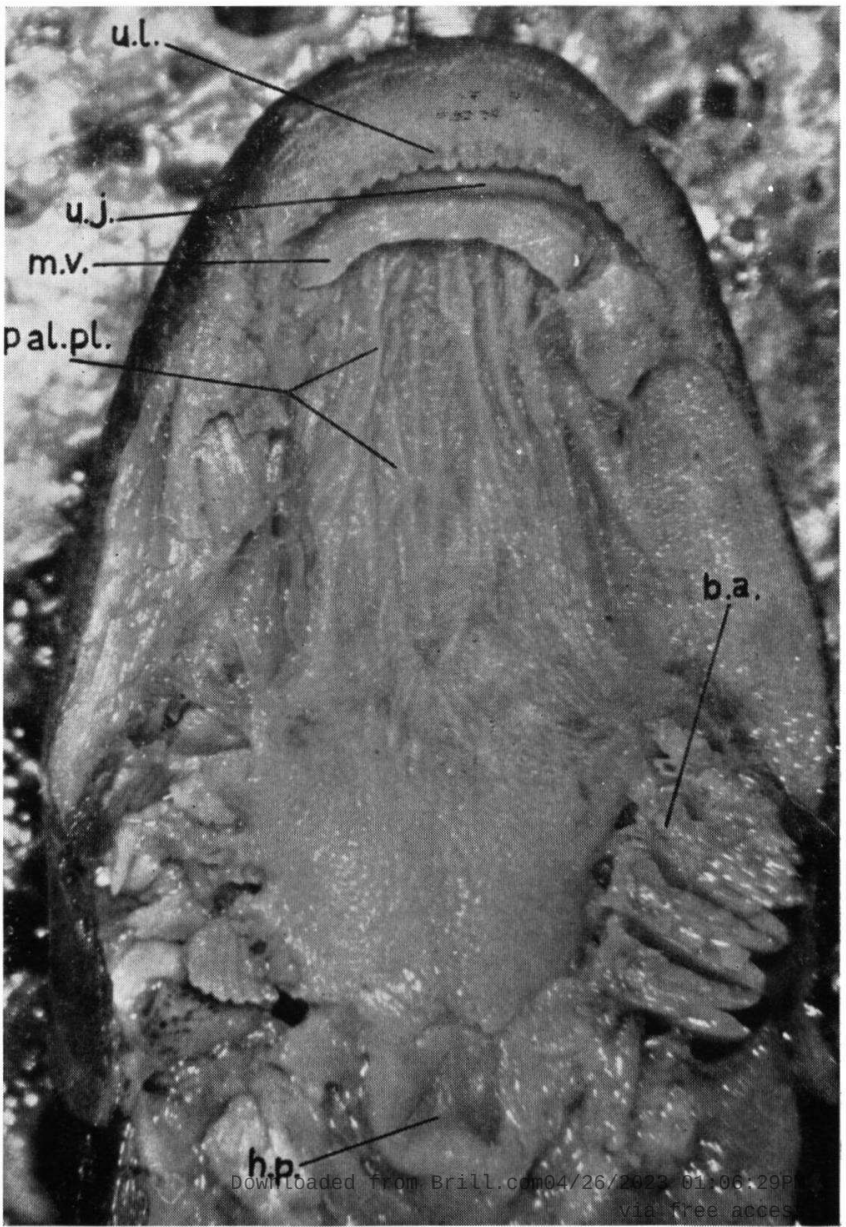


Plate V.

c. Pharyngeal hones of G. dembeensis (anterosuperior view) showing hooked teeth. (x 12)

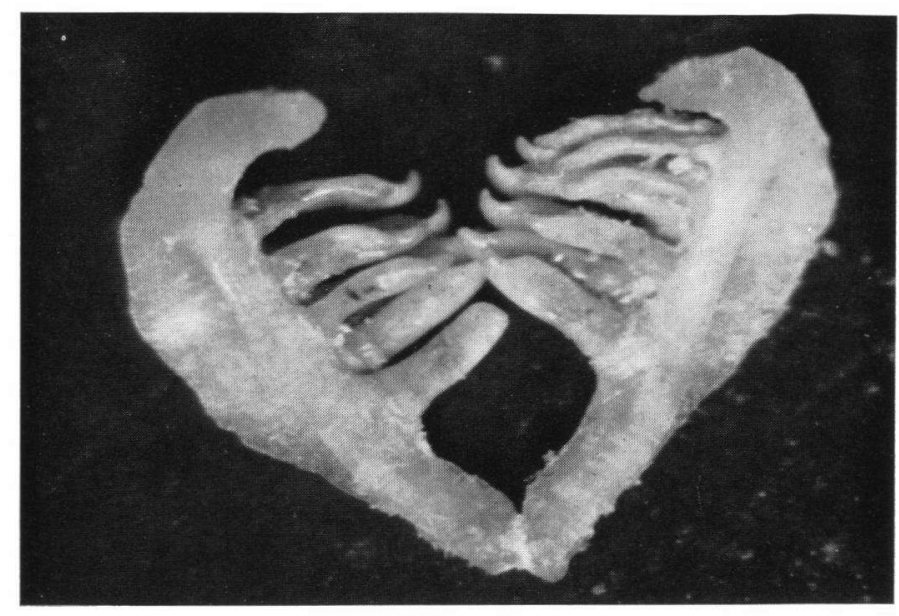

d. Head of Barbus altianalis, showing strongly protrusile mouth. (x 11/2)

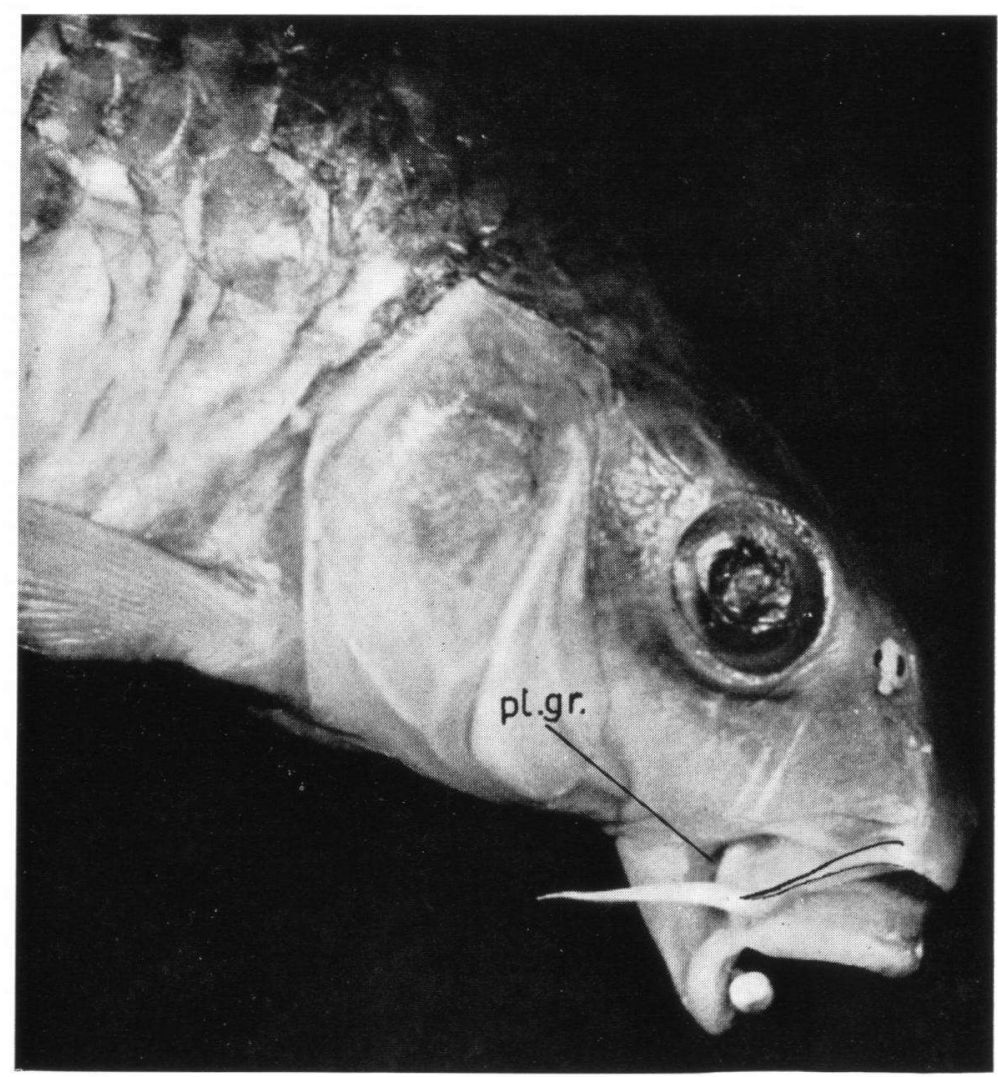


Plate VI.

a. Head of Barbus altianalis (ventral view) showing inferior mouth and throat musculature. ( $x$ 2)

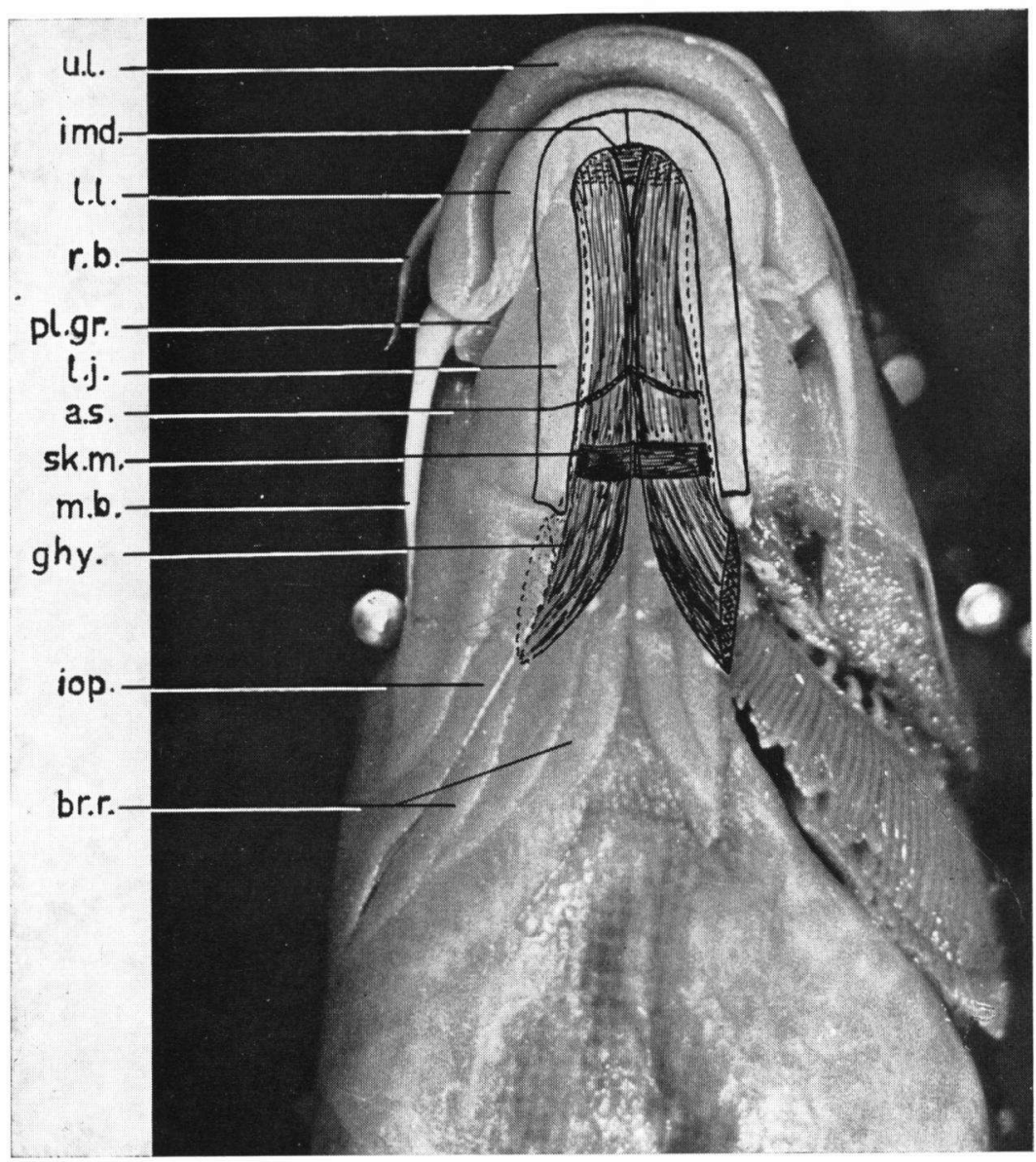

b. Palate of Barbus holotaenia, showing longitudinal plicae and pharyngeal pad. (x 2)

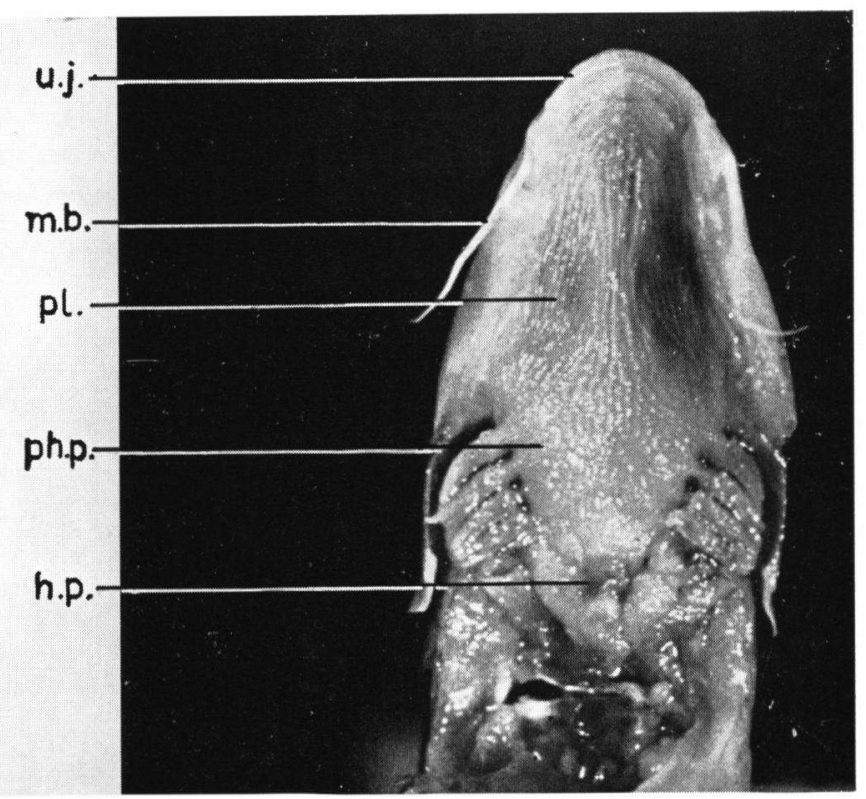


c. Branchial cavity of B. altianalis showing the gillrakers. (x 2)

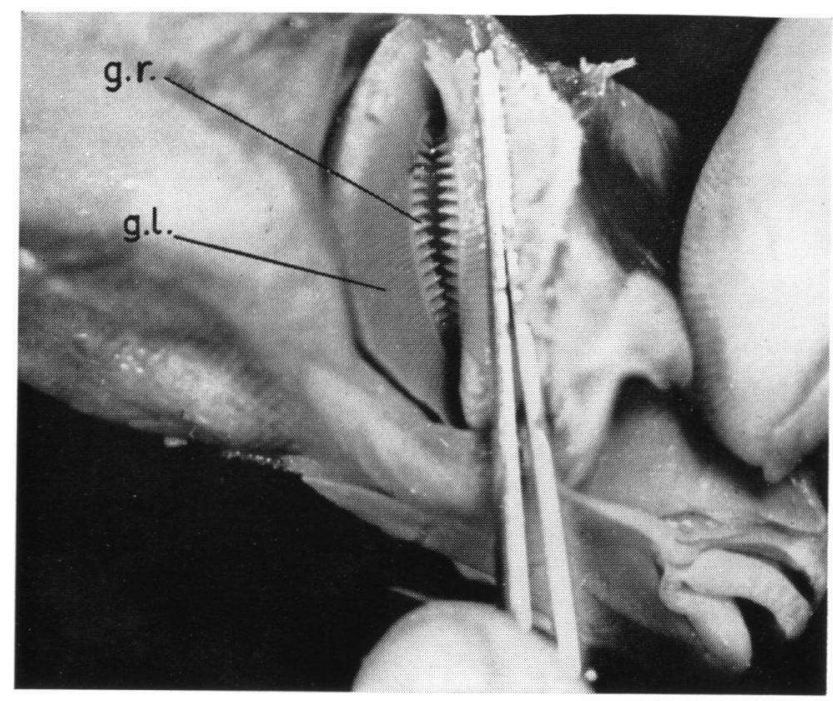

d. Isolated branchial arch of B. altianalis (superior view) showing papillose projections on the gillrakers. (x 4)

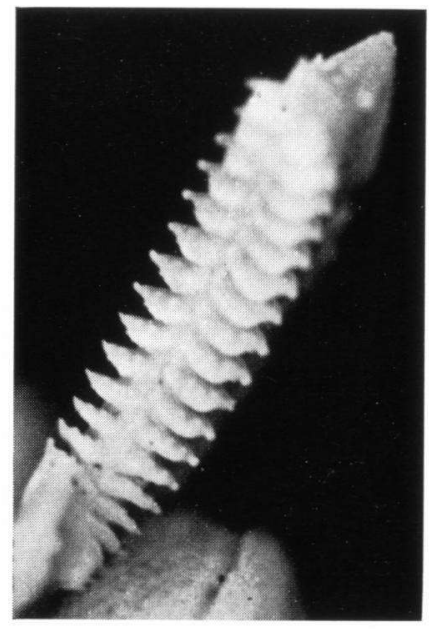


Plate VII.

a. Pharyngeal bones of Barbus tropidolepis (antero-superior view) showing molariform dentition. ( $x$ 21/2)

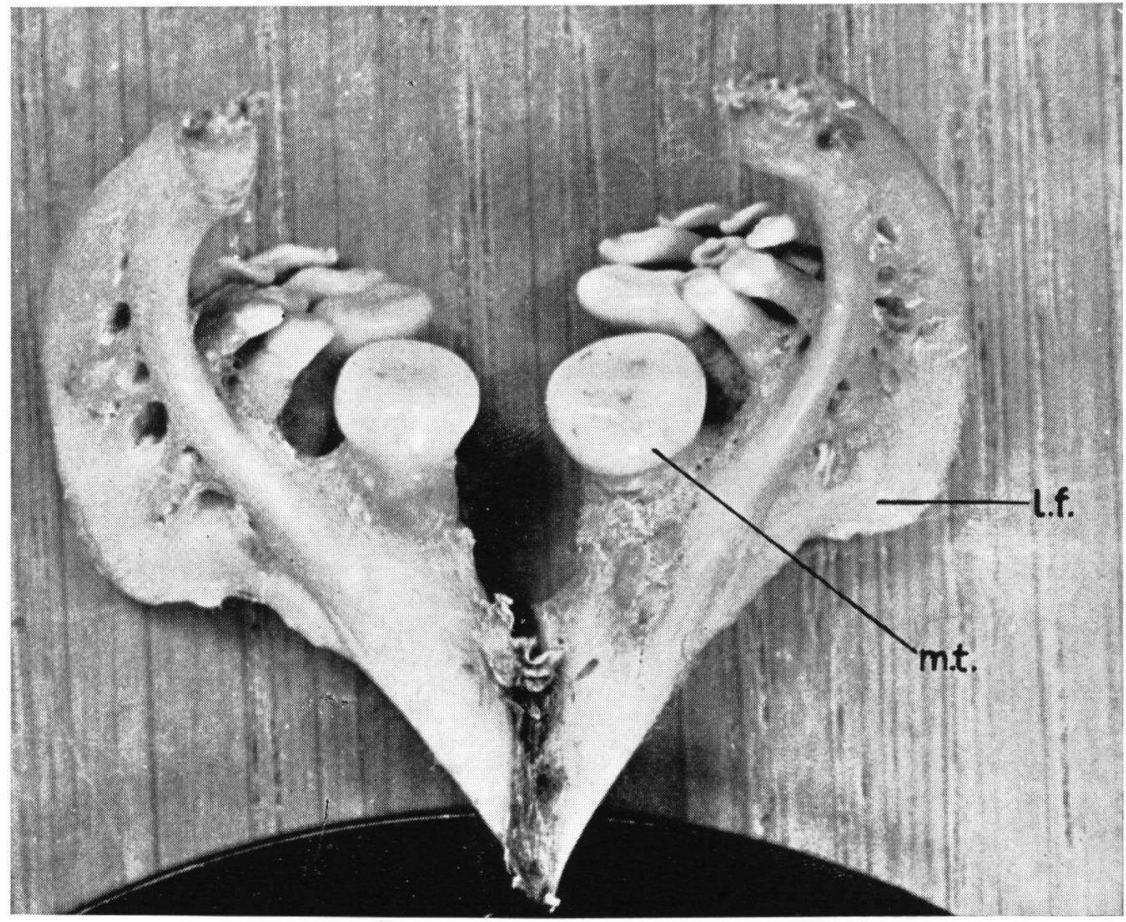

b. Lower pharyngeals of Barbus altianalis (antero-superior view) showing spoon-shaped teeth and alveolate lateral flange. (x 21/2)

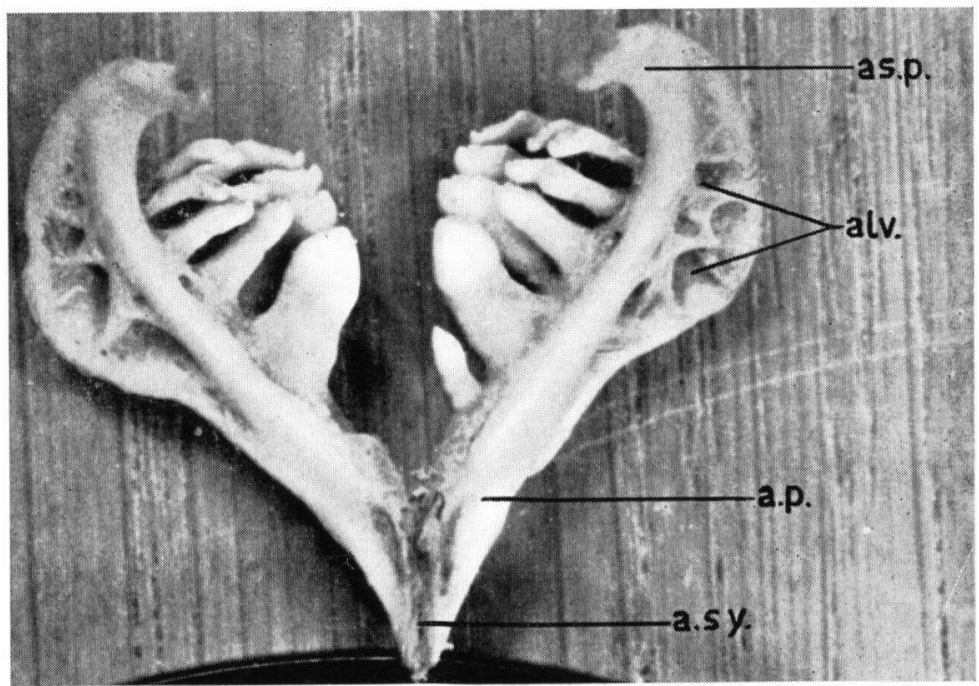


c. Masticatory plate of $B$. altianalis (ventral view) showing the postexior knob and undulated masticatory surface. (x 5).
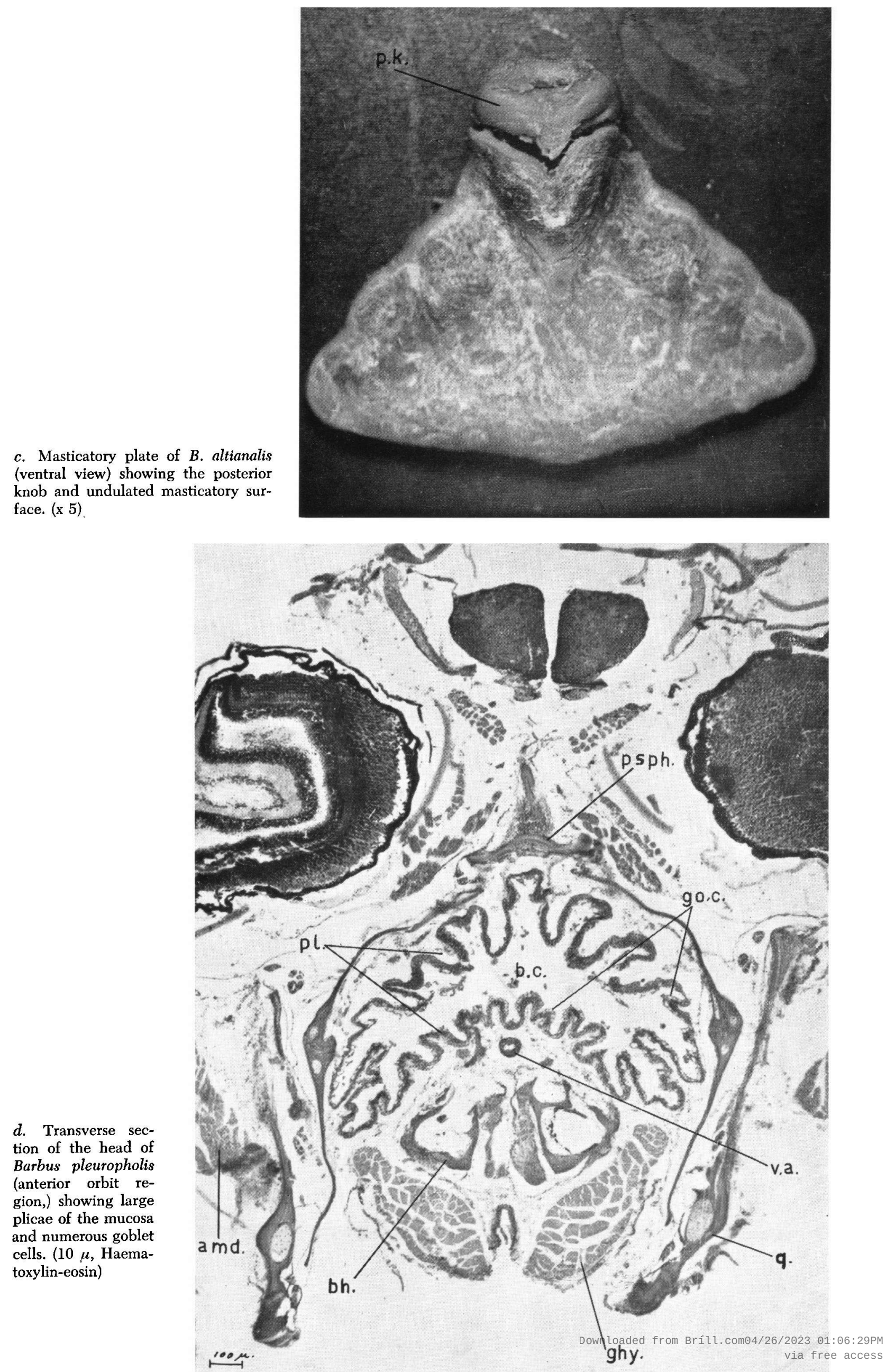


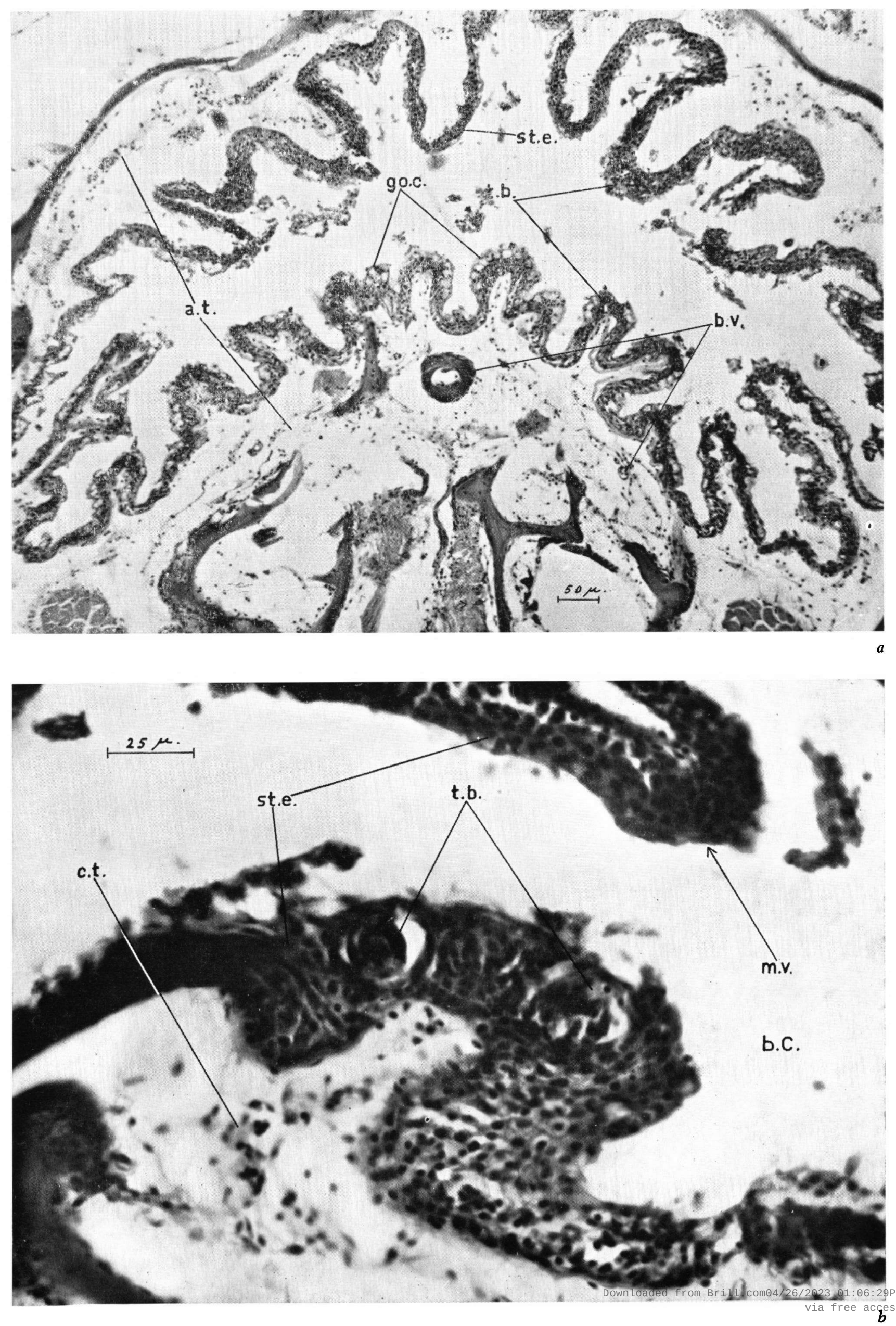




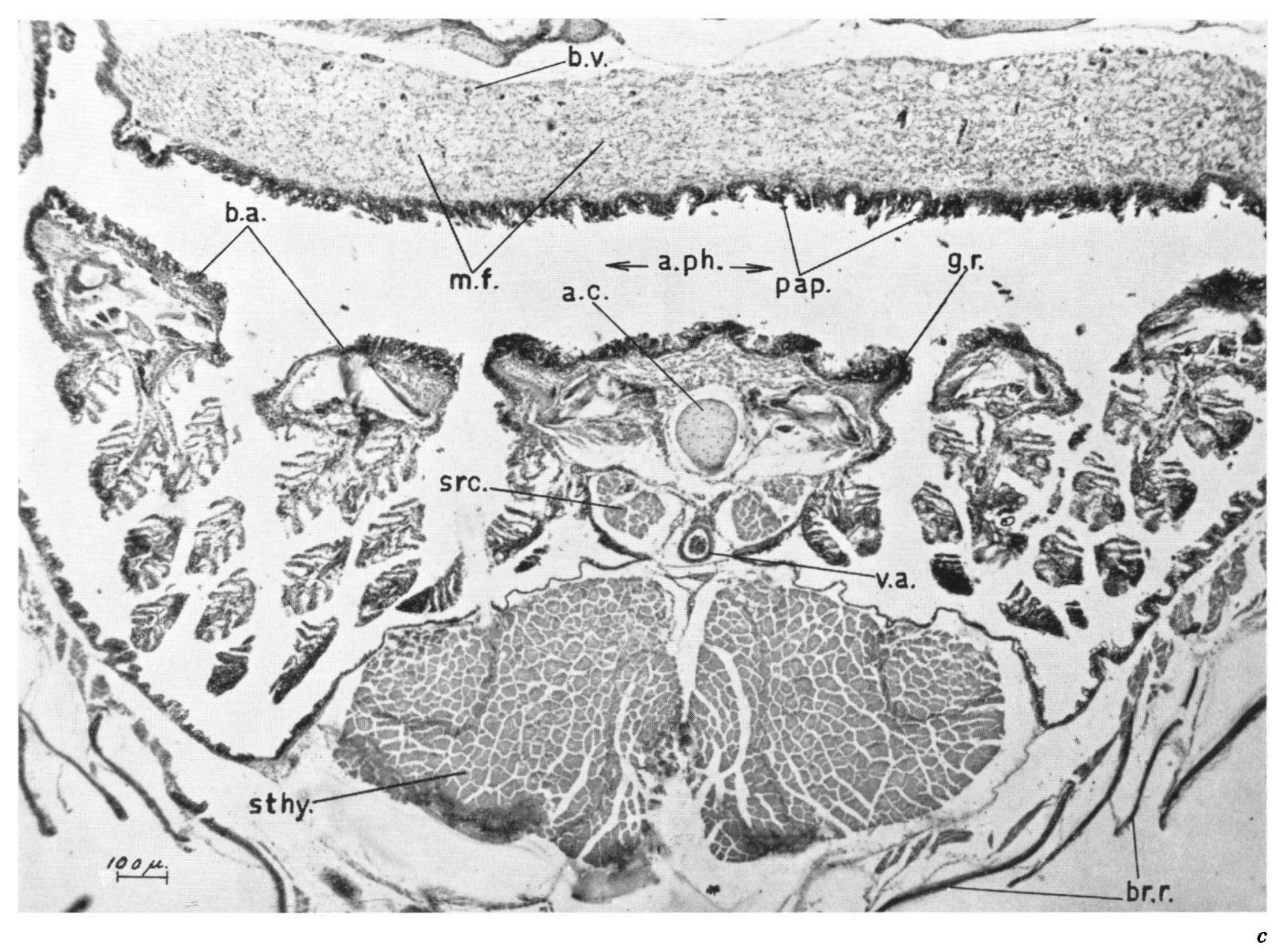

Plate VIII.

a. Transverse section of the anterior orbital region of Barbus pleuropholis, showing the more detailed histological structure of the buccal lining (10 $\mu$, Haematoxylin-eosin).

b. Anterior snout region of B. pleuropholis (transverse section), showing taste buds and stratified epithelium of the buccal mucosa (10 $\mu$, Weichert-von Gieson).

c. Anterior pharyngeal region of B. pleuropholis (transverse section), showing the structure of the pharyngeal pad. (1D $\mu$, Haematoxylin-phloxin) 
Plate IX.

a. Head of Barbus nedgia (Rüpp., 1837) (modified, after Boulenger, 1907) showing

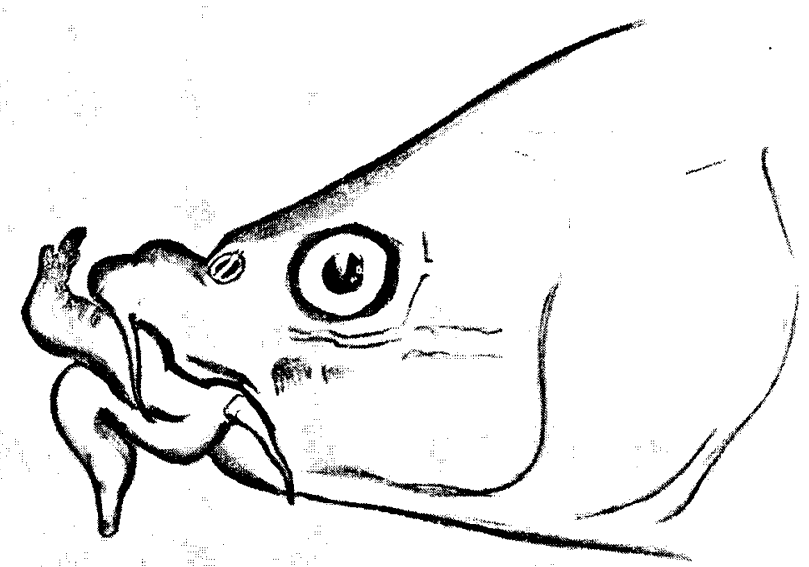

large, lobed lips.

b. Head of Barbus altianalis, showing bones and musculature of the mouth (semi-diagrammatic).

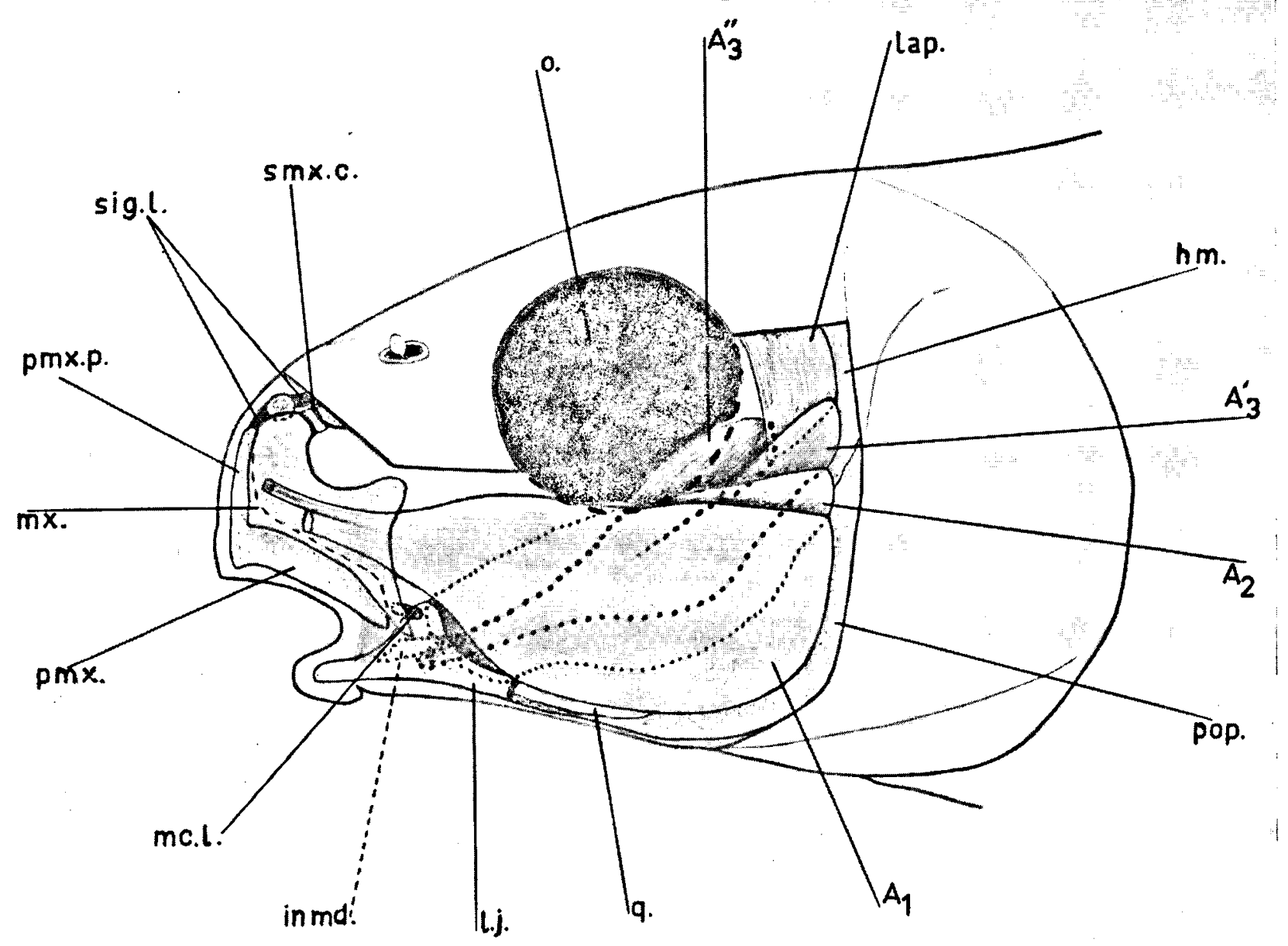




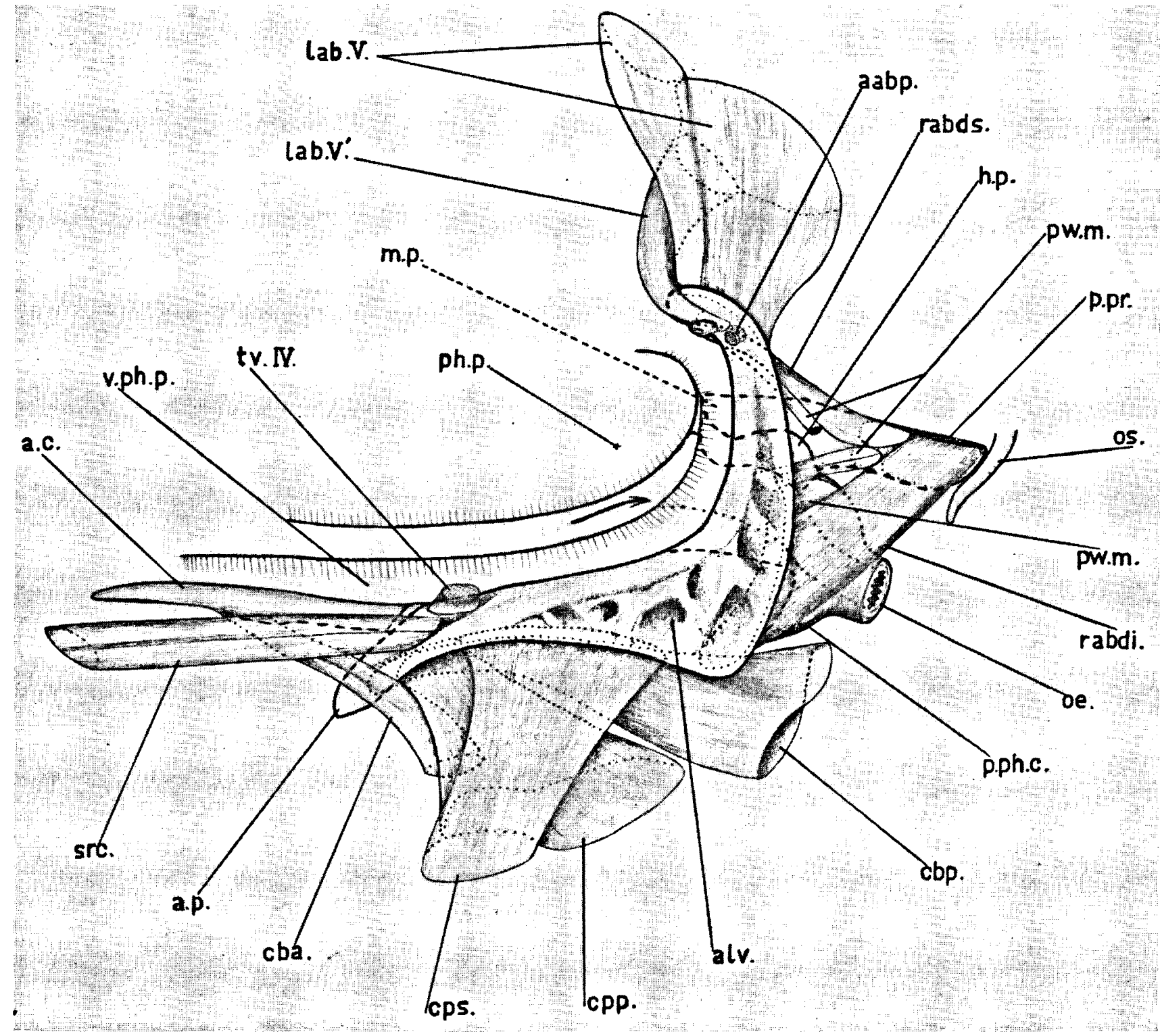

c. Left pharyngeal bone of $B$. altianalis (lateral view) showing masticatory muscles. 


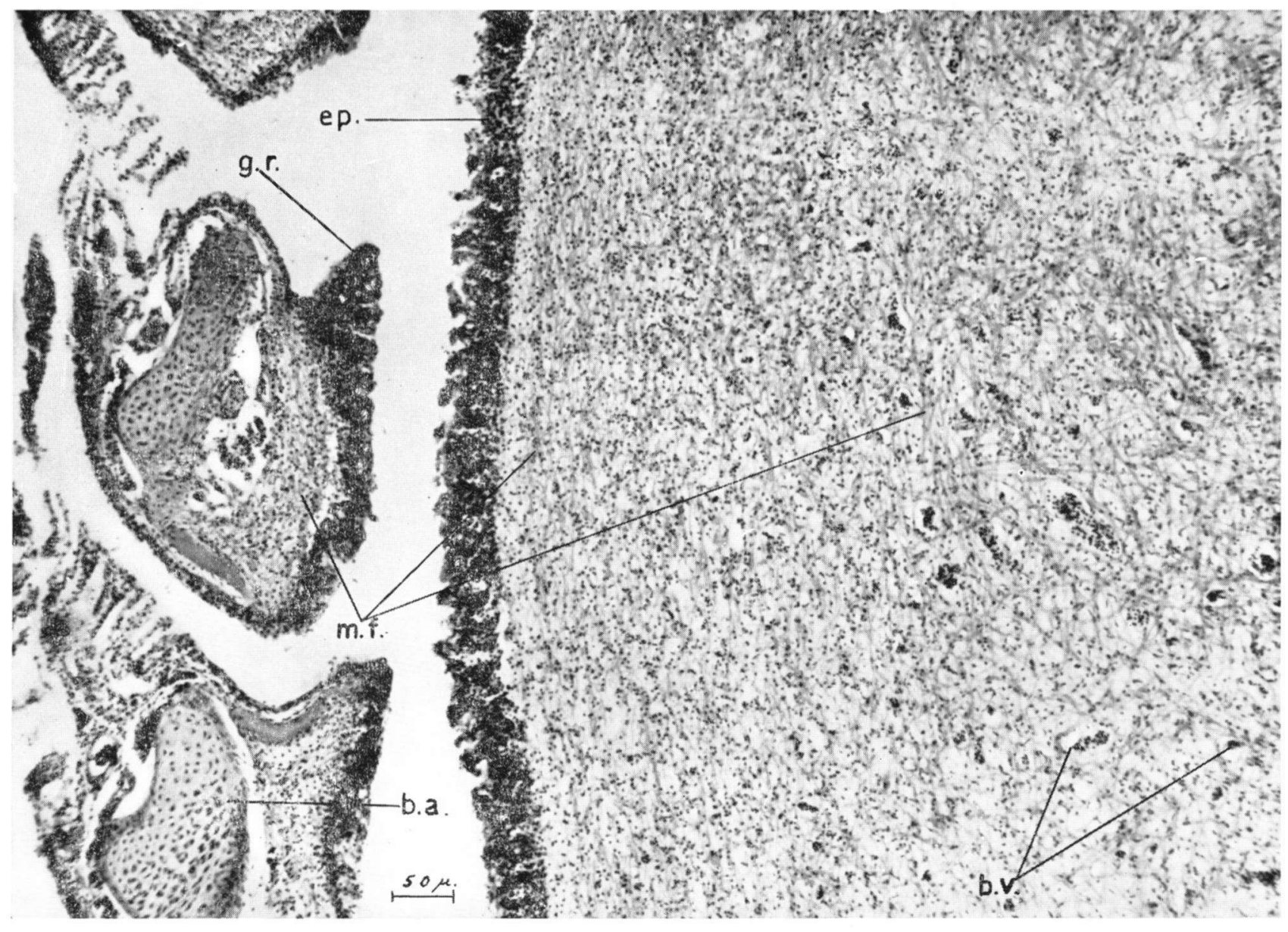

a. Pharyngeal pad of Barbus pleuropholis (longitudinal section) showing the criss-cross muscle fibres (10 $\mu$, Azan)

b. Palate of Varicorhinus tanganicae, showing large median ridge, feeble development of plicae, pharyngeal pad and masticatory plate. (x 2)

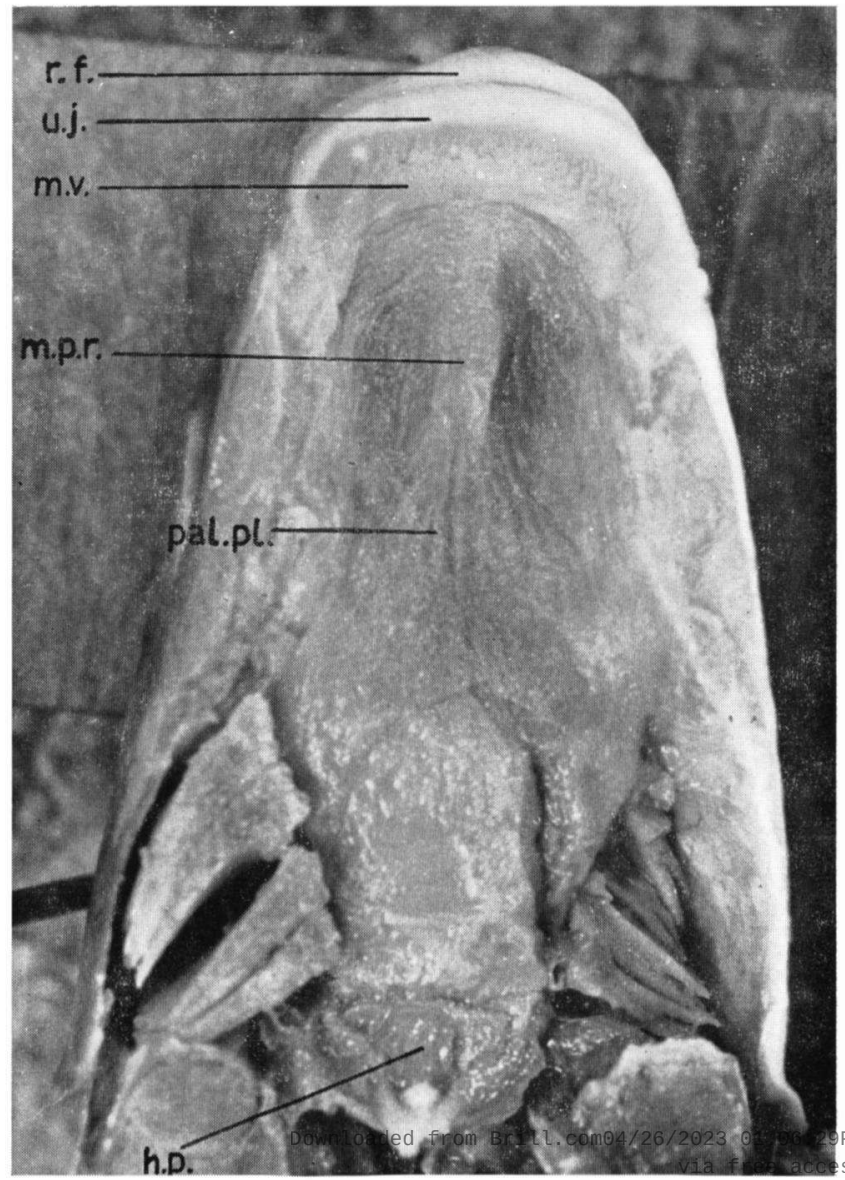


c. Lower pharyngeal bones of $\mathrm{V}$. tanganicae (antero-superior view) showing the close-set teeth. (x 6)

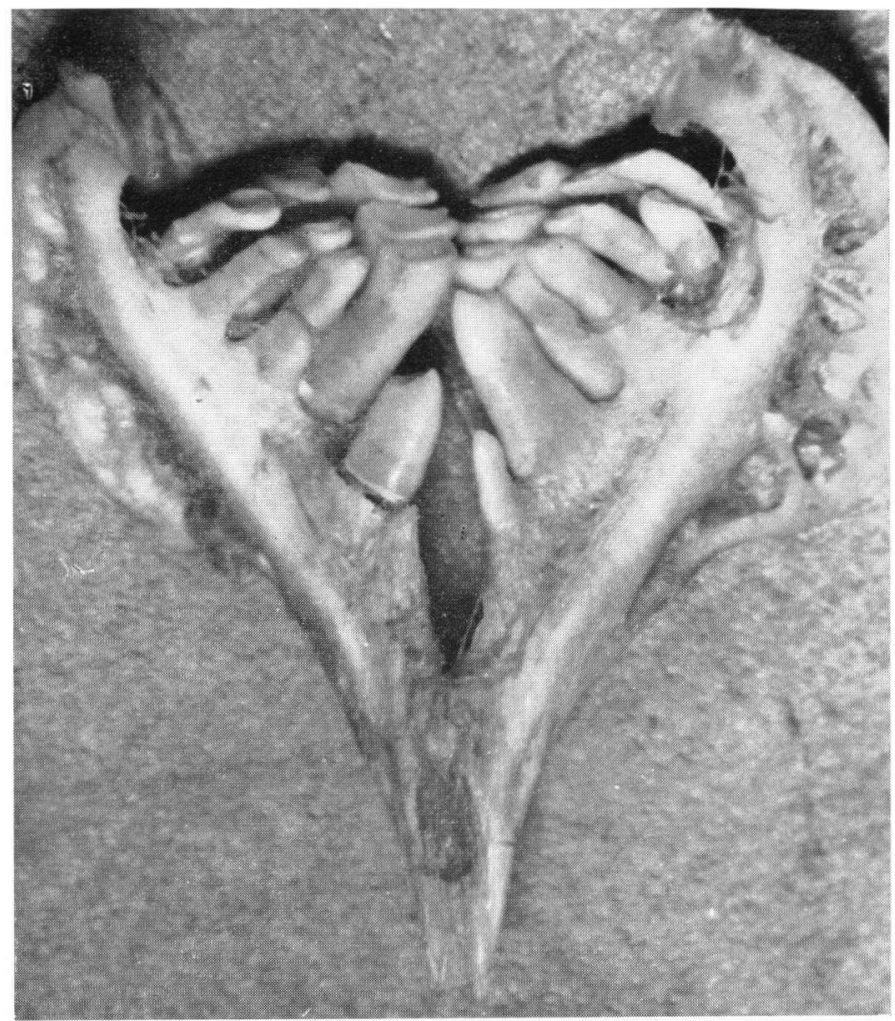

d. Head of Coptostomabarbus wittei with mouth cut open, showing the tongue. (Note vertical stance of mouth.) (x 8)

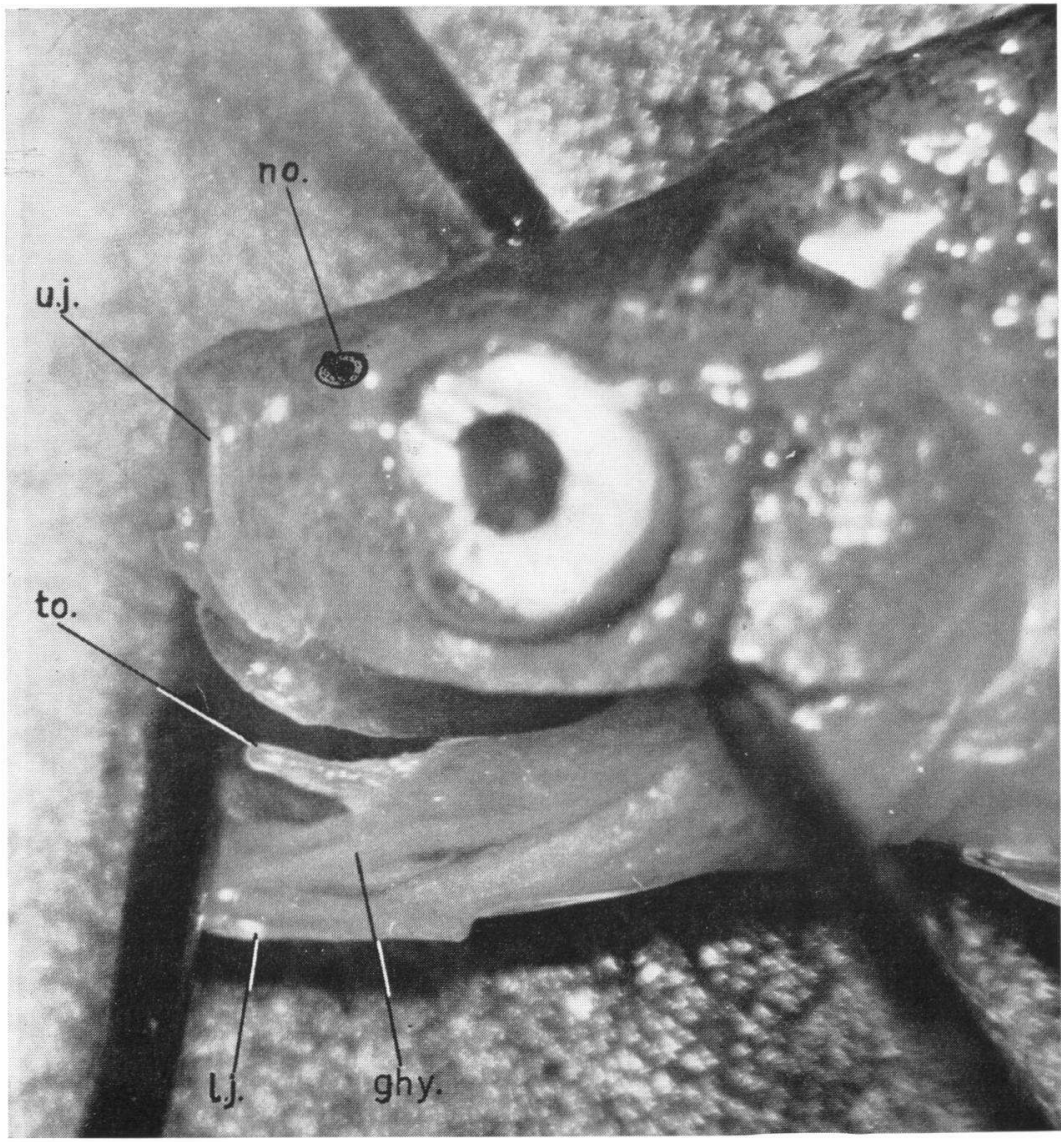


Plate XI.

a. Head of Barilius christyi, showing large, terminal mouth and symphysial knob. (x 2)

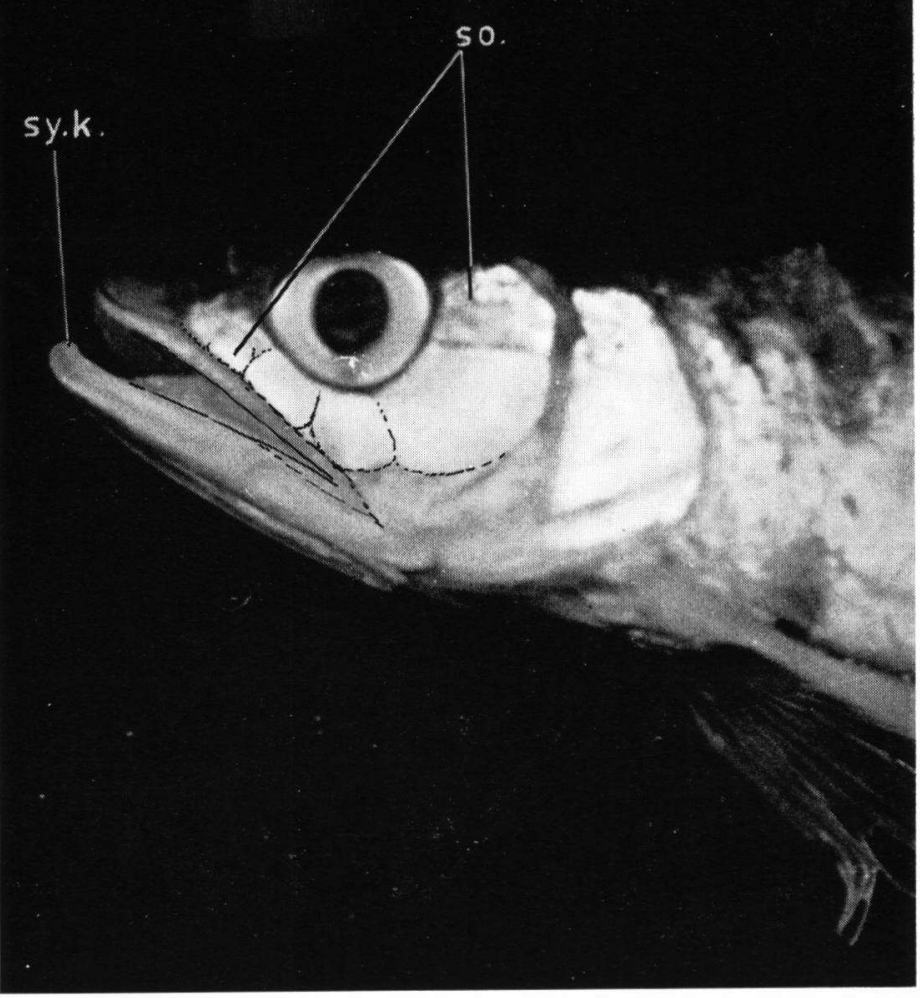

b. Palate of Barilius moorei, showing ridged jaw epithelium, anterior papillose pad, row of papillae along base of maxillary valve (right half cut away) and longitudinal plicae. ( $x 3$ )

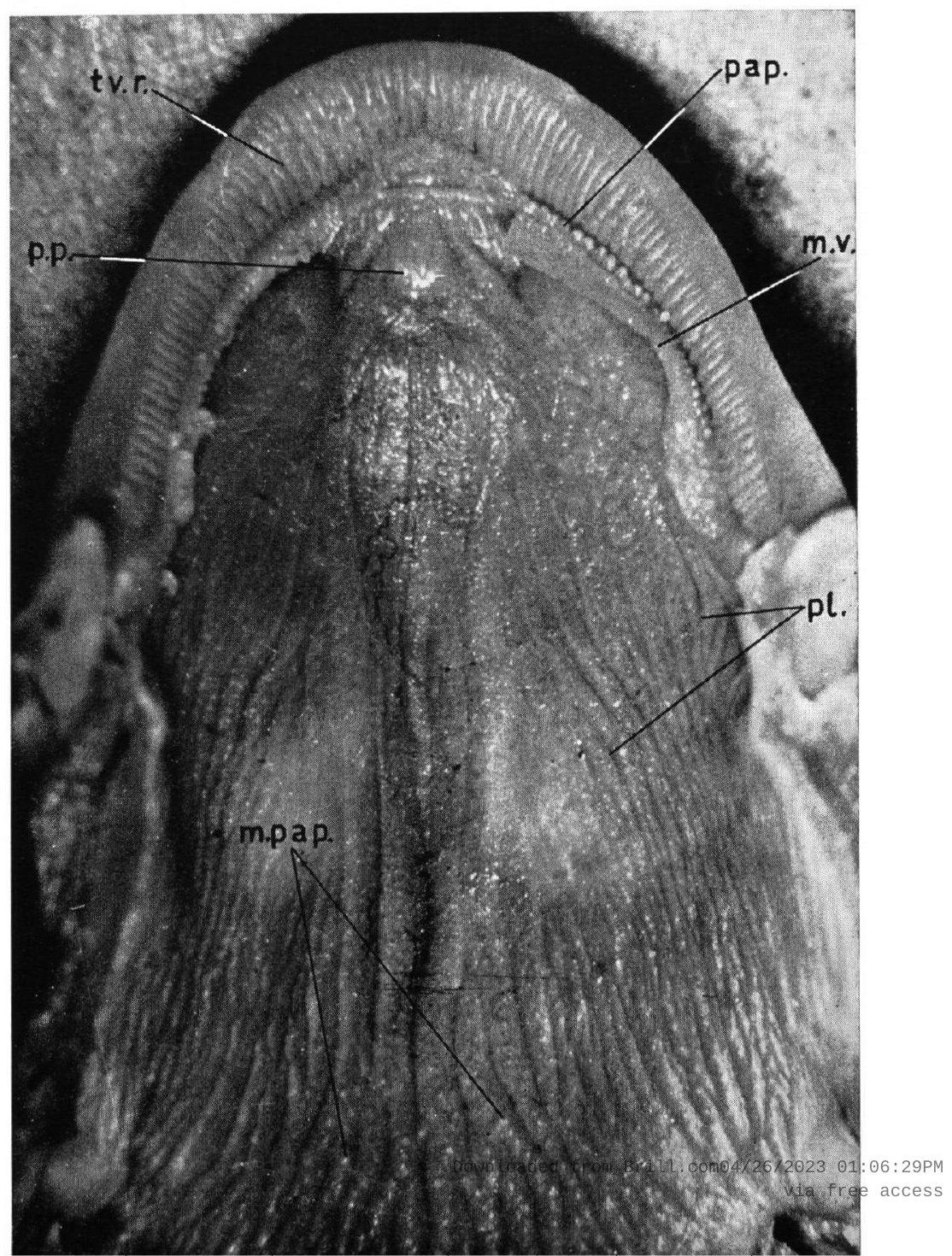


c. Pharyngeals of $B$. moorei (antero-superior view) showing sharp, hooked teeth. (x 6)

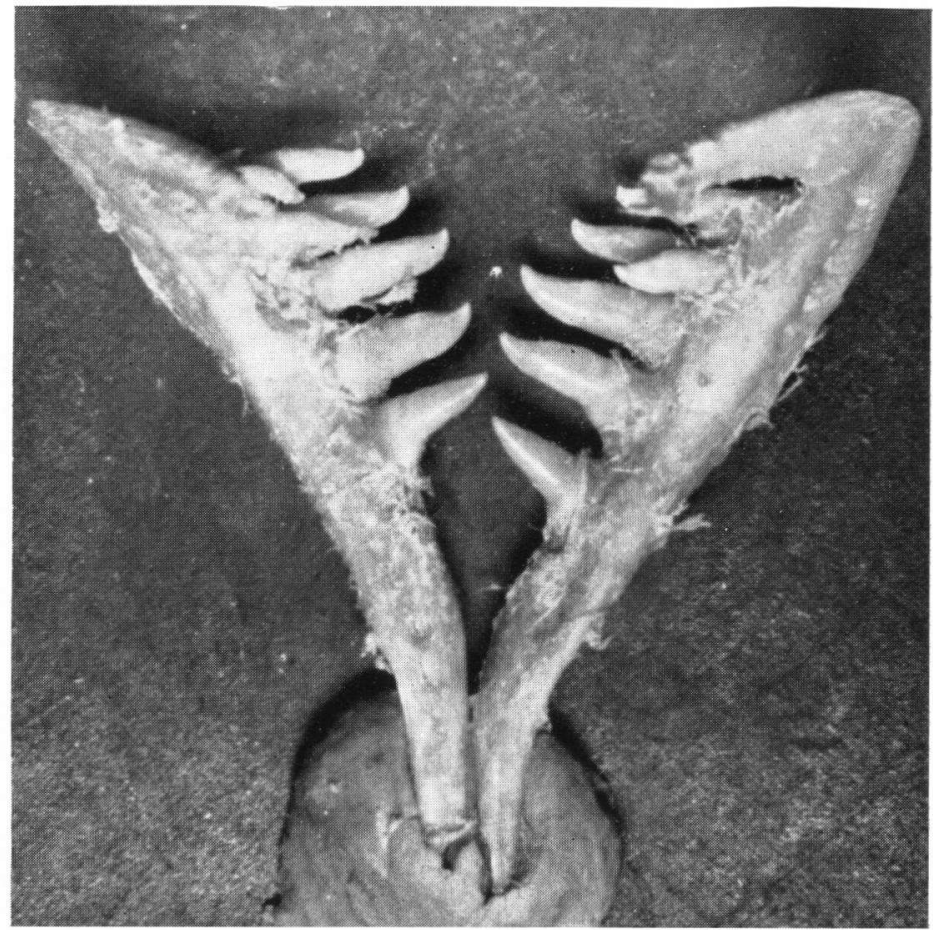

d. Head of Leptocypris modestus showing fully opened, small, sub-inferior mouth. (x 4)

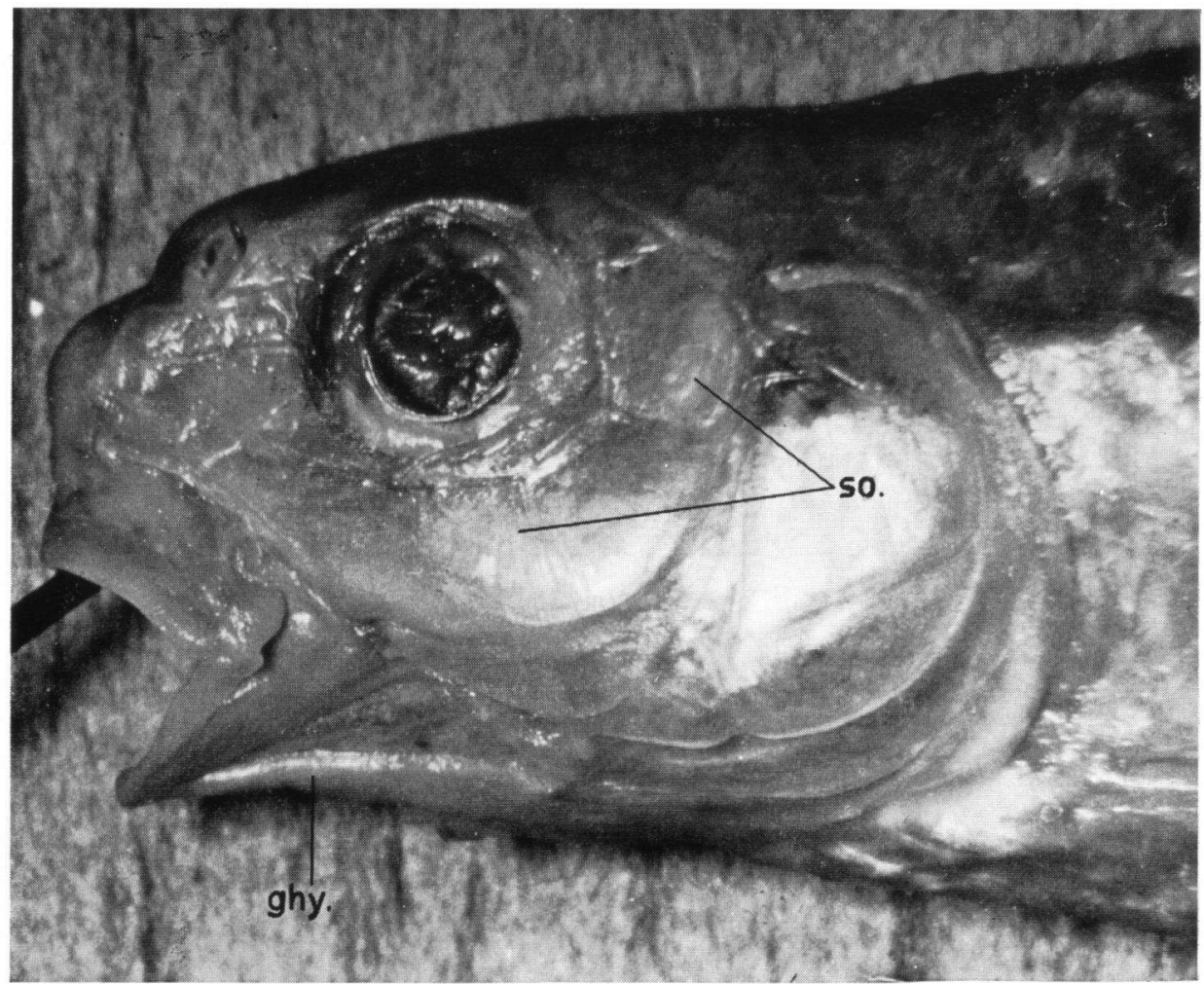


Plate XII.

a. Head of Barilius christyi, showing ventral musculature of mouth and anterior pharynx.

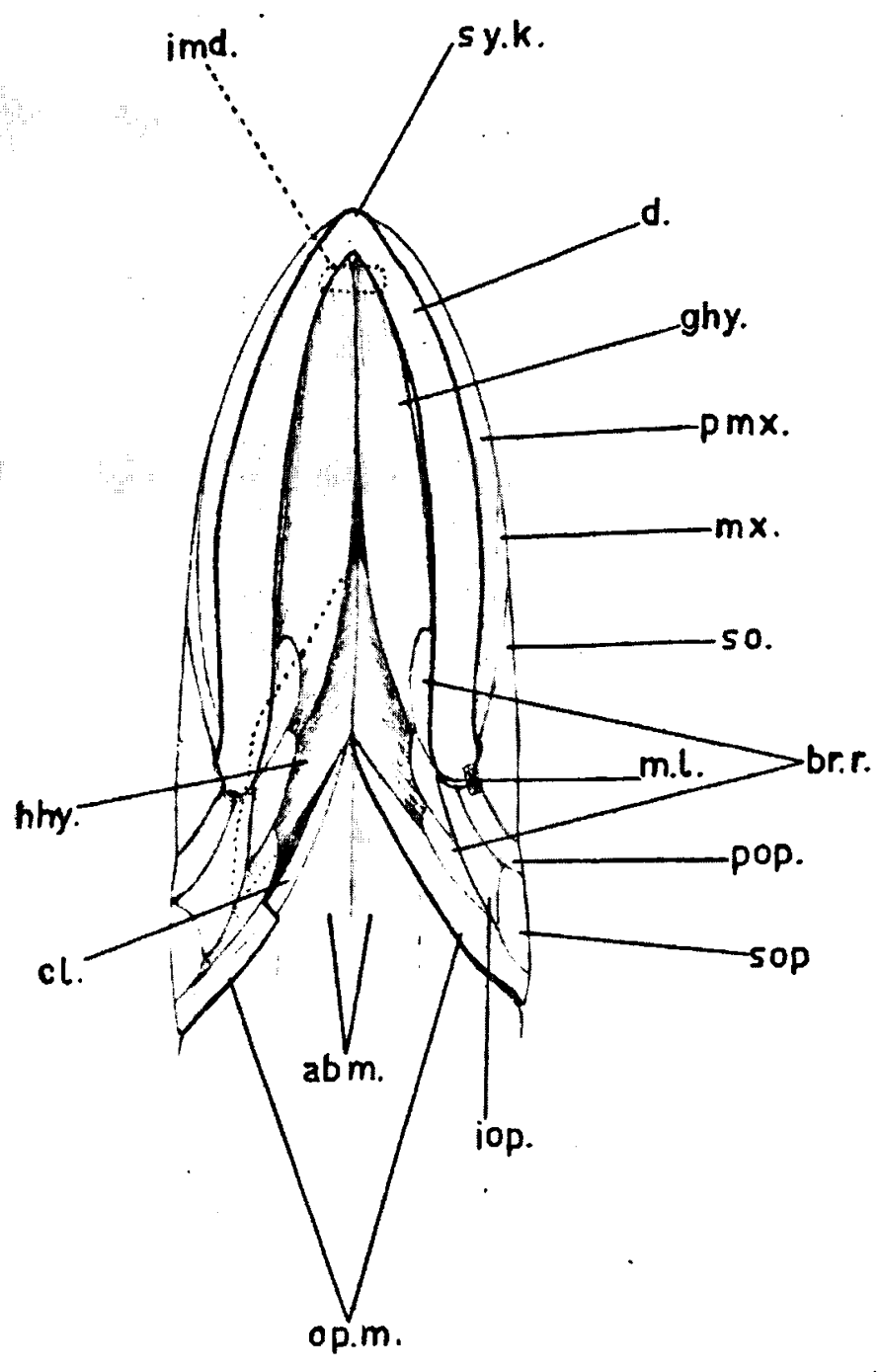

b. Head of B. christyi, showing bones and musculature of the mouth.

c. The same, $\mathrm{A}_{1} \beta$ and $\mathrm{A}_{1} \alpha$ (partly) removed, showing the deeper musculature. 

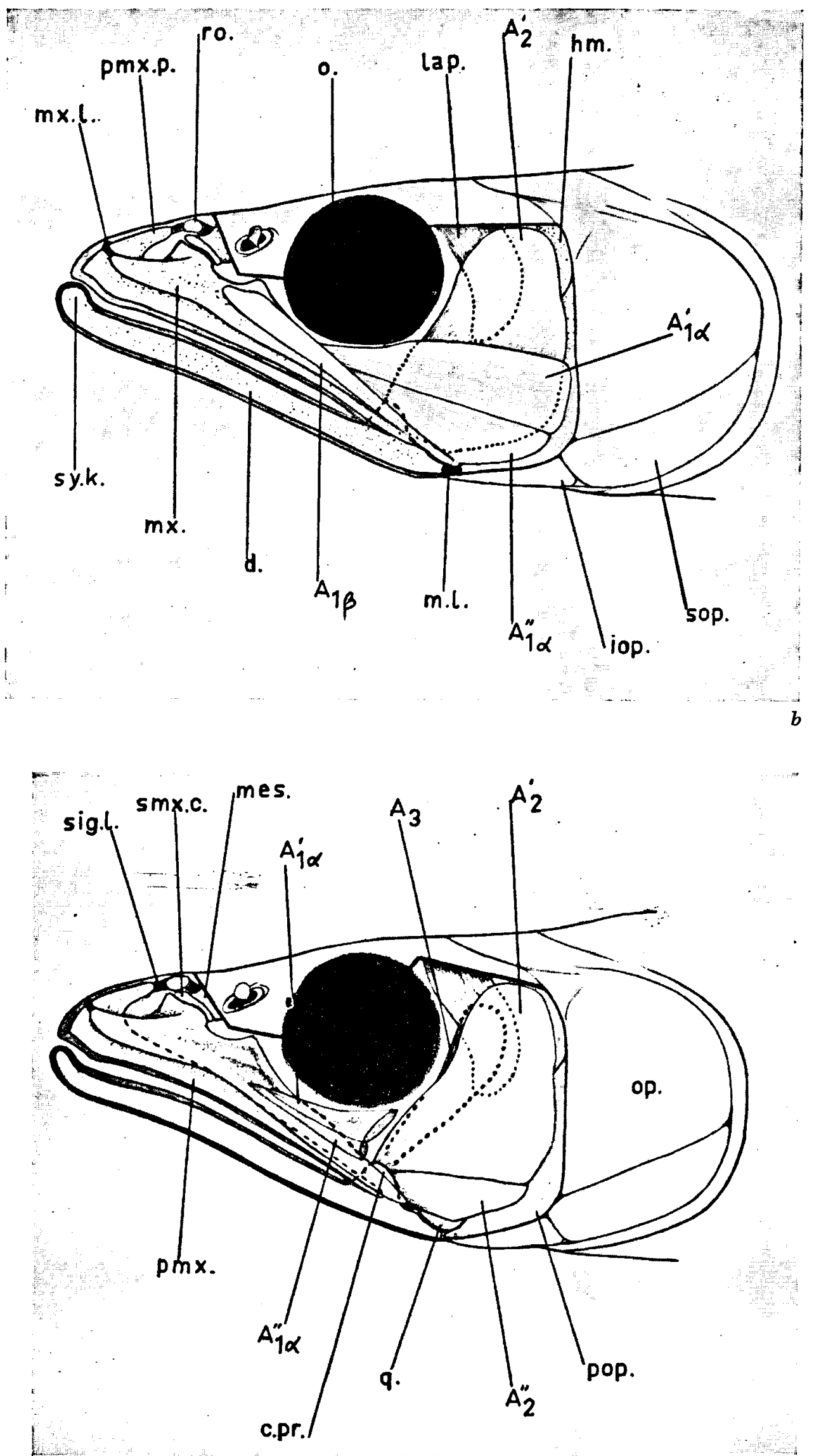

c

Downloaded from Brill.com๑4/26/2023 01:06:29PM

via free access 